\title{
ARTUR BARUCHI
}

\section{ORQUESTRAÇÃO DE MIGRAÇÃO MASSIVA DE MÁQUINAS VIRTUAIS BASEADA EM ANÁLISE CÍCLICA PARA AMBIENTES DE COMPUTAÇÃO NA NUVEM}

Tese apresentada à Escola Politécnica da Universidade de São Paulo para obtenção do Título de Doutor em Ciências. 


\section{ARTUR BARUCHI}

\section{ORQUESTRAÇÃO DE MIGRAÇÃO MASSIVA DE MÁQUINAS VIRTUAIS BASEADA EM ANÁLISE CÍCLICA PARA AMBIENTES DE COMPUTAÇÃO NA NUVEM}

Tese apresentada à Escola Politécnica da Universidade de São Paulo para obtenção do Título de Doutor em Ciências.

Área de Concentração:

Engenharia da Computação

Orientador:

Liria Matsumoto Sato 
Este exemplar foi revisado e corrigido em relação à versão original, sob responsabilidade única do autor e com a anuência de seu orientador.

São Paulo, de de

Assinatura do autor:

Assinatura do orientador:

Catalogação-na-publicação

Baruchi, Artur

Orquestração de Migração Massiva de Máquinas Virtuais Baseada em Análise Cíclica Para Ambientes de Computação na Nuvem / A. Baruchi -versão corr. -- São Paulo, 2015.

$145 \mathrm{p}$.

Tese (Doutorado) - Escola Politécnica da Universidade de São Paulo. Departamento de Engenharia de Computação e Sistemas Digitais.

1.COMPUTAÇÃO EM NUVEM 2.DESCRIÇÃO DE SISTEMAS 3.ANÁLISE DE DESEMPENHO I.Universidade de São Paulo. Escola Politécnica.

Departamento de Engenharia de Computação e Sistemas Digitais II.t. 


\section{AGRADECIMENTOS}

Inúmeras pessoas contribuíram, direta ou indiretamente, para o desenvolvimento do presente trabalho, tornando este período de cinco anos extremamente enriquecedor para mim.

Aos colegas do LAHPC que, com os momentos de descontração, tornaram esta jornada mais fácil.

A todos os colegas da HP, pela inestimável ajuda e compreensão. Em especial, aos meus amigos Juliano Costa e Laerte Fiorentini.

À minha orientadora, Liria Sato, uma das melhores pessoas que eu tive a oportunidade de conhecer e ao meu orientador, Edson Midorikawa, por suas incontáveis sugestões e por sua dedicação exemplar.

Aos meus pais, que sempre me apoiaram nos estudos e sem os quais jamais poderia ter chego até aqui.

Por fim, agradeço a minha esposa, Camila, a quem também dedico esta tese. Tornou suportáveis os momentos difíceis e adoçou os momentos felizes. Não há no mundo quem me faça mais feliz. 
Poucas, mas maduras.

(Carl Friedrich Gauss)

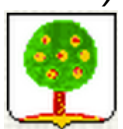




\section{RESUMO}

Um das principais características da tecnologia de virtualização é a Live Migration, que permite que máquinas virtuais sejam movimentadas entre máquinas físicas sem a interrupção da execução. Esta característica habilita a implementação de politicas mais sofisticadas dentro de um ambiente de computação na nuvem, como a otimização de uso de energia elétrica e recursos computacionais. Entretanto, a Live Migration pode impor severa degradação de desempenho nas aplicações das máquinas virtuais e causar diversos impactos na infraestrutura dos provedores de serviço, como congestionamento de rede e máquinas virtuais co-existentes nas máquinas físicas. Diferente de diversos estudos, este estudo considera a carga de trabalho da máquina virtual um importante fator e argumenta que escolhendo o momento adequado para a migração da máquina virtual pode-se reduzir as penalidades impostas pela Live Migration. Este trabalho introduz a Application-aware Live Migration (ALMA), que intercepta as submissões de Live Migration e, baseado na carga de trabalho da aplicação, adia a migração para um momento mais favorável. Os experimentos conduzidos neste trabalho mostraram que a arquitetura reduziu em até $74 \%$ o tempo das migrações para os experimentos com benchmarks e em até $67 \%$ os experimentos com carga de trabalho real. A transferência de dados causada pela Live Migration foi reduzida em até $62 \%$. Além disso, o presente introduz um modelo que faz a predição do custo da Live Migration para a carga de trabalho e também um algoritmo de migração que não é sensível à utilização de memória da máquina virtual. 


\section{ABSTRACT}

A key feature in virtualization technology is the Live Migration, which allows a Virtual Machine to be moved from a physical host to another without execution interruption. This feature enables the implementation of more sophisticated policies inside a cloud environment, such as energy and computational resources optimization. However, live migration can impose severe performance degradation for virtual machine application and cause multiple impacts in service provider infrastructure, such as network congestion and co-located virtual machine performance degradation. Unlike of several studies this work consider the virtual machine workload an important factor and argue that carefully choosing a proper moment to migrate it can reduce the live migration penalties. This work introduces the Application-aware Live Migration Architecture (ALMA), which intercepts live migrations submissions and, based in the application workload, postpone the migration to a more propitious live migration moment. The experiments conducted by this work demonstrated that the architecture reduced up to $74 \%$ for live migration time for benchmarks and $67 \%$ for real applications workload. The network data transfer during the live migration was reduced up to $62 \%$. Also, the present work introduces a model to predict live migration cost for the application and an algorithm that it is not memory usage sensitive. 


\section{SUMÁRIO}

\section{Lista de llustrações}

Lista de Tabelas

Lista de Abreviaturas e Siglas

$\begin{array}{lll}1 & \text { Introdução } & 17\end{array}$

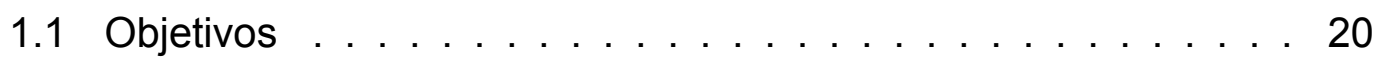

1.1 .1 Objetivos Específicos . . . . . . . . . . . . 21

1.2 Justificativa e Relevância . . . . . . . . . . . . . . . . . 22

1.3 Contribuições e Resultados . . . . . . . . . . . . . . . . 25

1.4 Organização . . . . . . . . . . . . . . . . 26

2 Virtualização e Computação na Nuvem 28

2.1 Conceitos . . . . . . . . . . . . . . . . . . . 28

2.1.1 Camada do Monitor de Máquinas Virtuais . . . . . . . . . 29

2.1 .2 Camada ISA . . . . . . . . . . . . 30

2.2 Computação na Nuvem . . . . . . . . . . . . . . . . . 32

2.2.1 Tipos de Serviços . . . . . . . . . . . . . . . . 34

2.2 .2 Tipos de Nuvens . . . . . . . . . . . . . . . . . . 35

2.2.2.1 Nuvens Públicas . . . . . . . . . . . . . . . . 36 
2.2.2.2 Nuvens Privadas . . . . . . . . . . . . . . . . 36

2.2.2.3 Nuvens Híbridas . . . . . . . . . . . . . . . . 37

3 Migração de Máquinas Virtuais $\quad 38$

3.1 Algoritmo Pré-Cópia . . . . . . . . . . . . . . . . . . 40

3.2 Algoritmo Pós-Cópia . . . . . . . . . . . . . . . . . . . . 42

3.3 Consolidação e Balanceamento de Carga . . . . . . . . . . . . 43

3.3 .1 Consolidação . . . . . . . . . . . . . . . . . . . . . . . . 44

3.3.2 Balanceamento de Carga . . . . . . . . . . . . . . 46

3.3.3 Taxonomia . . . . . . . . . . . . . . . . . . . 48

3.4 Trabalhos Relacionados . . . . . . . . . . . . . . . . . . . 49

3.4.1 Estratégias Analíticas de Live Migration . . . . . . . . 50

3.4.2 Estratégias de Controle de Live Migration . . . . . . . . 54

4 Caracterização e Análise Cíclica 57

4.1 Caracterização de Carga de Trabalho . . . . . . . . . . . 57

4.1 .1 Índices de Carga . . . . . . . . . . . . . . . . . . . . 59

4.1.1.1 Índices de Carga de Processador . . . . . . . 60

4.1.1.2 Índices de Carga de Memória . . . . . . . . 61

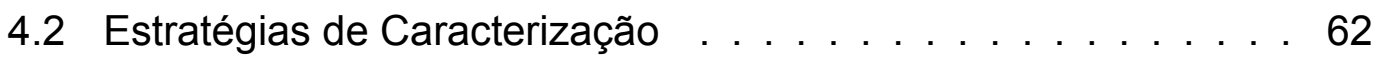

4.2.1 Naive Bayes . . . . . . . . . . . . . . . . . . 63

4.2.1.1 Discretização Entrópica . . . . . . . . . . . . . . 64

4.2 .2 Árvores de Decisão . . . . . . . . . . . . . . . . . 65 
4.2.3 Avaliação dos Algoritmos de Caracterização . . . . . . . 66

4.3 Análise Cíclica . . . . . . . . . . . . . . . . . . . . . . 73

5 Orquestração de Migração de Máquinas Virtuais Baseada em Aná$\begin{array}{ll}\text { lise Cíclica } & 78\end{array}$

5.1 Migração Orquestrada . . . . . . . . . . . . . . . . . . . . . . 79

5.2 Sinergia entre Análise Cíclica e Estratégias de Migração Massiva 81

5.3 Migração Individual de Máquinas Virtuais . . . . . . . . . . . . . 83

5.4 Custo da Live Migration . . . . . . . . . . . . . . . . . . . . . . 85

$\begin{array}{lrr}6 & \text { Arquitetura ALMA } & 87\end{array}$

6.1 Visão Geral da Arquitetura . . . . . . . . . . . . . . . . . . . 87

6.2 Algoritmos . . . . . . . . . . . . . . . . . 90

7 Resultados e Experimentos Com Arquitetura ALMA 95

7.1 Método de Avaliação . . . . . . . . . . . . . . . . . . . . 96

7.2 Experimentos com Benchmarks . . . . . . . . . . . . . . 101

7.3 Experimentos com Aplicações . . . . . . . . . . . . . . . . . 106

7.4 Análise de Escalabilidade . . . . . . . . . . . . . . . . . . . 111

7.4.1 Sobrecarga nas Máquinas Virtuais . . . . . . . . . . . . . 115

8 Migração Individual de Máquinas Virtuais 116

8.1 Custo da Live Migration . . . . . . . . . . . . . . . . . . . . . . . 117

8.1 .1 Formalização . . . . . . . . . . . . . . . . . . . 117 
8.1 .2 Experimento . . . . . . . . . . . . . 119

8.2 Protótipo do Algoritmo de Live Migration Independente do Uso de Memória . . . . . . . . . . . . . . . . . . . . . 121

8.2.1 Análise do Algoritmo . . . . . . . . . . . . . . . . . . 122

8.2.2 Protótipo e Resultados . . . . . . . . . . . . . . . . . 125

9 Conclusões e Trabalhos Futuros 129

9.1 Contribuições . . . . . . . . . . . . . . . . . . . . . . . . 131

9.2 Trabalhos Futuros . . . . . . . . . . . . . . . . . . 132

Referências

Apêndice A - Árvores de Decisão

Apêndice B - Naive Bayes 


\section{LISTA DE ILUSTRAÇÕES}

1 Cargas de trabalho reais. . . . . . . . . . . . . . . 24

2 MVs do (a) Tipo I e (b) Tipo II. . . . . . . . . . . . . . . . . 29

3 Taxonomia de acordo com a camada ISA . . . . . . . . . . 31

4 Convergência de tecnologias para o surgimento da computação na nuvem. . . . . . . . . . . . . . . . . . . . . . . 33

5 Cenários de Consolidação. . . . . . . . . . . . . . . . . . . 45

6 Cenários de Balanceamento de Carga. . . . . . . . . . . 47

7 Taxonomia de estratégias de consolidação e balanceamento de carga em computação na nuvem. . . . . . . . . . . . . . . . . . 49

8 Caracterização com Naive Bayes e Árvores de Decisão. . . . . . 71

9 Algoritmos de caracterização e Live Migration. . . . . . . . . . . 72

10 Composições de um mesmo ciclo . . . . . . . . . . . . . . 74

11 Exemplo de ciclo complexo. . . . . . . . . . . . . . . 75

12 Periodograma da carga do benchmark TPC. . . . . . . . 75

13 Identificação de ciclos na carga do benchmark TPC. . . . . . . 77

14 Orquestração de migração de máquinas virtuais utilizando análise cíclica. . . . . . . . . . . . . . . . . . . . . . . . 80

15 Migração Massiva e Orquestração migração de máquinas virtuais. 82

16 Modelos de migração existentes. . . . . . . . . . . . . . . . . 84

17 Representação do custo da Live Migration. . . . . . . . . . . . 86 
18 Componentes e fluxo de informação nas arquiteturas. . . . . . . 89

19 Processo de Decomposição do Ciclo. . . . . . . . . . . . . . . . 91

20 Identificação do momento correspondente ao ciclo. . . . . . . . . 93

21 Configuração da Nuvem Privada. . . . . . . . . . . . . . . . . 96

22 Nuvem Privada após consolidação em duas máquinas físicas. . 98

23 Exemplo do registro feito pelo Xen durante o processo de migração. . . . . . . . . . . . . . . . . . . . . . . . . 99

24 Saída do script de coleta do período de downtime. . . . . . . . . 100

25 Saída do script para coleta de dados trafegados. . . . . . . . . . 100

26 Diagrama de migração com três máquinas virtuais executando benchmarks. ..................... . . . . . . . . . . .

27 Métricas das três máquinas virtuais executando Benchmark. . . 103

28 Diagrama de migração com quatro máquinas virtuais executando benchmarks. . . . . . . . . . . . . . . . . . . . . . . 104

29 Métricas das quatro máquinas virtuais executando Benchmark. . 105

30 Diagrama de migração com três máquinas virtuais executando aplicações. . . . . . . . . . . . . . . . . . . . 107

31 Métricas das três máquinas virtuais executando aplicações. . . . 108

32 Diagrama de migração com quatro máquinas virtuais executando aplicações. . . . . . . . . . . . . . . . . . . . . . . . . . 109

33 Métricas das quatro máquinas virtuais executando aplicações. . 109

34 Taxa de Dirty Pages por Iteração. . . . . . . . . . . . . . . . . . 112

35 Estrutura dos processos dentro do MCLM. . . . . . . . . . . 113 
36 Sobrecarga do MCLM com até mil máquinas virtuais. . . . . . 114

37 Sobrecarga nas Máquinas Virtuais. . . . . . . . . . . . . . . . 115

38 Comparação entre execução real e estimativas. . . . . . . . . 120

39 Fases do Algoritmo. . . . . . . . . . . . . . . . . . . . . 122

40 Árvores de Decisão. . . . . . . . . . . . . . . . . . . . . . . . . 142 


\section{LISTA DE TABELAS}

1 Índices de carga de Processador. . . . . . . . . . . . . . 60

2 Índices de carga de Memória. . . . . . . . . . . . . . . . . . 61

3 Matriz de Confusão do Algoritmo Naive Bayes. . . . . . . . . . 65

4 Descrição dos benchmarks e da aplicação científica. . . . . . . . 67

5 Configurações das Máquinas Virtuais. . . . . . . . . . . . . . 68

6 Sumário das Caracterizações obtidas com os algoritmos. . . . . 68

7 Configuração das Máquinas Físicas do ambiente de teste. . . . 97

8 Configuração das Máquinas Virtuais do ambiente de teste. . . . 98

9 Resultados comparativos no experimento com três máquinas virtuais executando Benchmark. . . . . . . . . . . . . . . . . 104

10 Resultados comparativos no experimento com quatro máquinas virtuais executando Benchmark. . . . . . . . . . . . . . . . . . 104

11 Aplicações utilizadas para gerar a carga de trabalho nas máquinas virtuais. . . . . . . . . . . . . . . . . . . . . . 106

12 Resultados comparativos no experimento com três máquinas virtuais executando Aplicações. . . . . . . . . . . . . . . . . . . 107

13 Resultados comparativos no experimento com quatro máquinas virtuais executando Aplicações. . . . . . . . . . . . . . . . . 110

14 Taxa de Dirty Pages por Iteração. . . . . . . . . . . . . . . . . 111

15 Resultados obtidos no experimento de escalabilidate. . . . . . 114 
16 Benchmarks utilizados para simular carga nas máquinas virtuais. 119

17 Configuração das máquinas virtuais e sequência de benchmarks executados. . . . . . . . . . . . . . . . . . . . . . 120

18 Ferramentas e linguagens utilizadas na implementação do protótipo. . . . . . . . . . . . . . . . . . . . . . . 125

19 Comparação entre os algoritmos com benchmark de leitura e escrita intensiva. . . . . . . . . . . . . . . . . . . . 127

20 Comparação entre os algoritmos com benchmark de memória. . 127 


\section{LISTA DE ABREVIATURAS E SIGLAS}

ARP Address Resolution Protocol

BLCR Berkeley Lab Checkpoint Restart

CPU Central Processing Unit

DNS Domain Name Server

E/S Entrada e Saída

ICMP Internet Control Message Protocol

IO Input Output

IP Internet Protocol

LM Live Migration

LVM Logical Volume Manager

MMV Monitor de Máquinas Virtuais

MV Máquina Virtual

NLM Non-Live Migration

NPB Nasa Parallel Benchmark

QoS Quality of Service

RTO Retransmission Time Out

SDN Software Defined Network

SLA Service-Level Agreement

SNMP Simple Network Management Protocol 
SPEC Standard Performance Evaluation Corporation

TCP Transmission Control Protocol

TPC Transaction Processing Performance Council

TRF Transformada Rápida de Fourier

USP Universidade de São Paulo

ZFS Zettabyte File System 


\section{INTRODUÇÃO}

A computação como serviço é um antigo conceito da década de 60 (PARKHILL, 1966) que se popularizou como Computação na Nuvem (do inglês Cloud Computing). Apesar de ser factível a implementação de Computação na Nuvem com máquinas reais, como no caso de supercomputadores (MENESES et al., 2014), foi com o ressurgimento da virtualização na arquitetura x86 (SMITH; NAIR, 2005) que a Computação na Nuvem pôde prosperar na academia e na indústria. A virtualização, que, por meio de técnicas de multiplexação, possibilita que no mesmo hardware possam coexistir cargas e aplicações de diferentes usuários sem que haja interferência entre as máquinas virtuais, permitiu que empresas e universidades pudessem disponibilizar recursos computacionais para terceiros que de outra forma estariam ociosos.

A otimização do uso de recursos computacionais que é proporcionado pela virtualização vai além da multiplexação de máquinas virtuais. A Live Migration permite que uma Máquina Virtual possa ser movimentada de uma máquina física para outra sem que haja interrupção da execução do Sistema Operacional e, consequentemente, das aplicações subjacentes. Tal característica possibilita inúmeras vantagens ao provedor de Computação na Nuvem, como a execução de manutenção em máquinas físicas (hospedeiros) sem causar danos ao usuário. 
A migração de máquinas virtuais elevou os níveis de otimização de uso dos recursos computacionais ao permitir que os provedores pudessem consolidar diversas máquinas virtuais em alguns hospedeiros e desligando (ou colocando em estado de hibernação) os hospedeiros ociosos, com o objetivo de reduzir o consumo de energia. Essas estratégias são conhecidas como estratégias de consolidação (SRIKANTAIAH; KANSAL; ZHAO, 2008). Há também a possibilidade de distribuir a carga das máquinas virtuais em outros hospedeiros que dispõem de maior capacidade computacional em resposta à demanda circunstancial, estas conhecidas como estratégias de balanceamento de carga (NUAIMI et al., 2012).

Entretanto, tanto as estratégias de consolidação como as de distribuição de carga de trabalho geram significativa sobrecarga na infraestrutura do provedor de computação da nuvem, podendo causar considerável deterioração no desempenho das máquinas virtuais (ROYTMAN et al., 2013). O problema citado é devido principalmente aos algoritmos usados para realizar a Live Migration, cujo desempenho está fortemente atrelado à forma como a memória é utilizada na máquina virtual. A migração individual de uma máquina virtual irá transferir, no melhor cenário, uma quantidade de dados equivalente a quantidade de memória alocada a ela. Esse tráfego de dados excessivo gerado para transferir a memória da máquina virtual é amplificado de forma notável quando as estratégias de consolidação ou balanceamento de carga entram em cena.

Ao utilizar estratégias de consolidação ou de balanceamento de carga, é natural que ocorra uma migração massiva de máquinas virtuais, isto é, dezenas ou mesmo centenas de máquinas virtuais são migradas simultaneamente. Neste cenário, a excessiva quantidade de migrações simultâneas consequentemente causará congestionamento de rede, mesmo que o segmento de rede para migração seja dedicado, causando atrasos no processo de migração e, 
em última instância, gerando impactos na aplicação e na percepção do usuário.

A principal hipótese deste trabalho é que, escolhendo um instante conveniente para executar a Live Migration, pode-se reduzir consideravelmente os inerentes danos causados por esse processo na infraestrutura. A hipótese tem como fundamento duas observações: (1) a sensibilidade do desempenho dos algoritmos de Live Migration à utilização de memória e (2) muitas cargas de trabalho possuem natureza cíclica, isto é, um padrão bem definido de execução em função do tempo. Em geral, esse padrão pode ser sazonal tal como as cargas de ambientes web que possuem maior acesso em certos períodos do dia ou por conta de características da própria aplicação, como as científicas, que podem apresentar longos períodos de uso intensivo de processador seguido de alguns acessos a disco e uso de memória.

Neste trabalho, é apresentada uma orquestração de migração massiva de máquinas virtuais em que as execuções do conjunto de aplicações em processamento têm um comportamento cíclico, isto é, com períodos prédeterminados de operações de E/S, períodos de ociosidade e de computação intensiva (BARUCHI; MIDORIKAWA; SATO, 2015). As migrações são adiadas para os momentos do ciclo da aplicação que gerem menos carga no processo de migração. Os resultados obtidos, com a implementação da arquitetura ALMA (Application-aware Live Migration Architecture (BARUCHI; MIDORIKAWA; NETTO, 2014)) são positivos, mostrando que a hipótese considerada é válida.

Para a implementação da orquestração, que terá análise cíclica como principal critério para adiar migrações, naturalmente deve-se conhecer o comportamento da carga de trabalho da máquina virtual. Para esse fim, a arquitetura utiliza técnicas de classificação Bayesiana e análise de frequência, que iden- 
tifica o tempo de duração das cargas de trabalho das máquinas virtuais. As submissões de Live Migration são interceptadas e, de acordo com as características da carga de trabalho, a migração da máquina virtual pode ser executada imediatamente ou adiada até que o período da carga de trabalho seja mais favorável. A caracterização da carga de trabalho é realizada por classificadores Bayesianos e a identificação dos padrões cíclicos é feita utilizando-se a Transformada Rápida de Fourier (BERGLAND, 1968).

\subsection{Objetivos}

Este trabalho tem como objetivo apresentar uma nova forma de gerenciamento de migrações em uma infraestrutura de computação em nuvem, através de uma estratégia de orquestração de migração massiva de máquinas virtuais baseada em análise cíclica de cargas de trabalho. A migração massiva de máquinas virtuais ocorre quando dezenas ou centenas de máquinas virtuais são migradas em um curto intervalo de tempo. A orquestração da migração apresentada tem como principal critério a análise cíclica das cargas de trabalho das aplicações em execução. Esta análise busca encontrar o momento adequado para as migrações, otimizando aspectos globais, tais como congestionamento de rede e tempo de migração. Para tanto, é necessário identificar e caracterizar os períodos cíclicos da carga de trabalho durante a execução da aplicação. Um método de caracterização e identificação dos ciclos é apresentado neste trabalho. Para a implementação da orquestração proposta é apresentada a arquitetura ALMA.

A estratégia de orquestração proposta é uma solução macro para o problema da migração massiva de máquinas virtuais, como o congestionamento de rede e o tempo de migração das máquinas virtuais. Entretanto, na migração de máquinas virtuais individuais, estes problemas são causados, majoritária- 
mente, pelo algoritmo de migração de máquinas virtuais que é implementado na camada do monitor de máquinas virtuais. É neste contexto que foi desenvolvido um algoritmo cujo desempenho, avaliado em quantidade de dados trafegados durante o processo de migração, não depende de como a memória está sendo utilizada e, por essa razão, tem um comportamento determinístico. Esse algoritmo atuaria em um meio termo entre a migração inteira da máquina virtual e a migração de um único processo, como os implementados em clusters de alto desempenho. Com essa característica, a quantidade de dados trafegados na rede seria reduzido consideravelmente e a migração continuaria sendo um processo imperceptível do ponto de vista do usuário.

Em um planejamento de migrações de máquinas virtuais é interessante mensurar o impacto que o processo de migração imporá à aplicação em execução das máquinas virtuais. Esta métrica baseia-se no histórico das migrações anteriores para estimar a sobrecarga na aplicação da máquina virtual e poderia ser utilizada para prevenir que migrações desvantajosas sejam realizadas.

\subsubsection{Objetivos Específicos}

Tem-se como objetivos específicos:

- Desenvolver uma metodologia para classificar cargas de trabalho que sejam favoráveis ou não para a migração;

- Elaborar um método para extrair padrões repetitivos em uma carga de trabalho;

- A partir dos padrões extraídos dessa carga de trabalho, determinar os períodos que imponham menor sobrecarga no ambiente durante uma migração; 
- Desenvolver um modelo de estimativa de sobrecarga que é imposta à aplicação pelo processo de migração;

- Desenvolver um algoritmo de migração de máquinas virtuais cujo desempenho seja independente da carga de trabalho da máquina virtual.

\subsection{Justificativa e Relevância}

Nos últimos anos, tanto a comunidade acadêmica como a indústria têm voltado atenção ao paradigma de Computação Verde (Green Computing) (WANG; WANG, 2011). Uma das principais preocupações desse paradigma é a redução do consumo de energia de Data Centers. Assim, estratégias de consolidação de servidores são fundamentais para sua implementação (TSAI; LIAO, 2012) (ARTHI; HAMEAD, 2013) (ZUO; JIA, 2013).

Nesse contexto, as estratégias de consolidação têm o papel de concentrar a carga de diversas máquinas virtuais em um grupo reduzido de máquinas físicas, também chamadas de hospedeiros. Antigos hospedeiros, que tiveram suas respectivas máquinas virtuais movimentadas para os novos hospedeiros, são então desligados ou colocados em um estado reduzido de consumo de energia (ou hibernação). Entretanto, estratégias de consolidação possuem dois problemas fundamentais: (1) decidir para qual hospedeiro uma determinada máquina virtual deve ser migrada e (2) sobrecarga gerada na infraestrutura por conta de uma quantidade excessiva de Live Migrations ocorrendo simultaneamente.

Decidir quais máquinas virtuais devem ser migradas e para quais hospedeiros é, em geral, feito por estratégias baseadas em heurísticas, pois trata-se de um problema de otimização combinatória NP-Difícil (VERMA; AHUJA; NEOGI, 2008), análogo ao problema do Mochileiro (do inglês, Bin Packing). A 
sobrecarga imposta na infraestrutura tem se tornado um ponto de atenção e algumas estratégias também passaram a considerá-la como um dos parâmetros a serem analisados durante o processo de avaliação e decisão de quais máquinas devem ser migradas e para qual destino (TZIRITAS et al., 2013).

Além da Computação Verde, outros paradigmas computacionais também têm tirado proveito da possibilidade de migrar máquinas virtuais para outros hospedeiros. A computação de alto desempenho na nuvem, por exemplo, tem se tornado um tema relevante de pesquisa (GUPTA et al., 2013) e com grande potencial para usufruir das características da Live Migration. Um exemplo típico seria a migração de diversas máquinas virtuais para hospedeiros com maior poder computacional ou ainda diminuir a latência de comunicação colocando máquinas virtuais que fazem constantes trocas de mensagens mais próximas umas das outras. Esse paradigma não sofre tanto com o problemas de explosão combinatória, como ocorre com a consolidação, mas a migração em massa de máquinas virtuais pode vir a ocorrer, causando sobrecarga na infraestrutura e, consequentemente, a degradação de desempenho.

Lidar com problemas de sobrecarga na infraestrutura ou mesmo com impacto que a Live Migration impõe na aplicação é deixado em segundo plano pelas estratégias atuais de consolidação e de balanceamento de carga. Isso se deve ao fato de que a sobrecarga do processo de Live Migration é causada pelos próprios algoritmos de Live Migration, como o Pré-Cópia (THEIMER; LANTZ; CHERITON, 1985) e o Pós-Cópia (HINES; GOPALAN, 2009), sendo que, a princípio, não é escopo dessa estratégias lidar com os problemas gerados por eles. Como resultado dessa limitação de escopo, as estratégias de consolidação e balanceamento de carga são pouco utilizadas - ou acabam não sendo utilizadas - por provedores de serviço na nuvem (BIRKE et al., 2013) para evitar penalidades em decorrência do não atendimento a Níveis de 
Serviço (do inglês Service Level Agreement - SLA) contratados.

A arquitetura proposta nesta tese explora as características dos algoritmos de Live Migration e faz a mediação entre as estratégias de consolidação e de balanceamento de carga e os algoritmos de Live Migration, minimizando impactos causados por uma migração em massa de máquinas virtuais, típicos dessas estratégias.

Figura 1: Cargas de trabalho reais.

(a) Banco de Dados.

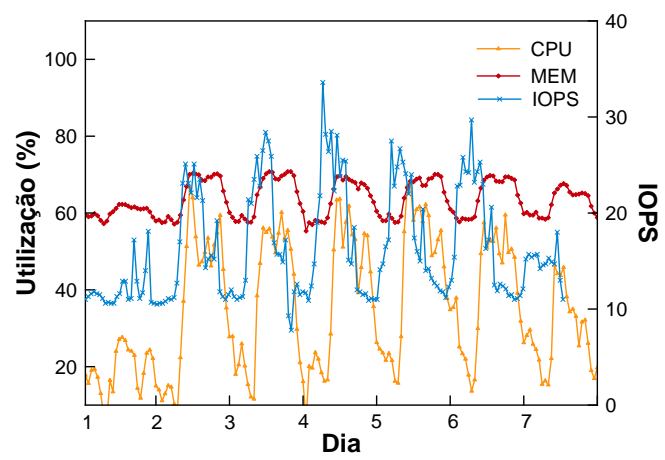

(b) Ambiente WEB.

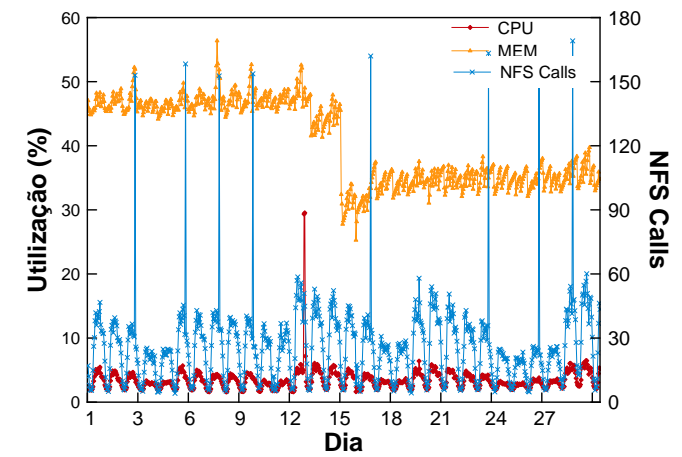

Fonte: Próprio Autor (2015).

A estratégia baseia-se na observação de que algumas cargas de trabalho possuem padrões cíclicos. Dois exemplos de cargas reais estão apresentados na Figura 1. As Figuras 1a e 1b apresentam a utilização média de recursos de um servidor de Banco de Dados de uma empresa de telecomunicações e um conjunto de servidores Web virtuais de uma grande editora, respectivamente, sendo que em ambas nota-se de forma nítida que há um padrão cíclico de uso de recursos no decorrer do tempo. Nas duas cargas, o ideal é que, qualquer que seja a necessidade, a migração dessas máquinas virtuais ocorra em períodos que o uso de recursos computacionais esteja mais baixo.

O padrão cíclico pode ser temporal, como observado nos exemplos da Figura 1, cuja carga possui variações de acordo com o horário do dia e períodos do mês/ano. Um exemplo de cargas que seguem esse padrão, são sites de vendas que podem ter maior acesso durante períodos específicos do ano, pró- 
ximo de dias comemorativos. Podem ocorrer padrões cíclicos que são inerentes da própria aplicação. Em geral, aplicações científicas e paralelas possuem um comportamento cíclico inerente que pode depender dos parâmetros de entrada, como arquivos ou argumentos.

\subsection{Contribuições e Resultados}

As principais contribuições deste trabalho são:

- A apresentação e a implementação de uma arquitetura para controlar a migração de máquinas virtuais que considera a carga de trabalho e a identificação de padrões cíclicos (BARUCHI; MIDORIKAWA; NETTO, 2014). Essa arquitetura tem como principal característica a implementação de uma camada entre os hospedeiros e o orquestrados de máquinas virtuais, onde geralmente são desenvolvidas as estratégias de balanceamento de carga e consolidação. Basicamente, quando uma migração é executada, a ALMA intercepta a solicitação e pode adiar a migração da(s) máquina(s) virtual(is), evitando degradação de desempenho da aplicação e sobrecarga na infraestrutura do provedor de serviços;

- O desenvolvimento de uma metodologia para caracterizar a carga de trabalho e, com isso, determinar o comportamento cíclico da carga de trabalho da máquina virtual;

- Apresentação de um método para quantificar e predizer a degradação de desempenho de uma aplicação durante o processo de Live Migration. Esse tipo de informação pode ser de grande valia, pois possibilita determinar se a migração compensa. Em um cenário em que a migração da máquina virtual provocará um período maior de processamento devido ao impacto do processo da Live Migration, pode ser mais vantajoso 
manter o processamento no hospedeiro atual;

- Desenvolvimento de um algoritmo para migração de máquinas virtuais cujo desempenho é independente da carga de trabalho em execução. Esse algoritmo, diferente dos algoritmos tradicionais de Live Migration, não depende de como a memória é usada pela máquina virtual. Para esse fim, ao invés de enviar o conteúdo de toda a memória da máquina virtual, o algoritmo enviará a memória do ambiente de execução da aplicação (processos, arquivos abertos, estado da rede, entre outros), permitindo que o algoritmo seja determinístico e que a quantidade de dados trafegados na rede seja conhecida a priori.

\subsection{Organização}

O restante desta Tese está organizado da seguinte forma: o capítulo 2 aborda conceitos sobre virtualização e computação na nuvem; no capítulo 3 é abordado o tema migração de máquinas virtuais em que são abordados os algoritmos de migração de Live Migration e os conceitos de consolidação e balanceamento de carga, bem como os trabalhos relacionados a este trabalho e no capítulo 4 são apresentadas as técnicas de caracterização e de identificação de ciclos, que posteriormente serão usados na implementação da arquitetura ALMA e também contém conceitos para o entendimento do mecanismo de orquestração de migração de máquinas virtuais. No capítulo 5 é discute-se como a orquestração de máquinas virtuais utiliza a análise cíclica para definir o instante das migrações e também apresenta-se a idéia do funcionamento de um algoritmo de live migration de desempenho independente do uso da memória da máquina virtual. A implementação do orquestrador de migração de máquinas virtuais na arquitetura ALMA é apresentada no capítulo 6 e os resultados obtidos com esta arquitetura apresentados e discutidos no capítulo 7 . 
No capítulo 8 é apresentada uma métrica de custo da migração de máquinas virtuais e o protótipo do algoritmo de migração de máquinas virtuais. Por fim, as conclusões e trabalhos futuros são abordados no capítulo 9. 


\section{VIRTUALIZAÇÃO E COMPUTAÇÃO NA NUVEM}

No decorrer deste capítulo serão abordados alguns conceitos necessários para o entedimento da proposta. Isso é importante para demonstrar a situação atual da virtualização, principalmente no que diz respeito ao processo de Live Migration e computação na nuvem.

\subsection{Conceitos}

Apesar de ser uma tecnologia bastante difundida nos dias de hoje, a virtualização é um conceito do início dos anos 70 (GOLDBERG, 1974) e foi comercializada pela primeira vez no IBM/370. Atualmente, existem diversas técnicas de implementação da virtualização e também diversas maneiras de classificá-las. A técnica de virtualização empregada é determinante em diversos aspectos como, desempenho, escalabilidade, portabilidade e isolamento. Neste trabaIho serão apresentadas duas formas de classificação (SMITH; NAIR, 2005):

- De acordo com a camada em que o Monitor de Máquinas Virtuais é implementado;

- De acordo com a camada ISA. 


\subsubsection{Camada do Monitor de Máquinas Virtuais}

Esta forma de classificação de máquinas virtuais é bastante comum na literatura por ser uma taxonomia bastante genérica e que engloba praticamente todas as técnicas de virtualização disponíveis. De acordo com essa classificação, existem dois tipos de virtualização: o tipo I e o tipo II. Pode existir, ainda, uma terceira classificação denominada Híbrida, que utiliza algumas técnicas de otimização ao implementar o tipo I ou II. As figuras 2a e 2b ilustram estas duas classificações de virtualização.

Figura 2: MVs do (a) Tipo I e (b) Tipo II.

(a)

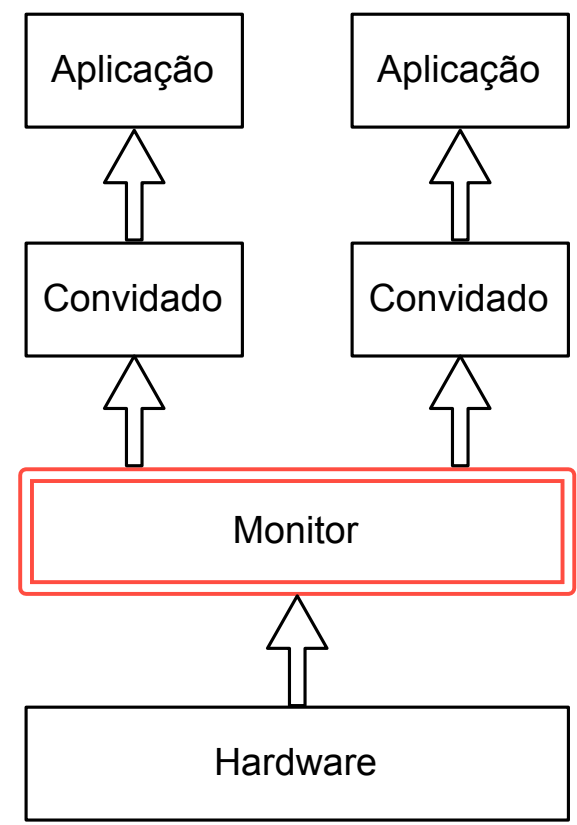

(b)

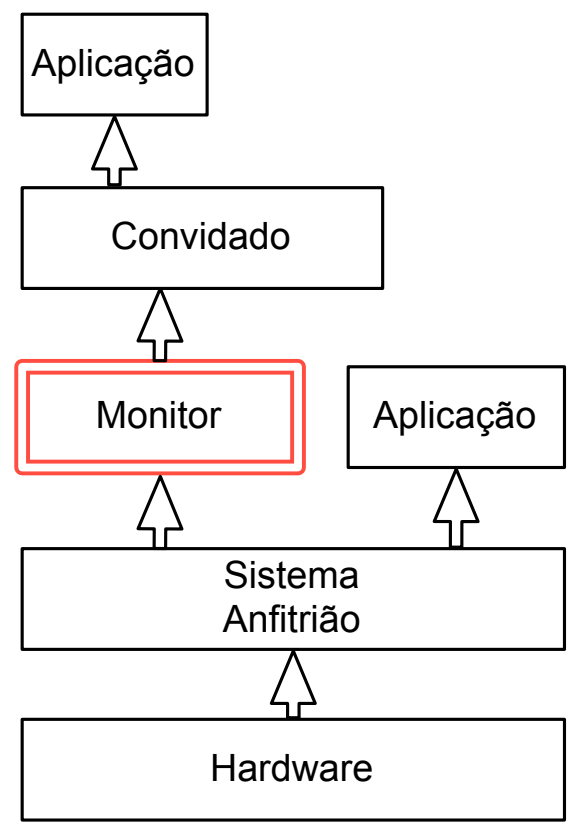

Fonte: Smith e Nair (2005)

- Tipo I: neste tipo de virtualização o monitor de máquinas virtuais situa-se entre o Hardware e a Máquina Virtual (ou sistema convidado);

- Tipo II: neste tipo de virtualização, o monitor de máquinas virtuais é implementado como um processo ordinário no Sistema Operacional afitrião; 
- Híbrido: em linhas gerais, o tipo Híbrido pode ser um monitor de máquina virtual do tipo I ou II mas com algumas técnicas de otimização que são implementadas em ambos os tipos, I ou II.

Os monitores de máquinas virtuais do tipo I possuem controle sobre o Hardware e, acima dele, são criadas as máquinas virtuais que podem executar o seu próprio sistema operacional. Como exemplos, podem ser citados o VMWare ESX Server (WALDSPURGER, 2002) e o Xen (BARHAM et al., 2003).

Em contra partida, os monitores de máquinas virtuais do tipo II são implementados como um processo comum dentro do sistema operacional anfitrião. Nesse tipo de virtualização, o sistema operacional é uma camada adicional entre o monitor de máquinas virtuais e o Hardware. Como exemplos deste tipo de virtualização, podem ser citados o Virtual Box ${ }^{1}$ e o Bochs ${ }^{2}$.

\subsubsection{Camada ISA}

A segunda forma de classificação de monitores de máquinas virtuais é realizada de acordo com a camada ISA (do inglês, Instruction Set Architecture). Essa taxonomia é utilizada tanto para máquinas virtuais de sistemas como para máquinas virtuais de processos (como a Java Virtual Machine JVM (LINDHOLM; YELLIN, 1999)). Nesta classificação, as máquinas virtuais são divididas primeiramente em máquinas virtuais de sistema ou de processo e, em seguida, são classificadas de acordo com a ISA, isto é, se a máquina virtual possui ou não emulação da camada ISA.

A máquina virtual do tipo I é chamada de máquina virtual clássica (Classic System) e a máquina virtual do tipo II é chamada de máquina virtual convi-

\footnotetext{
${ }^{1}$ Disponível em: <https://www.virtualbox.org/>

${ }^{2}$ Disponível em: <http://bochs.sourceforge.net/>
} 
Figura 3: Taxonomia de acordo com a camada ISA.

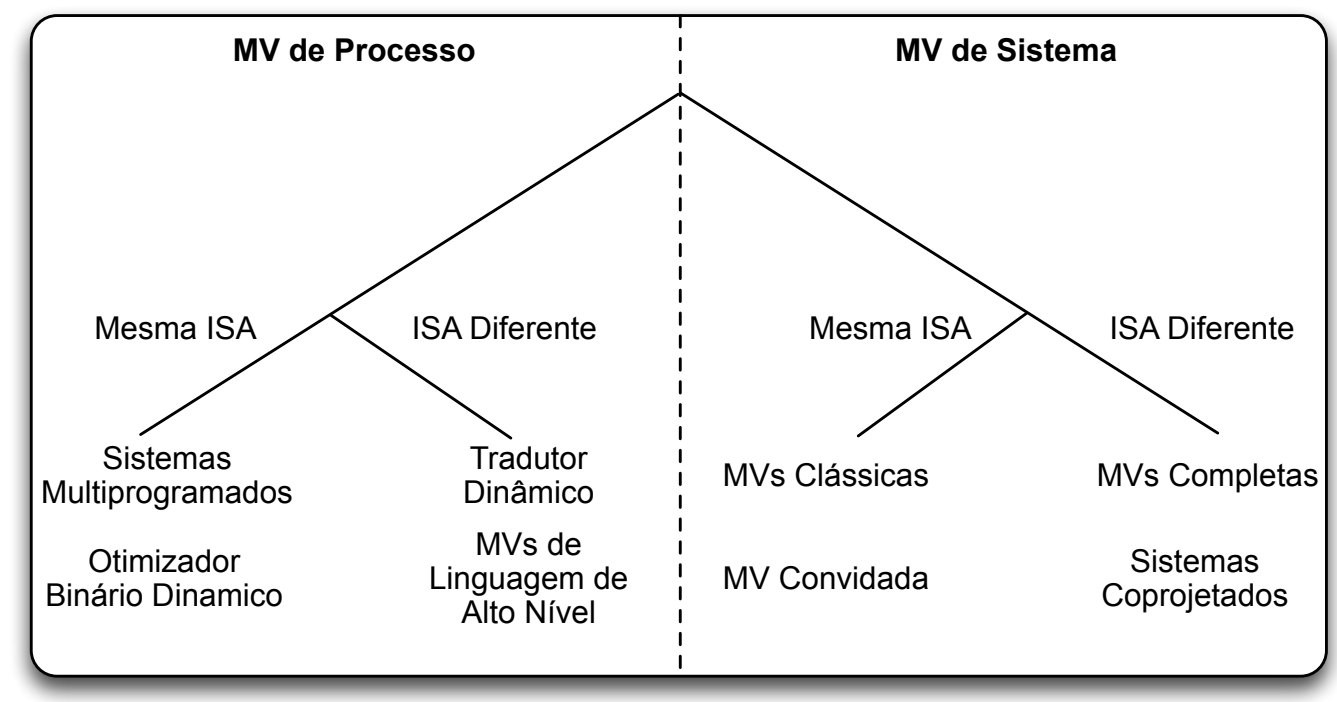

Fonte: Smith e Nair (2005)

dada. Como se observa na Figura 3, as máquinas virtuais do tipo I e do tipo Il estão na mesma classe, uma vez que possuem a mesma camada ISA. $\mathrm{Na}$ classe em que a camada ISA do hospedeiro e da máquina virtual convidada são diferentes, estão as máquinas virtuais completamente virtualizadas e as coprojetadas.

- Máquinas Virtuais Completamente Virtualizadas: todo o sistema e as aplicações dependem de uma determinada camada ISA para funcionar corretamente (por exemplo, Windows IA32 e Apple PowerPC). Nesse cenário, a máquina virtual deve emular tanto o código da aplicação como do sistema operacional. Um exemplo desse tipo de virtualização é o Wine (AMSTADT; JOHNSON, 1994);

- Máquinas Virtuais Coprojetadas: nesse tipo de virtualização é implementado um tipo de camada ISA proprietária para melhorar o desempenho e a eficiência do Hardware. Uma máquina virtual coprejatada não possui aplicações ISA nativas, isto é, o próprio monitor de máquinas virtuais se apresenta como parte da implementação do Hardware. Sua prin- 
cipal função é emular a camada ISA da máquina virtual convidada. Um exemplo é o Transmeta Crusoe (HALFHILL, 2000).

\subsection{Computação na Nuvem}

O conceito de computação como serviço é análogo a outros serviços de que usufruímos atualmente, como a energia elétrica ou de telefonia: ao ligar um aparelho elétrico na tomada não há necessidade de conhecer detalhes de como a energia elétrica é gerada ou mesmo como ela percorre o caminho até chegar ao equipamento. O principal objetivo da computação na nuvem é tornar a computação acessível da mesma forma, abstraindo as partes complexas de seus usuários. 
Figura 4: Convergência de tecnologias para o surgimento da computação na nuvem.

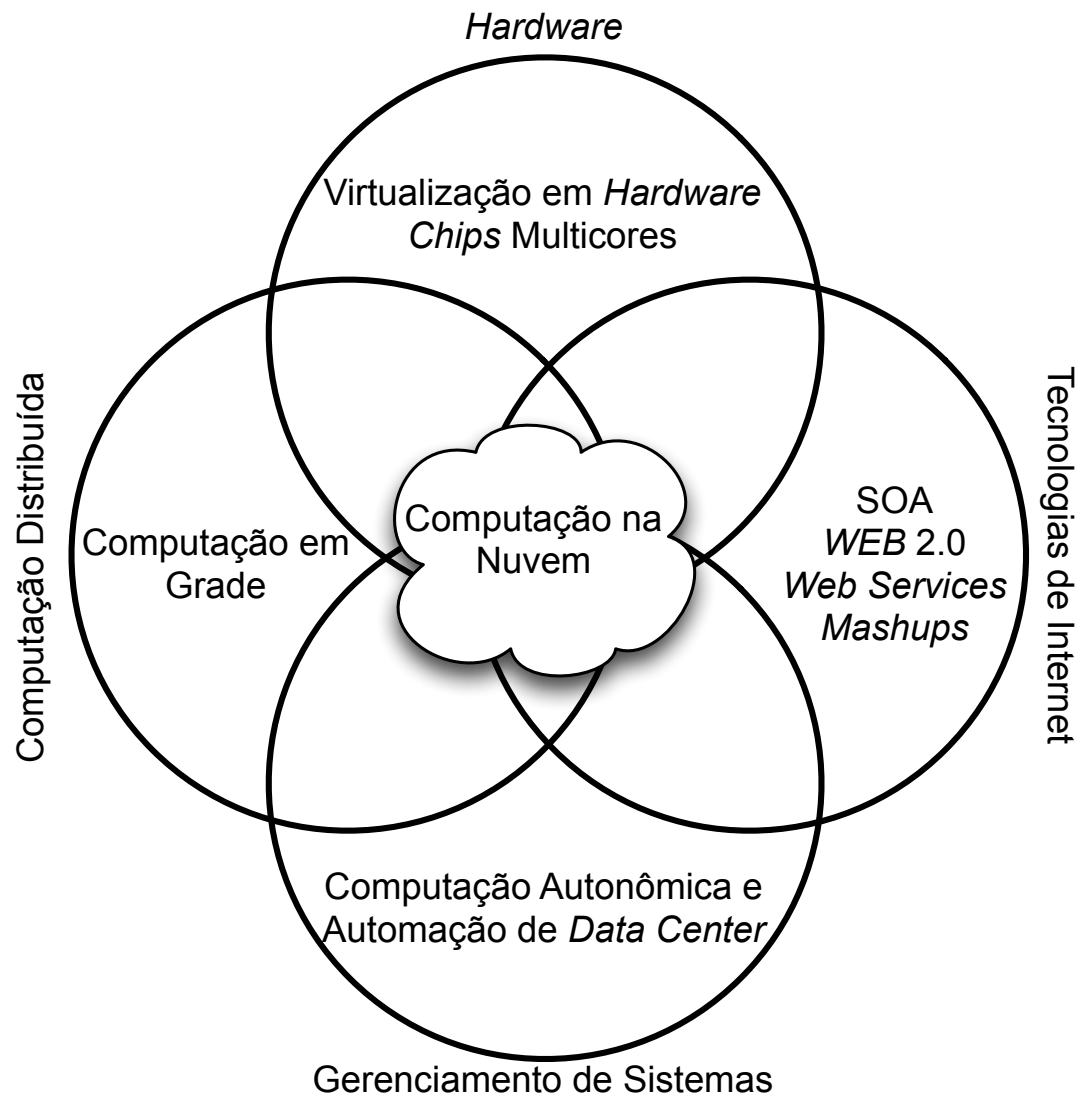

Fonte: Buyya, Broberg e Goscinski (2011) 
Além das características técnicas da computação na nuvem, há também características de negócio. Assim como alguns serviços públicos tradicionais, como energia e saneamento básico, a computação na nuvem oferece um modelo de pagamento de acordo com a utilização dos recursos computacionais, sem a necessidade de contratos caros e de longo prazo com empresas de terceirização (ARMBRUST et al., 2009).

O amadurecimento da computação na nuvem e sua rápida adoção nas empresas deve-se ao advento e convergência de outras tecnologias que viabilizaram o seu modelo. A Figura 4 ilustra a convergência das principais tecnologias que tornaram possível a computação na nuvem da forma como é implementada atualmente.

\subsubsection{Tipos de Serviços}

Apesar de diversos serviços serem oferecidos na nuvem, basicamente, estes podem ser divididos em três classes de acordo com o nível de abstração. Todos os serviços são entregues e consumidos pelos usuários em tempo real através da Internet ou de uma rede local. As três classes de serviços são (BUYYA; BROBERG; GOSCINSKI, 2011):

- Infraestrutura como Serviço (Infrastructure as a Service - laaS): esse tipo de serviço oferece recursos computacionais virtualizados, como Storages e servidores. O usuário pode escolher diversas imagens de instalação de sistema operacional, configuração do hardware entre outras customizações, permitindo a instalação de suas aplicações livremente no servidor (ou em qualquer que seja o equipamento) disponibilizado. Exemplos de provedores de laaS são a Amazon EC2 e Rackspace; 
- Plataforma como Serviço (Platform as a Service - PaaS): os provedores desse tipo de serviço oferecem um nível de abstração acima do laaS. A PaaS é um serviço orientado ao desenvolvimento de aplicações por meio do qual usuários podem criar e executar suas aplicações na nuvem sem se preocupar, por exemplo, com a configuração de hardware ou software, pois o provedor fornece um ambiente pronto para o trabalho de desenvolvimento de software. Exemplos de provedores desse tipo de serviço são o Google AppEngine e Microsoft Azure;

- Software como Serviço (Software as a Service - SaaS): por meio desse serviço os usuários podem acessar aplicações completas, como bancos de dados, Enterprise Resource Planning (ERPs), pacotes de produtividade (como planilhas e editores de texto), entre outros. Esse serviço representa o mais alto nível de abstração, pois os usuários não precisam possuir conhecimento algum sobre computação e, em geral, o serviço é acessado apenas pelo navegador. Aqui a aquisição de licenças de uso de software não são mais necessárias, o que o torna atraente.

É possível encontrar referências na Internet e na literatura a respeito de outros tipos de serviço como DaaS (Data as a Service) ou STaaS (Storage as a Service), etc. Entretanto, esses serviços mais especializados poderiam ser reduzidos a qualquer um dos tipos de serviços citados acima, de acordo com o grau de abstração que é oferecido.

\subsubsection{Tipos de Nuvens}

Além da classificação dos tipos de serviços oferecidos, há também classificação do tipo de nuvem. A classificação da nuvem varia de acordo com quais usuários podem ter acesso aos serviços disponibilizados pelo provedor 
(RIMAL; CHOI; LUMB, 2009), e também de acordo com o meio de acesso. Nesse último caso, a nuvem pública é acessível pela Internet, enquanto uma nuvem privada pode ser, eventualmente, acessada pela Internet.

\subsubsection{Nuvens Públicas}

Uma nuvem será considerada pública quando o acesso aos seus serviços for realizado através da Internet e quando puder ser acessada pelo público em geral, bastando somente um meio de pagamento válido. Nesse modelo de nuvem, os usuários pagam pelos serviços de acordo com a demanda solicitada.

Apesar dos fornecedores desse tipo de nuvem oferecerem excelentes níveis de disponibilidade, a dependência da Internet (muitas vezes com alta latência, variação de banda e falta de segurança) pode ser um fator limitador desse modelo. Além disso, provedores de nuvens públicas possuem suas próprias APIs, dificultando, por exemplo, a migração de serviços entre provedores diferentes.

\subsubsection{Nuvens Privadas}

Em contraponto à nuvem pública, há o conceito de nuvem privada. Em geral, as nuvens privadas são criadas a partir de recursos computacionais ociosos dentro da própria empresa, que são virtualizados e disponibilizados aos usuários, os quais fazem uso do serviço através de uma rede local privada. Esse tipo de nuvem é acessível somente a pessoas autorizadas e sua principal vantagem é o controle da empresa sobre os recursos disponibilizados e a segurança do ambiente.

Entretanto, para que uma empresa possa implementar esse modelo, é necessário que ela tenha alguma maturidade, tanto em conhecimento técnico como em governança. A criação descontrolada de máquinas virtuais, por 
exemplo, poderia causar diversos problemas, como: congestionamento de equipamentos de rede, desperdício de recursos computacionais, entre outros.

\subsubsection{Nuvens Híbridas}

As nuvens híbridas são uma combinação das nuvens públicas e privadas, na qual há uma sinergia entre ambas as nuvens. Os principais exemplos de aplicação de nuvens híbridas são:

- Ambiente de Disaster Recovery (DR): a nuvem pública, ou a nuvem privada, fica em estado de espera (ou standby). Na ocorrência de uma indisponibilidade, a nuvem em espera assume a função principal, diminuindo o tempo de interrupção do serviço oferecido;

- Prolongamento: modelo em que, a nuvem pública serve como um prolongamento da nuvem privada, isto é, os dados mais críticos ficam armazenados e são processados na nuvem privada enquanto a nuvem pública assume um trabalho "menos nobre", processando dados de baixa criticidade. Há também a situação na qual as empresas utilizam temporariamente alguma nuvem pública para dar vazão a picos de demanda, que de outra forma não poderiam ser supridos pelo parque computacional interno. 


\section{MIGRAÇÃO DE MÁQUINAS VIRTUAIS}

A propriedade de encapsular o ambiente de execução de um sistema operacional é fundamental para que a Live Migration possa ser realizada (SMITH; NAIR, 2005). A virtualização permite: (1) que, a qualquer momento, uma máquina virtual seja congelada, (2) que todas as informações necessárias para que ela continue a executar do ponto de parada sejam armazenadas (ou encapsuladas) em um arquivo e (3) que, a partir dessas informações, o processamento possa ser retomado em qualquer máquina física. Entretanto, para que a Live Migration ocorra com sucesso, algumas condições precisam ser satisfeitas ${ }^{1}$ :

- Armazenamento Compartilhado: os discos das máquinas virtuais, que podem ser um arquivo convencional ou dispositivos de bloco, devem estar acessíveis tanto para a máquina de origem como para a máquina de destino;

- Mesma Arquitetura: os processadores das máquinas físicas envolvidas na Live Migration devem possuir a mesma arquitetura. Em geral microarquiteturas diferentes são aceitas com algumas restrições que podem variar de acordo com o fornecedor do monitor de máquinas virtuais;

\footnotetext{
${ }^{1}<$ https://access.redhat.com/documentation/en-US/Red_Hat_Enterprise_Virtualization/3. 0/html/Administration_Guide/References_RHEV_3_Migration_Migration_Prerequisites.html>
} 
- Mesma Rede Local: é necessário que os hospedeiros estejam na mesma rede. Em alguns casos, é recomendável que a rede usada para o tráfego de dados da Live Migration seja separada das demais.

Deve-se notar que essas três condições são de sérios limitadores do processo de Live Migration, as quais têm sido objeto de diversos estudos (NAGIN et al., 2011), pois impõem limites para que este seja implementado, por exemplo, em sites geograficamente distribuídos.

A classificação dos algoritmos de Live Migration pode ser feita de acordo com o momento em que o conteúdo da memória da máquina virtual é copiado para sua réplica no hospedeiro de destino. Os dois tipos de algoritmos de migração são: Pré-cópia e Pós-cópia. O primeiro faz a cópia da memória antes da máquina virtual iniciar a execução no hospedeiro destino, enquanto o último realiza a cópia depois que a máquina virtual iniciou sua execução no hospedeiro de destino.

Para que os algoritmos possam ser comparados, a grande maioria dos estudos utilizam, basicamente, quatro métricas. No quesito de desempenho da Live Migration, tem-se duas métricas:

- Tempo Total de Migração: intervalo de tempo entre o início do processo de Live Migration até o reinício da execução da máquina virtual no hospedeiro destino;

- Downtime: intervalo de tempo durante o qual a máquina virtual não está executando e, consequentemente, não está disponível para o usuário.

As outras duas métricas de avaliação são referentes ao impacto da Live Migration na carga de trabalho da máquina virtual.

- Tempo de Execução: refere-se ao tempo que uma aplicação levará 
para executar, dado que durante sua execução a máquina virtual sofreu uma migração;

- Vazão: quantidade de processamento executado na máquina virtual em um intervalo de tempo com e sem a ocorrência de Live Migration.

\subsection{Algoritmo Pré-Cópia}

Esse algoritmo inicia a cópia do conteúdo da memória da máquina virtual para o novo local antes que a máquina virtual comece a executar no hospedeiro de destino. Além disso, por ser um algoritmo que possui mais segurança, é amplamente usado pelos monitores de máquinas virtuais comerciais, pois a máquina virtual somente é efetivamente migrada quando toda memória já está no hospedeiro de destino.A cópia da memória entre os hospedeiros é realizada de forma iterativa. Este algoritmo pode ser dividido em cinco estágios (KIKUCHI; MATSUMOTO, 2012):

- Estágio 1 - Reserva de Recursos: verifica se o hospedeiro de destino possui recursos suficientes para receber a máquina virtual;

- Estágio 2 - Pré-Cópia Iterativa: transfere toda a memória da máquina virtual para o hospedeiro de destino na primeira iteração. Nas iterações subsequentes, somente as páginas de memória alteradas (dirty pages) durante o processo de cópia da iteração anterior são transferidas;

- Estágio 3 - Parada e Cópia: a máquina virtual é suspensa no hospedeiro de origem e uma última iteração de cópia da memória é realizada;

- Estágio 4 - Encerramento: a máquina virtual é descartada no hospedeiro de origem e todos os recursos que estavam assinalados para ela 
são liberados;

- Estágio 5 - Ativação: o hospedeiro de destino ativa a máquina virtual.

Um dos problemas desse algoritmo é a possibilidade dos ciclos de cópia de memória continuarem indefinidamente. Uma forma de conter esse problema é criar condições de parada. Tomando como exemplo o monitor de máquinas virtuais Xen (BARHAM et al., 2003), as condições de parada dos ciclos de cópia são:

- Menos de cinquenta páginas foram atualizadas desde a última iteração (páginas de memória marcadas como dirty pages);

- Máximo de 29 iterações de ciclos de cópia;

- Quantidade de dados transferidos superior a 3 vezes a memória RAM alocada para a máquina virtual.

Além disso, observa-se que esse algoritmo pode sofrer grande variação de desempenho em função da taxa de atualização de páginas de memória (dirty page rate) e também da banda de rede disponível para transferir a memória. Alguns estudos, como o apresentado por Strunk (2012), formalizam a dependência do algoritmo com a taxa de atualização de páginas e a banda de rede. O autor define limites inferiores e superiores, apresentados nas inequações 3.1 e 3.2 para o tempo de migração e tempo de downtime, respectivamente:

$$
\begin{gathered}
\frac{V_{\text {mem }}}{B} \leq T_{m i g} \leq \frac{(M+1) * V_{\text {mem }}}{B} \\
0 \leq T_{\text {down }} \leq \frac{(M+1) * V_{\text {mem }}}{B}
\end{gathered}
$$


Onde:

$V_{\text {mem }}$ : quantidade de memória alocada na máquina virtual que será migrada;

B: banda de rede disponível para transferir a memória;

$T_{\text {mig }}:$ tempo de migração;

$T_{\text {down }}:$ tempo de downtime;

M: número máximo de vezes que a memória total pode ser transferida na fase de pré-cópia.

O limite inferior das inequações 3.1 e 3.2 refere-se à situação em que a máquina virtual está ociosa. Nessa situação, o tempo de migração é limitado somente pela banda de rede entre os dois hospedeiros e o tempo de downtime é mínimo devido à baixa atualização de páginas de memória. Já o limite superior das inequações está relacionado a uma alta taxa de modificação de páginas de memória, levando a ocorrência de vários ciclos de cópia. O pior caso acontece quando a taxa de modificação de páginas for superior à vazão de rede entre os hospedeiros envolvidos.

Existem outros fatores que podem influenciar no tempo de migração, conforme observado por Xu et al. (2013), como a quantidade de migrações concorrentes. Entretanto a taxa de atualização das páginas de memória ainda é fator dominante no desempenho da Live Migration.

\subsection{Algoritmo Pós-Cópia}

A ideia principal desse algoritmo é realizar a migração o mais rápido possível para o hospedeiro de destino. Inicialmente, a máquina virtual é suspensa e as informações pertinentes ao seu estado, como os valores dos registradores e um conteúdo mínimo da memória, são enviadas ao hospedeiro de destino. Entretanto, a execução será iniciada com informações parciais do estado cor- 
rente da máquina virtual. Assim, uma severa degradação de desempenho nos momentos iniciais de execução poderá ser percebida.

Como somente parte da memória é transferida em um primeiro instante, o restante da memória deve ser preenchido à medida que os acessos a ela ocorrem. Como grande parte da memória ainda está localizada no hospedeiro de origem, o usuário pode experimentar períodos de degradação de desempenho, até que a memória seja devidamente preenchida.

O principal benefício desse algoritmo é a redução do tempo de downtime, comparado com o algoritmo de Pré-Cópia durante o processo de migração, pois assim que a máquina virtual é suspensa, a execução é iniciada no hospedeiro de destino. A degradação de desempenho e o longo processo de migração são os pontos fracos do algoritmo pós-cópia.

\subsection{Consolidação e Balanceamento de Carga}

Estratégias de consolidação e balanceamento de carga possuem objetivos diferentes, sendo que as primeiras tem como meta principal concentrar as máquinas virtuais em algumas máquinas físicas e as segundas, distribuir as máquinas virtuais entre diversas máquinas físicas. É importante observar que um provedor de serviço na nuvem pode implementar uma estratégia de consolidação ou de balanceamento de carga com finalidades diferentes. Por exemplo, pode-se executar um processo de consolidação com a finalidade de redução de consumo de energia ou simplesmente por conta de uma manutenção em diversas máquinas físicas. O mesmo princípio pode ser aplicado às estratégias de balanceamento de carga, nas quais um provedor pode distribuir as máquinas virtuais em diversas máquinas físicas para otimizar o uso de recursos computacionais ou para não ferir níveis de serviço acordados. 
Como as finalidades da implementação de qualquer que seja a estratégia são muitas e variam de acordo com a necessidade de cada provedor e, mais importante, são indiferentes para o entendimento deste trabalho, elas não serão aprofundadas ${ }^{2}$.

\subsubsection{Consolidação}

Estratégias de consolidação (de carga ou de máquinas virtuais) consistem em escolher, de acordo com algum(s) critério(s), determinadas máquinas virtuais e concentrá-las em alguns poucos hospedeiros. Em geral, essas estratégias de consolidação são aplicadas quando o provedor de serviços precisa reduzir o consumo de energia elétrica, procedimento muito comum quando há interesse em implementar um data center verde (ou computação verde).

O principal problema das estratégias de consolidação é encontrar uma combinação ótima de concentração de máquinas virtuais, minimizando a quantidade de máquinas físicas ligadas com a maior quantidade possível de máquinas virtuais. Outro dilema da consolidação é evitar quantidade excessiva de Live Migrations (FERRETO et al., 2011) para alcançar algum resultado.

É importante notar que a soma dos recursos alocados paras as máquinas virtuais não deve exceder a quantidade de recursos existentes na máquina hospedeira. Essa restrição, como discutido na Introdução, torna a consolidação um problema NP-Difícil de otimização combinatória, análogo ao problema do Mochileiro (do inglês Bin Packing).

A ilustração apresentada na Figura 5 é um cenário simplificado em que se deseja desligar um dos hospedeiros, no caso, o host_A. Inicialmente, tem-se duas máquinas virtuais no host_A e uma máquina virtual no host_X e outra no

\footnotetext{
${ }^{2}$ As estratégias de consolidação e de balanceamento de carga serão referenciadas como Função Objetivo, quando a estratégia utilizada for indiferente para a discussão.
} 
Figura 5: Cenários de Consolidação.

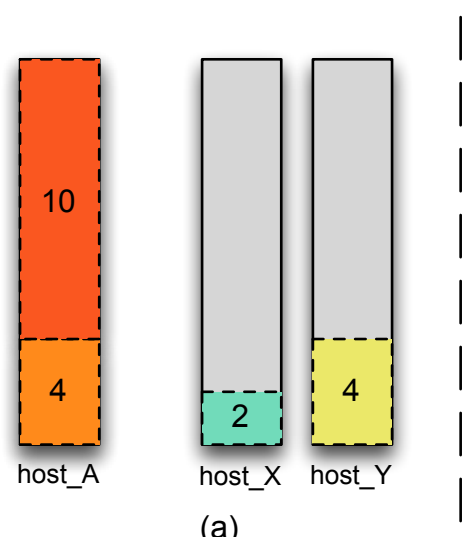

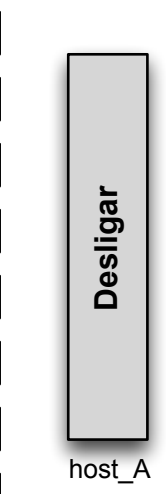

Fonte: Próprio Autor (2015).

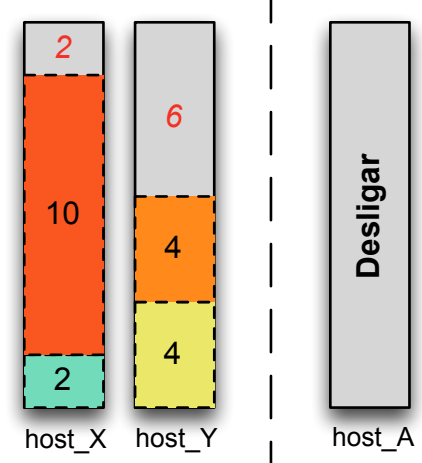

(b)

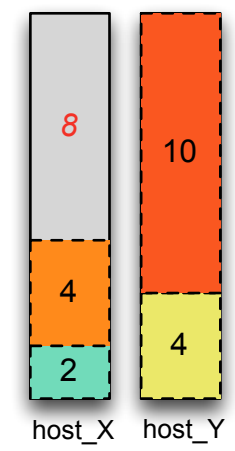

(c)

host_Y (Figura 5a). Mesmo neste cenário simplificado, temos duas soluções possíveis: uma que deixa os dois hospedeiros com algum recurso livre (Figura $5 b)$ e outra na qual um dos hospedeiros (host_X) fica com muito recurso livre e o outro saturado (Figura 5c). Ambos os casos apresentam uma solução satisfatória, entretanto, ao extrapolar para um cenário com centenas ou milhares de máquinas virtuais e máquinas físicas o problema torna-se muito complexo para ser resolvido em tempo polinomial.

Os métodos mais comuns de implementação de estratégias de consolidação é por Heurísticas (FELLER; MORIN; ESNAULT, 2012) ou Programação Linear (FERRETO et al., 2011), sendo que a primeira forma é a mais explorada por pesquisadores. Implementações utilizando Heurísticas costumam ser mais flexíveis e a solução (mesmo que subótima) pode ser obtida mais rapidamente. Já estratégias que implementam a Programação Linear são eficientes quando existem mais restrições a serem satisfeitas, como Nível de Serviço e quantidade máxima de Live Migrations. 


\subsubsection{Balanceamento de Carga}

O oposto da Consolidação é o Balanceamento de Carga, cujo objetivo é distribuir as máquinas virtuais e suas respectivas cargas de trabalho em diversos hospedeiros. As estratégias de balanceamento de carga são empregadas em situações em que se quer extrair melhor utilização dos recursos computacionais (DOMANAL; REDDY, 2014). O ambiente de computação na nuvem é bastante dinâmico com máquinas virtuais sendo criadas e destruídas a todo momento, sendo que essa característica pode concentrar máquinas virtuais em alguns poucos hospedeiros a longo prazo, gerando gargalos na infraestrutura. Ainda assim, o balanceamento de carga é característica essencial para que um provedor de computação na nuvem seja escalável (RANDLES; LAMB; TALEB-BENDIAB, 2010). Outro cenário não muito comum é a necessidade de privilegiar o processamento de algum usuário com níveis de serviço mais agressivos, logo com maior prioridade.

Na Figura 6, o estado inicial (Figura 6a) é idêntico ao discutido na sessão anterior. Entretanto, nesse caso o host_A está sobrecarregado e as máquinas virtuais hospedadas nele devem ser distribuídas entre o host_X e o host_Y. No primeiro cenário ocorre uma troca de máquinas virtuais entre o host_X e o host_A (Figura 6b). No cenário ilustrado na Figura 6c, os três hospedeiros são envolvidos no processo. Uma máquina virtual do host_A é migrada para o host_X e, por sua vez, o host_Y recebe uma máquina virtual do host_X.

Os principais desafios das estratégias de balanceamento de carga são (NUAIMI et al., 2012):

- Distribuição Geográfica dos Nós: provedores de maior porte estão começando a construir data centers em diversas localidades, geograficamente distribuídos. Levar em consideração hospedeiros em outras ci- 
Figura 6: Cenários de Balanceamento de Carga.

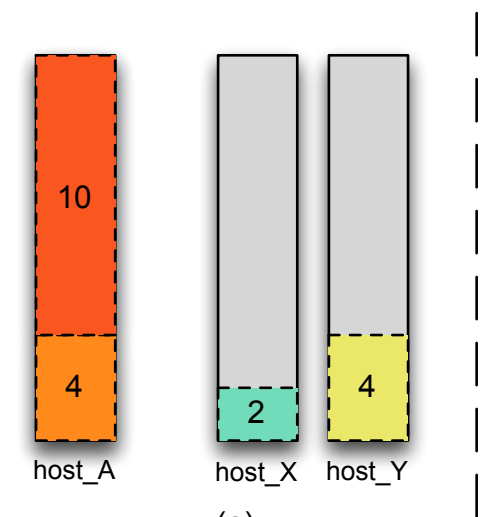

(a)

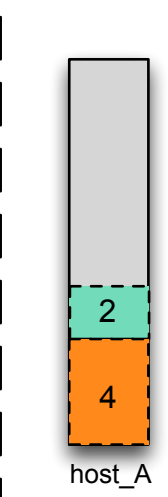

Fonte: Próprio Autor (2015).

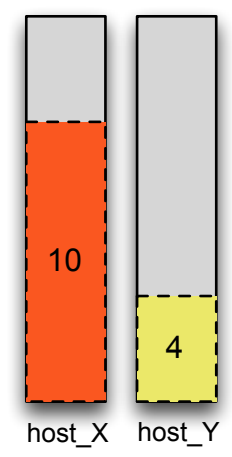

(b)
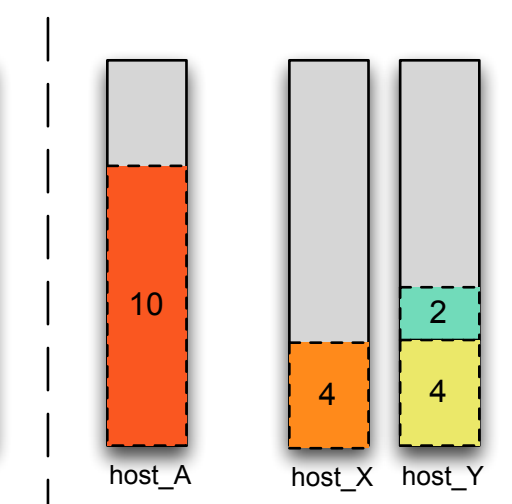

(c)

(c)

dades ou mesmo países é um grande desafio, pois variáveis como a velocidade da rede e localização dos usuários em relação aos recursos computacionais começam a exercer maior influência;

- Replicação e Armazenamento: em geral, os algoritmos de balanceamento de carga não consideram a utilização dos recursos de armazenamento. Além disso, implementar técnicas de replicação de dados em longas distâncias pode gerar maior lentidão no processo de migração de máquinas virtuais;

- Complexidade do Algoritmo: para que um algoritmo tome decisões mais acertadas é interessante que haja coletas de dados dos hospedeiros e da situação das cargas de trabalho e que tudo isso seja processado e levado em consideração. Entretanto, a coleta excessiva de dados e imposição de muitas restrições pode torná-lo mais complexo e, consequentemente, mais ineficiente;

- Ponto de Falha: algoritmos de balanceamento de carga centralizados possuem maior controle sobre a situação atual do ambiente, contudo, a centralização das decisões de balanceamento de carga torna-se um ponto único de falha, podendo comprometer a escalabilidade e o desem- 
penho do provedor de serviços.

\subsubsection{Taxonomia}

As estratégias de consolidação e balanceamento de carga podem ser implementadas de diversas maneiras de acordo com os fatores a serem considerados para solucionar o problema. É comum a implementação de estratégias centralizadas (HERMENIER et al., 2009) (SONI; KALRA, 2014) quando a solução para o problema é tratada de forma macro, desconsiderando o estado individual das aplicações ou de um hospedeiro específico. As soluções distribuídas (RANDLES; LAMB; TALEB-BENDIAB, 2010) (FELLER; MORIN; ESNAULT, 2012) lidam com o problema em uma granularidade menor, respeitando a situação individual dos hospedeiros ou de alguma aplicação. A Figura 7 resume as principais formas de implementação das estratégias de consolidação e balanceamento de carga em um diagrama de Venn.

As implementações dinâmicas das estratégias de balanceamento de carga (CHEN et al., 2014) e de consolidação (BELOGLAZOV; BUYYA, 2013) têm como principal característica a constante atualização do estado do data center. Novas medições são realizadas de forma automática regularmente ou executadas por mecanismos de monitoração. As implementações dinâmicas são atraentes, pois conseguem captar o estado do ambiente contudo, constantes atualizações podem causar problemas de desempenho ou então gerar o efeito ping-pong ${ }^{3}$.

Em contra partida, as implementações estáticas de consolidação (VENKATARAMAN et al., 2013) e balanceamento de carga (RAHMAWAN; GONDOKARYONO, 2009) são executadas somente com intervenção humana e dependem da experiência e habilidade dos administradores de sistemas. A

\footnotetext{
${ }^{3}$ Quando uma máquina virtual é constantemente migrada entre dois hospedeiros.
} 
Figura 7: Taxonomia de estratégias de consolidação e balanceamento de carga em computação na nuvem.

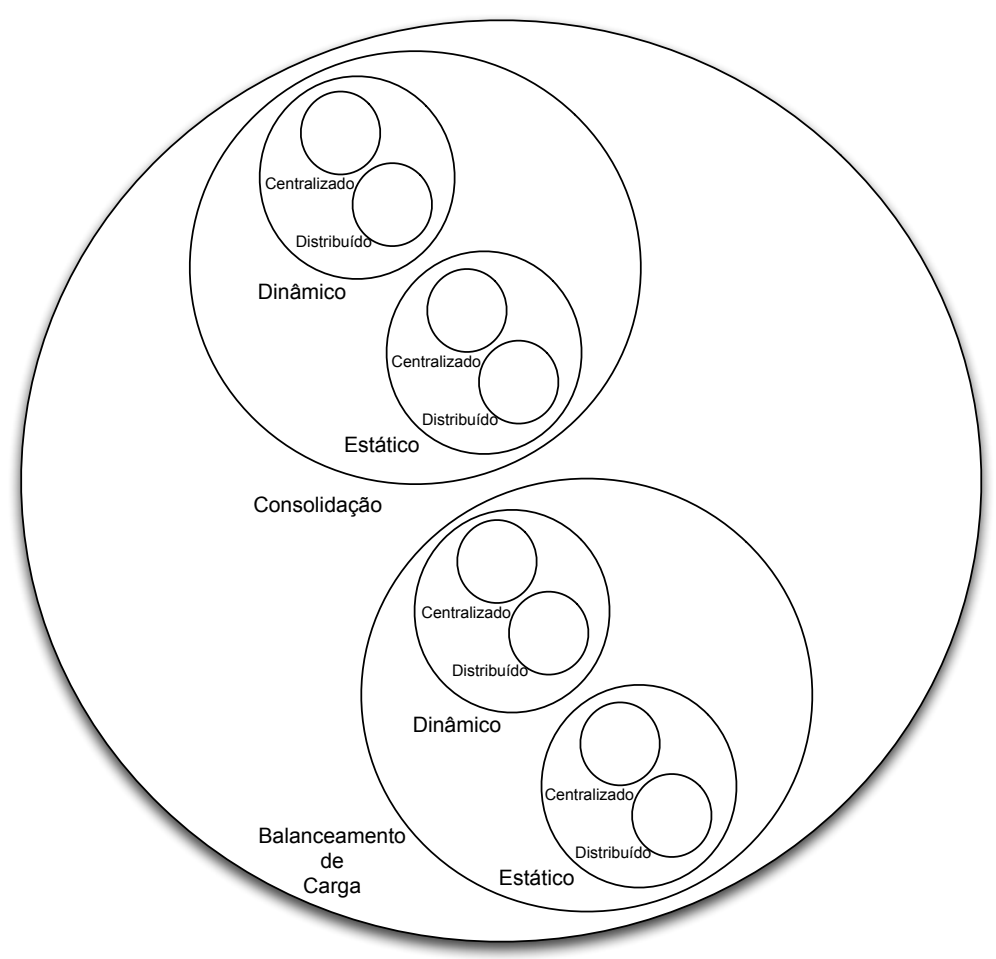

Fonte: Próprio Autor (2015).

computação de um novo mapa ${ }^{4}$, através de estratégias estáticas, costumam ser mais elaboradas pois contam com a interação humana.

\subsection{Trabalhos Relacionados}

Os principais estudos que, de alguma forma, tratam o problema de sobrecarga e do custo da Live Migration em um ambiente de computação na nuvem estão relacionados à consolidação de máquinas virtuais. A consolidação tem sido o foco de muitas pesquisas, pois um bom algoritmo de consolidação poderá proporcionar uma redução significativa de custos ao provedor de serviços e, consequentemente, retornos financeiros.

\footnotetext{
${ }^{4}$ Uma mapa, em computação na nuvem, é a localização das máquinas virtuais nos hospedeiros.
} 
Neste capítulo os trabalhos relacionados foram divididos em dois tipos. Os primeiros são os trabalhos que analisam o comportamento da Live Migration, isto é, que contabilizam o processo de migração como sobrecarga ou para a aplicação ou para a infraestrutura. Esses trabalhos serão descritos na seção de estratégias analíticas de Live Migration. Os trabalhos do segundo tipo são aqueles que apresentam alguma estratégia para controlar a migração de máquinas virtuais visando a redução do congestionamento de rede gerado pela migração em massa de máquinas virtuais. Esses trabalhos são apresentados na seção de estratégias de controle de Live Migration.

\subsubsection{Estratégias Analíticas de Live Migration}

Como discutido na seção 3.3, a consolidação trata, em linhas gerais, da seleção de algumas máquinas virtuais e sua movimentação para algum hospedeiro de destino em comum, a fim de desligar ou reduzir o consumo dos hospedeiros de origem. Por se tratar de um problema NP-Difícil, diversas soluções baseadas em heurística são abordadas na literatura. Entretanto, a maioria das estratégias não contabiliza a sobrecarga da migração na infraestrutura e nas próprias cargas de trabalho das máquinas virtuais, isto é, uma vez que foi definida a necessidade da migração, elas são executadas imediatamente.

No trabalho apresentado por Xu et al. (2013), é apresentada uma estratégia que leva em conta o custo computacional da migração nos hospedeiros envolvidos no processo (origem e destino), nas máquinas virtuais a serem migradas e também nas máquinas já em execução no hospedeiro de destino. O iAware é uma estratégia de migração de máquinas virtuais que tem como principal objetivo evitar violações em acordos de níveis de serviço, prevenindo que uma migração afete outras máquinas virtuais. No trabalho, os autores mostram que o processo de migração é, essencialmente, de uso intensivo de 
rede e de processamento moderado e, por esta razão, afeta não somente a máquina virtual a ser migrada, mas também as máquinas virtuais já em execução nos hospedeiros envolvidos.

Um aspecto muito importante do iAware é a modelagem do impacto da migração em outras máquinas virtuais baseando-se no uso de recursos dos hospedeiros, principalmente na quantidade de interrupções geradas pelas máquinas virtuais. De forma similar ao trabalho aqui apresentado, o iAware é uma técnica que pode ser incorporada em estratégias já existentes de consolidação ou de balanceamento de carga. Além disso, ambas as estratégias tem como objetivo a redução da degradação de desempenho causada pelo processo de migração.

Entretanto, apesar de haver similaridades nítidas entre os dois trabalhos, o iAware não considera a carga de trabalho da máquina virtual, mas somente a sobrecarga nos hospedeiros que, quando perto da saturação, causam impacto em todas as máquinas virtuais que estejam em execução. O processo de migração por si só tem um custo computacional, portanto, postergar a migração de máquinas virtuais para períodos em que a máquina virtual está com uma carga mais favorável irá, consequentemente, reduzir o custo computacional do algoritmo de migração e a sobrecarga no hospedeiro.

O trabalho de Verma et al. (2011), em que é apresentado o CosMig, versa sobre o impacto da migração nas cargas de trabalho e no tempo que uma migração levará para finalizar em função da carga de trabalho. Os autores argumentam que um ambiente de computação na nuvem é bastante dinâmico por conta de alterações constantes, como a criação e a remoção de máquinas virtuais, oscilações de cargas de trabalho, entre outros. O modelo apresentado no CosMig é baseado em parâmetros de uso de processador e memória. Para determinar o impacto de migração de uma máquina virtual, os autores utilizam 
as seguintes métricas:

- Duração: Tempo que leva para uma migração finalizar;

- Impacto Próprio: Razão entre a redução da vazão de processamento durante a migração e a vazão de processamento sem a ocorrência da migração;

- Impacto em Máquinas Virtuais Coexistentes: Razão entre a redução da vazão de processamento durante a migração e a vazão de processamento sem a ocorrência da migração, mas em máquinas virtuais instaladas no mesmo hospedeiro que a máquina virtual a ser migrada.

Algumas das conclusões dos autores corroboram as observações feitas neste trabalho, entre elas; (1) um modelo de migração efetivo de máquinas virtuais deve levar em conta o comportamento da aplicação, (2) a migração, por si só, não melhora o desempenho de uma aplicação; são diversos os fatores que podem promover a melhora do desempenho que vão desde a capacidade computacional do hospedeiro de destino até a ocorrência de desfragmentação da memória da máquina virtual.

A principal similaridade entre o presente trabalho e o CosMig é a avaliação do impacto da migração na carga de trabalho da máquina virtual. Apesar das métricas utilizadas para a modelagem serem distintas, os dois estudos realizam uma modelagem do impacto da Live Migration na carga de trabalho. A diferença fundamental entre os trabalhos é a forma como as informações sobre a carga da máquina virtual é utilizada. No CosMig a pergunta feita é se a migração de uma determinada máquina virtual trará ou não ganhos de desempenho para a aplicação. Na arquitetura ALMA a pergunta realizada é quando uma migração poderá ser executada sem gerar impactos na infraestrutura e, consequentemente, na aplicação. 
Por fim, o trabalho de Stage e Setzer (2009) introduz um modelo de escalonamento de migração de máquinas virtuais as classifica de acordo com a carga de trabalho e, baseando-se nessa informação, identifica os requisitos mínimos de recursos de rede necessários para que uma migração seja executada. De acordo com os autores, a migração de uma única máquina virtual pode consumir uma significativa parte da banda de rede por um intervalo considerável de tempo (em torno de $500 \mathrm{Mb} / \mathrm{s}$ por dez segundos para migrar uma máquina virtual com um web server instalado). Nesse trabalho os autores apresentam uma arquitetura com alguns aspectos similares com a arquitetura ALMA. Há um gerenciador de escalonamento de migração, que decide quando uma máquina virtual será migrada de acordo com o consumo de rede e os parâmetros necessários (banda de rede e tempo mínimo aceitável para o tempo de migração) para que a migração seja executada dentro do tempo previsto. $\mathrm{Na}$ arquitetura também há um classificador de cargas de trabalho, que pode classificar uma carga de trabalho de acordo com os seguintes atributos:

- Previsível: Uma carga de trabalho é dita previsível se o seu comportamento tem um prognóstico confiável por um dado período de tempo;

- Tendenciosa: Refere-se ao grau de oscilação de uma tendência;

- Cíclica: Indica o comprimento e o grau de recorrência de padrões.

De acordo com os atributos de uma carga de trabalho, os autores definem grupos de aplicações e estimam o tempo e recursos computacionais necessários para que a migração de cada grupo ocorra dentro de um determinado prazo. A principal diferença é que, no trabalho apresentado por Stage e Setzer (2009), o escalonamento e a migração das máquinas virtuais ocorrem em função do consumo da banda de rede. De acordo com estimativas baseadas no tipo da carga de trabalho e no tempo máximo aceitável de duração de uma 
migração (definido pelo administrador ou pelo usuário), a arquitetura escalona as migrações para que sejam atendidas dentro do tempo estimado. Apesar de haver uma classificação da carga de trabalho, a arquitetura utiliza essa informação apenas para agrupar as máquinas virtuais e não para definir o instante ideal de migração para uma carga específica, como feito na arquitetura ALMA.

\subsubsection{Estratégias de Controle de Live Migration}

O trabalho de Beloglazov e Buyya (2013) propõe uma estratégia de consolidação dinâmica de máquinas virtuais, mas que difere de outras estratégias, pois além das métricas tradicionais para definir quais máquinas virtuais devem ser migradas e para qual hospedeiro, os autores também levam em conta quando a migração deve ocorrer. Os autores argumentam que a migração instantânea, tão logo as migrações a serem executadas estejam definidas, pode levar a diversos problemas, principalmente o congestionamento da rede e elevados períodos de downtime. A abordagem apresentada tem como principal objetivo minimizar o consumo de energia e maximizar a qualidade de serviço (QoS) entregue pelo provedor de serviços que, segundo os autores, formam o impasse energia-desempenho. Para que seja possível maximizar a qualidade de serviço, a principal métrica de referência para os autores, umas das estratégias abordadas é evitar que diversas migrações ocorram simultaneamente. Para isso desenvolve-se uma estratégia para identificar os hospedeiros mais sobrecarregados e definem-se intervalos de tempo em que as migrações podem ocorrer com o objetivo de não prejudicar a qualidade de serviço.

A principal semelhança entre os trabalhos é a determinação de momentos mais favoráveis para a migração das máquinas virtuais. Entretanto, a maneira como as migrações são adiadas é a principal diferença. Enquanto no trabalho de Beloglazov e Buyya (2013) a migração é adiada segundo a carga de traba- 
Iho dos hospedeiros, na arquitetura ALMA a migração é adiada de acordo com a carga de trabalho das máquinas virtuais. Basicamente, nada na estratégia desenvolvida pelos autores impede que uma máquina virtual seja migrada durante uma carga de trabalho que seja nociva ao processo de migração e, na arquitetura ALMA, nada impede que duas máquinas virtuais sejam migradas simultaneamente, desde que possuam cargas favoráveis para isso.

No trabalho de Ye et al. (2012) é introduzido um framework, chamado VCMigration que controla a migração em um cluster composto por máquinas virtuais. O VC-Migration possui estratégias de migração previamente configuradas que decide quantas máquinas virtuais serão migradas (granularidade) em um dado momento. A decisão baseia-se, principalmente, na situação atual de utilização de recursos computacionais dos hospedeiros. As estratégias definidas pelo framework são:

- Migração Concorrente: Estratégia de migrar diversas máquinas virtuais simultaneamente de um mesmo cluster;

- Migração Mútua: Estratégia aplicada quando os hospedeiros envolvidos na migração migram máquinas virtuais entre si;

- Migração Homogênea de Multi-Clusters: Quando diversos clusters virtuais, com a mesma quantidade de máquinas virtuais, são migrados;

- Migração Heterogênea Multi-Clusters: Mesma estratégia que a homogênea, mas quando os clusters envolvidos possuem tamanhos diferentes.

O framework opta pela melhor estratégia em função da quantidade de máquinas virtuais a serem migradas e do consumo de rede. De acordo com os autores a inter-dependência da aplicação, comum em ambientes de cluster, 
reduz o impacto na infraestrutura de rede e na própria aplicação ao organizar a migração das máquinas virtuais de um mesmo cluster. A principal diferença com o presente trabalho é o foco em ambientes de alto desempenho do framework VC-Migration. 


\section{CARACTERIZAÇÃO E ANÁLISE CÍCLICA}

Neste capítulo é abordado o modelo proposto de caracterização e de análise cíclica da carga de trabalho de uma máquina virtual. Os modelos que serão discutidos a seguir são de extrema importância para o entendimento da solução final.

Inicialmente será abordado o modelo de caracterização de cargas de trabalho e serão detalhadas as coletas de índices de carga de trabalho e os métodos probabilísticos de caracterização. A análise cíclica será abordada em seguida, pois depende da caracterização obtida para que seja possível extrair os resultados deste modelo.

\subsection{Caracterização de Carga de Trabalho}

As estratégias de caracterização de cargas de trabalho são ferramentas de grande importância na computação na nuvem. Muitas delas são usadas na implementação de consolidação ou de balanceamento de carga, pois é desejável que cargas de trabalho que concorrem com o mesmo recurso computacional não fiquem no mesmo hospedeiro. Existem alguns desafios na caracterização em ambientes de computação na nuvem e a maior parte delas surge devido às características da própria computação na nuvem, como a elasticidade (ARMBRUST et al., 2009) (capacidade de adaptação a uma determinada carga de trabalho sem downtime). Entretanto, a variação de recursos computacionais 
nas máquinas virtuais podem causar situações de ambiguidades caso a estratégia de caracterização utilizada não esteja pronta para lidar com este tipo de cenário.

Outro problema encontrado em ambientes de computação na nuvem é a coleta e a interpretação das métricas das máquinas virtuais. O problema de Gap Semântico (GARFINKEL; ROSENBLUM, 2005) torna a coleta e a interpretação dos dados difícil e pode levar a caracterizações imprecisas ou erradas.

A maioria das técnicas tradicionais de caracterização de carga de trabalho são computacionalmente caras e tornam-se proibitivas em um ambiente de computação na nuvem com centenas ou milhares de máquinas virtuais sendo executadas simultaneamente. As recentes técnicas de caracterização especializadas em ambientes virtualizados possuem alta complexidade para serem implementadas em um provedor de computação na nuvem, pois baseiam-se em métricas especializadas do monitor de máquinas virtuais (AHMAD, 2007) ou em alterações na própria máquina virtual e no monitor de máquinas virtuais subjacente (DU; SEHRAWAT; ZWAENEPOEL, 2011).

Desse modo, uma estratégia de caracterização para ambientes de computação na nuvem deve possuir as seguintes características (BARUCHI; MIDORIKAWA, 2013):

- Independência: as métricas utilizadas devem ser independentes da tecnologia de virtualização empregada;

- Não Intrusiva: os dados não devem ser gerados ou coletados a partir de alterações no código-fonte ou no comportamento da máquina virtual e do monitor de máquinas virtuais;

- Segurança: em ambientes de computação na nuvem é comum o compartilhamento do mesmo hospedeiro entre diversos usuários. Os dados 
coletados não devem ser observados nem alterados por terceiros;

- Baixa Complexidade: o algoritmo de caracterização deve possuir baixa complexidade computacional (linear ou, no pior caso, polinomial);

- Precisão: a caracterização deve ser a mais exata possível. Estratégias de caracterização imprecisas podem ser mais nocivas do que a ausência de caracterização.

\subsection{1 Índices de Carga}

Um índice de carga é uma métrica cujo objetivo é quantificar o estado da carga em um dado instante ou intervalo de tempo que dependerá da frequência em que a métrica é atualizada (BRANCO, 2004). As principais características que um índice de carga deve possuir são (BRANCO, 2004):

- A métrica deve refletir com precisão o real estado do sistema;

- Deve ser facilmente calculado ou coletado, gerando o mínimo de sobrecarga no sistema;

- Deve ser capaz de absorver e representar de maneira correta picos de carga;

- Capacidade de medir, com a mesma precisão, sistemas heterogêneos.

Os índices de carga podem ser classificados como simples ou compostos, o que dependerá da extensão e composição da métrica. Os índices de carga simples são aqueles baseados em apenas um valor e, em geral, representam o uso de apenas um recurso computacional, como uso de memória ou disco. Por outro lado, os índices de carga compostos são a combinação de uso de diversos recursos em um único valor. 
Para este trabalho, foram desenvolvidos índices de carga simples que são submetidos ao algoritmo de caracterização.

Os índices de carga estão relacionados a dois recursos computacionais: processador e memória. Entretanto, é importante salientar que, apesar dos índices estarem associados somente a dois recursos computacionais, é possível identificar outros tipos de cargas, como uso de disco, por exemplo.

\subsubsection{1 Índices de Carga de Processador}

A avaliação da utilização do processador é feita a partir de cinco índices distintos. A Tabela 1 apresenta uma breve descrição dos índices que são coletados nas máquinas virtuais e o intervalo de valores que estes retornam. As métricas utilizadas são amplamente disponíveis na maioria dos Sistemas Operacionais de propósito geral.

Tabela 1: Índices de carga de Processador.

\begin{tabular}{|c|l|c|}
\hline ID. Índice & \multicolumn{1}{|c|}{ Descrição } & Valor (intervalo) \\
\hline \hline P1 & $\begin{array}{l}\text { Mede a razão entre o tamanho da fila de } \\
\text { processos (run queue) e a quantidade de } \\
\text { processadores. }\end{array}$ & {$[0, \infty]$} \\
\hline P2 & $\begin{array}{l}\text { Mede a proporção entre o tempo de pro- } \\
\text { cessamento em rotinas do Kernel (sys) e o } \\
\text { tempo total. }\end{array}$ & {$[0,1]$} \\
\hline P3 & $\begin{array}{l}\text { Mede a proporção entre o tempo gasto de } \\
\text { processamento do usuário (usr) e o tempo } \\
\text { total. }\end{array}$ & {$[0,1]$} \\
\hline P4 & $\begin{array}{l}\text { Mede a proporção entre o tempo gasto de } \\
\text { processamento esperando por operações } \\
\text { de E/S (I/O Wait) e o tempo total. }\end{array}$ & {$[0,1]$} \\
\hline P5 & $\begin{array}{l}\text { Mede a proporção entre o tempo gasto de } \\
\text { processamento ocioso (idle) e o tempo to- } \\
\text { tal. }\end{array}$ & \\
\hline
\end{tabular}

Os índices P1 e P3 foram usados por indicar o uso do processador em períodos de uso intensivo de processamento. As cargas com estas características forçam outros processos a esperarem por uma liberação do Processador 
e, com isso, aumentam a fila de processos (run queue).

Os índices P2 e P4, tem como objetivo inferir cargas que geram muito consumo de dispositivos de E/S (como disco e memória) e medem o tempo gasto em processamento de rotinas do Kernel e o tempo gasto esperando por operações de E/S. Por fim, o índice P5 tem a função de ajudar a identificar quando o sistema está ocioso.

\subsubsection{2 Índices de Carga de Memória}

Ao todo são avaliados seis índices de carga relacionados ao uso de memória. Os índices, apresentados na Tabela 2, indicam a intensidade do uso de memória e também a forma como a memória está sendo usada pelo Sistema Operacional.

Tabela 2: Índices de carga de Memória.

\begin{tabular}{|c|c|c|}
\hline ID. Índice & Descrição & Valor (Intervalo) \\
\hline M1 & $\begin{array}{l}\text { Mede a proporção entre a quantidade de } \\
\text { páginas modificadas (dirty pages) e a quan- } \\
\text { tidade total de páginas. }\end{array}$ & {$[0,1]$} \\
\hline M2 & $\begin{array}{l}\text { Mede a proporção entre a quantidade de } \\
\text { memória usada em cache e a quantidade } \\
\text { total de memória. }\end{array}$ & {$[0,1]$} \\
\hline M3 & $\begin{array}{l}\text { Mede a proporção entre a quantidade de } \\
\text { memória usada em buffer e a quantidade } \\
\text { total de memória. }\end{array}$ & {$[0,1]$} \\
\hline M4 & $\begin{array}{l}\text { Mede a proporção entre a quantidade de } \\
\text { memória Livre (free) e a quantidade total de } \\
\text { memória. }\end{array}$ & {$[0,1]$} \\
\hline M5 & $\begin{array}{l}\text { Mede a proporção entre a quantidade de } \\
\text { memória ativa (memória não sujeita a pa- } \\
\text { ginação) e a quantidade total de memória. }\end{array}$ & {$[0,1]$} \\
\hline M6 & $\begin{array}{l}\text { Mede a proporção entre a quantidade de } \\
\text { memória anativa (memória sujeita a pagi- } \\
\text { nação) e a quantidade total de memória. }\end{array}$ & {$[0,1]$} \\
\hline
\end{tabular}


Os índices M1 e M5 são utilizados para inferir cargas que dependem e geram muitos acessos e modificação na memória. O índice M1 indica a quantidade de memória que sofreu alterações e o índice M5 indica a quantidade de memória que está efetivamente em uso. Os índices M2, M3 e M6 são utilizados para inferir cargas de uso intensivo de E/S, pois indicam a quantidade de memória que está sendo usada para cache e buffers. O índice M4 é análogo ao índice P5 do processador e é utilizado para identificar a ociosidade do sistema.

\subsection{Estratégias de Caracterização}

Neste trabalho, foram avaliados dois algoritmos de caracterização de carga de trabalho, Naive Bayes e Árvores de Decisão, sendo que ambos são algoritmos amplamente utilizados na área de mineração de dados (WITTEN; FRANK; HALL, 2011) (TAN; STEINBACH; KUMAR, 2005). A escolha dos algoritmos deve-se principalmente à baixa complexidade computacional, característica de grande importância para um ambiente de computação na nuvem.

Além da baixa complexidade, os dois algoritmos utilizam o método de Aprendizagem Supervisionada que indica a necessidade de submissão de uma massa de dados previamente rotulados ao crivo do algoritmo de caracterização. Os dados para a fase de aprendizagem foram gerados a partir do Isolation Benchmark, que foi avaliado e utilizado em trabalhos anteriores (WU; LIU; YANG, 2012) (BARUCHI; MIDORIKAWA, 2012). 


\subsubsection{Naive Bayes}

Este algoritmo de classificação é baseado no teorema de Bayes, que é amplamente utilizado no campo de probabilidade. O termo Naive (em português, ingênuo) deve-se à premissa de que os eventos para realizar o cálculo das probabilidades são independentes.

Os classificadores Bayesianos, como são chamados os algoritmos baseados no teorema de Bayes, têm como objetivo estimar a classe mais provável de um conjunto de características utilizando probabilidades conhecidas a priori, calculadas a partir dos dados de aprendizagem. O teorema de Bayes exige, no mínimo, três termos - uma probabilidade condicional e duas probabilidades incondicionais - para calcular uma terceira probabilidade condicional (RUSSELL; NORVIG, 2009). Formalmente, pode-se escrever o teorema de Bayes como:

$$
P(Y \mid X)=\frac{P(X \mid Y) P(Y)}{P(X)}
$$

Onde:

$\mathrm{P}(\mathrm{Y} \mid \mathrm{X})$ : probabilidade do evento $\mathrm{Y}$ ocorrer dado que $\mathrm{X}$ ocorreu; $\mathrm{P}(\mathrm{X} \mid \mathrm{Y})$ : probabilidade do evento $\mathrm{X}$ ocorrer dado que $\mathrm{Y}$ ocorreu; $P(X)$ : probabilidade do evento $X$ ocorrer; $\mathrm{P}(\mathrm{Y})$ : probabilidade do evento $\mathrm{Y}$ ocorrer.

Uma das principais características de classificadores Bayesianos é o resultado quantitativo. Ao submeter uma entrada para classificação, o algoritmo retornará a classe mais provável que aquela entrada possui e sua respectiva probabilidade, sendo possível, dessa forma, tratar desvios ou elaborar mecanismos de otimização. 


\subsubsection{Discretização Entrópica}

A despeito da boa precisão do algoritmo Naive Bayes (NB), foi observado que, ao utilizar valores discretos, a precisão das classificações melhorou de forma considerável. O processo de discretização consiste em atribuir um número inteiro para um determinado intervalo de valores.

Um dos desafios para utilização desse processo é a definição de critérios para dividir o conjunto de dados da melhor forma possível. Para esse fim, foi utilizada a técnica de discretização entrópica (ou discretização baseada em entropia) (WITTEN; FRANK; HALL, 2011). Em um primeiro momento, o algoritmo de discretização escolhe alguns candidatos a serem utilizados como limite inferior e superior do intervalo por meio de uma medida chamada de entropia de classe, que mede a quantidade de informações necessárias para descrever uma determinada classe.

Em geral, o primeiro intervalo escolhido pelo algoritmo é bastante amplo. Utilizando recursão, este particiona o intervalo inicial em frações menores até que alguma condição de parada seja satisfeita, condições estas que podem variar de acordo com o algoritmo implementado. Neste trabalho, o critério de parada utilizado é o Minimum Description Lenght (MDL) (versão implementada no software de aprendizagem de máquina Weka (HALL et al., 2009)), que utiliza como critério a quantidade mínima de atributos para definir uma determinada classe.

Para demonstrar a melhora obtida com a discretização no algoritmo Naive Bayes, foi construída uma matriz de confusão, apresentada na Tabela 3. A partir dos dados de treinamento do algoritmo, foram selecionadas aleatoriamente 1014 amostras (aproximadamente 33\% do total) de cada classe e submetidas ao crivo do algoritmo. Nota-se que a precisão do algoritmo com a discretiza- 
ção (CD) é consideravelmente melhor do que a classificação sem discretização (SD).

A classificação de cargas de E/S intensivo são as mais difíceis de serem identificadas pois estressam diversos subsistemas, principalmente o processador. Entretanto, com a discretização foi possível melhorar significativamente a classificação desse tipo de carga.

Tabela 3: Matriz de Confusão do Algoritmo Naive Bayes.

\begin{tabular}{|c|c|c|c|c|}
\hline & $\begin{array}{c}\text { CPU } \\
\text { (Predição) }\end{array}$ & $\begin{array}{c}\text { MEM } \\
\text { (Predição) }\end{array}$ & $\begin{array}{c}\text { IO } \\
\text { (Predição) }\end{array}$ & $\begin{array}{c}\text { Precisão } \\
(\%)\end{array}$ \\
\hline \multirow{2}{*}{$\begin{array}{l}\text { CPU } \\
\text { (Real) }\end{array}$} & $\begin{array}{l}1013 \\
\text { (SD) }\end{array}$ & $\begin{array}{c}0 \\
(S D)\end{array}$ & $\begin{array}{c}1 \\
\text { (SD) }\end{array}$ & $\begin{array}{l}99,9 \\
\text { (SD) }\end{array}$ \\
\hline & $\begin{array}{l}1014 \\
\text { (CD) }\end{array}$ & $\begin{array}{c}0 \\
(\mathrm{CD})\end{array}$ & $\begin{array}{c}0 \\
(\mathrm{CD})\end{array}$ & $\begin{array}{l}100 \\
\text { (CD) }\end{array}$ \\
\hline \multirow{2}{*}{$\begin{array}{l}\text { MEM } \\
\text { (Real) }\end{array}$} & $\begin{array}{c}0 \\
(S D)\end{array}$ & $\begin{array}{l}1014 \\
\text { (SD) }\end{array}$ & $\begin{array}{c}0 \\
(S D)\end{array}$ & $\begin{array}{l}100 \\
\text { (SD) }\end{array}$ \\
\hline & $\begin{array}{c}0 \\
(\mathrm{CD})\end{array}$ & $\begin{array}{l}1014 \\
\text { (CD) }\end{array}$ & $\begin{array}{c}0 \\
(\mathrm{CD})\end{array}$ & $\begin{array}{l}100 \\
\text { (SD) }\end{array}$ \\
\hline \multirow{2}{*}{$\begin{array}{c}10 \\
\text { (Real) }\end{array}$} & $\begin{array}{c}1 \\
\text { (SD) }\end{array}$ & $\begin{array}{c}43 \\
\text { (SD) }\end{array}$ & $\begin{array}{l}957 \\
\text { (SD) }\end{array}$ & $\begin{array}{l}95,6 \\
\text { (SD) }\end{array}$ \\
\hline & $\begin{array}{c}2 \\
(\mathrm{CD})\end{array}$ & $\begin{array}{c}1 \\
\text { (CD) }\end{array}$ & $\begin{array}{l}1011 \\
\text { (CD) }\end{array}$ & $\begin{array}{l}99,7 \\
\text { (CD) }\end{array}$ \\
\hline
\end{tabular}

\subsection{2 Árvores de Decisão}

As árvores de decisão (AD) pertencem a uma classe de mineração de dados que é baseada em disciplinas estatísticas, assim como a regressão linear (TAN; STEINBACH; KUMAR, 2005). O objetivo da árvore de decisão é encontrar uma relação entre os dados de entrada e o conjunto de dados utilizados para construir a árvore, no caso, os dados utilizados na fase de aprendizagem.

Entre as principais características das árvores de decisão, pode-se citar (TAN; STEINBACH; KUMAR, 2005): (1) facilidade em produzi-las, interpretálas e utilizá-las, e (2) agilidade de adaptação a novos dados, isto é, as árvores de decisão podem ser expandidas ou reduzidas com a contabilização de novos dados de aprendizagem. Considerando-se essas características, o uso de 
árvores de decisão torna-se muito atrativo em ambientes de computação na nuvem.

Existem diversas implementações e metodologias para gerar árvores de decisão. O algoritmo ora utilizado é o C4.5, implementado no software de Aprendizagem de Máquina Weka. Entretanto, diferentemente do que ocorre com o Naive Bayes, as árvores de decisão mantiveram a precisão sem a necessidade de submeter os dados a um processo de discretização.

\subsubsection{Avaliação dos Algoritmos de Caracterização}

A avaliação dos algoritmos de caracterização foi realizada com dois benchmarks e uma aplicação científica, descritos na Tabela 4. Os benchmarks possuem um comportamento mais constante no decorrer da execução e por esta razão, são mais indicados para verificar a precisão dos algoritmos apresentados. Por outro lado, a aplicação científica apresenta oscilações ao longo da execução, possibilitando a comparação da sensibilidade dos algoritmos quando o tipo de carga é alterado.

Para tal avaliação, os benchmarks e a aplicação foram executados em quatro diferentes configurações de máquinas virtuais, de acordo com as descrições na Tabela 5. Para cada uma das configurações, cada um dos benchmarks e a aplicação foram executados dez vezes. No decorrer dos testes, foram coletadas informações pertinentes ao uso dos recursos computacionais, como processador, memória e disco. As máquinas virtuais foram configuradas em um hardware composto por um processador Intel Core2 Quad de 2,66MHz, 2 Gigabytes de memória RAM e um disco com capacidade de 500 Gigabytes de 5400 RPM e vazão nominal de 3Gigabytes/Segundo. Para configuração de software, foi utilizado como monitor de máquinas virtuais o Xen 4.1 .3 e o Sistema Operacional, no hospedeiro, OpenSuse 12.1 com Kernel 3.1.10. 
As máquinas virtuais foram instaladas com imagens do CentOS 5.9 e kernel 2.6.18.

Tabela 4: Descrição dos benchmarks e da aplicação científica.

\begin{tabular}{|c|l|}
\hline $\begin{array}{c}\text { Aplicação / } \\
\text { Benchmark }\end{array}$ & \multicolumn{1}{c|}{ Descrição } \\
\hline \hline $\begin{array}{c}\text { SPEC CPU2000 } \\
\text { (SAIR; CHARNEY, 2000) }\end{array}$ & $\begin{array}{l}\text { Um benchmark amplamente utilizado para comparação de sistemas computacionais. } \\
\text { Possui diversos subprogramas que estressam o processador. Dentre os programas que } \\
\text { o compõe, foi utilizado o MCF para este trabalho, pois trata-se de um programa de otimização combinatória. }\end{array}$ \\
\hline $\begin{array}{c}\text { LAME } \\
\text { (JOHNSTON; FERREIRA, 1992) }\end{array}$ & $\begin{array}{l}\text { O LAME é um codificador MP3 utilizado como Benchmark. Recebe como entrada } \\
\text { arquivos em diversos formatos e transforma para o formato MP3. Para os testes } \\
\text { apresentados, o arquivo de entrada possuia tamanho em torno de 2,8 GB. }\end{array}$ \\
\hline $\begin{array}{c}\text { openModeller } \\
\text { (MUñOZ et al., 2011) }\end{array}$ & $\begin{array}{l}\text { É uma aplicação científica utilizada na Biologia, que faz a modelagem } \\
\text { de distribuição de espécies baseada em pré-requisitos ecológicos (como a } \\
\text { composição da vegetação, altitude, etc.) e extrapola o modelo para diversas regiões do planeta. }\end{array}$ \\
\hline
\end{tabular}

Os resultados obtidos com os algoritmos estão sumarizados na Tabela 6, na qual é apresentado o uso médio dos recursos computacionais, com os respectivos desvio-padrão entre parênteses e as classificações, nas últimas colunas, obtidas pelo algoritmo Naive Bayes (NB) e pela Árvore de Decisão (AD). Como a caracterização é feita no decorrer da execução dos experimentos, podem ocorrer variações e para captar essa oscilação, foi elaborada uma notação que representa a carga predominante e a carga secundária (quando identificada pelo algoritmo) que é feito da seguinte maneira:

\section{CP/CS}

Onde:

CP: Classificação Predominante;

CS: Classificação Secundária.

Para cada algoritmo avaliado, existe uma classificação usando apenas os índices de processador (coluna CPU) e outra com os índices de memória (coluna MEM). Esta divisão permite que os algoritmos de caracterização consigam identificar cargas de trabalhos mistas. Alguns tipos de cargas ficam mais evidentes ao avaliar índices de processador e outros índices de memória.

A coluna da Tabela 6, que apresenta o uso médio do processador (coluna CPU \%), não distingue se o processador está sendo usado na camada 
Tabela 5: Configurações das Máquinas Virtuais.

\begin{tabular}{|c|c|c|}
\hline $\begin{array}{c}\text { ID. } \\
\text { Configuração }\end{array}$ & $\begin{array}{c}\text { Processador } \\
\text { (VCPUs) }\end{array}$ & $\begin{array}{c}\text { Memória } \\
\text { (GB) }\end{array}$ \\
\hline \hline C1 & \multirow{2}{*}{1} & 1 \\
\cline { 1 - 1 } \cline { 1 - 1 } C2 & & 2 \\
\cline { 1 - 1 }$C 3$ & 2 & 1 \\
\cline { 1 - 1 } C4 & 2 & 2 \\
\hline
\end{tabular}

do usuário (usr) ou na camada do sistema (sys). A mesma coisa ocorre com o uso médio da memória (coluna MEM \%) que não faz distinção entre o que está sendo usado em Buffers ou Cache. A métrica utilizada para mensurar as operações de E/S neste trabalho é a quantidade de operações de E/S realizadas por segundo (do inglês, Input Output Per Second - IOPS). Essa métrica sintetiza tanto leitura como escrita em uma única grandeza (GULATI; AHMAD; WALDSPURGER, 2009).

Tabela 6: Sumário das Caracterizações obtidas com os algoritmos.

\begin{tabular}{|c|c|c|c|c|c|c|c|c|}
\hline \multirow{2}{*}{\multicolumn{5}{|c|}{ Utilização Média Recursos Computacionais }} & \multicolumn{4}{|c|}{ Caracterização } \\
\hline & & & & & \multicolumn{2}{|c|}{ NB } & \multicolumn{2}{|c|}{ AD } \\
\hline Benchmark & Conf. ID & $\begin{array}{c}\text { CPU } \\
(\%)\end{array}$ & $\begin{array}{c}\text { MEM } \\
(\%)\end{array}$ & IOPS & CPU & MEM & CPU & MEM \\
\hline \multirow{4}{*}{ SPEC } & C1 & $96( \pm 18)$ & $17( \pm 5)$ & $85771( \pm 851811)$ & $\mathrm{CPU} / \mathrm{IO}$ & CPU/MEM & CPU/IO & CPU/MEM \\
\hline & $\mathrm{C} 2$ & $96( \pm 18)$ & $9_{( \pm 2)}$ & $93674( \pm 898949)$ & $\mathrm{CPU} / \mathrm{IO}$ & MEM & CPU/IO & IO/MEM \\
\hline & C3 & $49_{( \pm 12)}$ & $17( \pm 5)$ & $93226( \pm 699789)$ & 10 & IO/MEM & 10 & MEM/CPU \\
\hline & $\mathrm{C} 4$ & $49_{( \pm 11)}$ & $10_{( \pm 3)}$ & $93830( \pm 931227)$ & IO/MEM & 10 & 10 & IO/MEM \\
\hline \multirow{4}{*}{ LAME } & C1 & $98( \pm 15)$ & $7( \pm 1)$ & $7646221( \pm 2680530)$ & CPU/IO & IO/CPU & CPU/IO & 10 \\
\hline & $\mathrm{C} 2$ & $98( \pm 15)$ & $5( \pm 1)$ & $7630012( \pm 2650733)$ & $\mathrm{CPU} / \mathrm{IO}$ & 10 & CPU/IO & 10 \\
\hline & C3 & $50( \pm 11)$ & $7( \pm 1)$ & $7810689_{( \pm 2968733)}$ & 10 & 10 & 10 & 10 \\
\hline & $\mathrm{C} 4$ & $51( \pm 11)$ & $5( \pm 1)$ & $7585084( \pm 2774450)$ & 10 & 10 & 10 & 10 \\
\hline \multirow{4}{*}{ OpenModeller } & C1 & $100_{( \pm 5)}$ & $15( \pm 1)$ & $490064_{( \pm 733006)}$ & $\mathrm{CPU} / \mathrm{IO}$ & 10 & CPU/IO & 10 \\
\hline & $\mathrm{C} 2$ & $99( \pm 11)$ & $8( \pm 1)$ & $533604( \pm 1121545)$ & CPU/IO & 10 & CPU/IO & 10 \\
\hline & C3 & $51( \pm 11)$ & $15( \pm 1)$ & $573838( \pm 1162654)$ & IO/MEM & 10 & 10 & 10 \\
\hline & $\mathrm{C} 4$ & $51( \pm 11)$ & $9_{( \pm 1)}$ & $568933( \pm 1177646)$ & IO/MEM & 10 & 10 & 10 \\
\hline
\end{tabular}

Nas classificações do SPEC, utilizando a configuração C1 e C2, quando a máquina virtual estava configurada com apenas um processador, ambos os algoritmos classificaram a carga predominantemente como CPU intensivo, com algumas flutuações para 10 e Memória. Os momentos classificados como IO devem-se ao fato do SPEC esporadicamente armazenar informações em arquivos sobre a execução do benchmark, como tempo de execução, FLOPS, entre outras informações. As classificações pontuais de uso intensivo de Me- 
mória também eram esperadas, pois dentre os algoritmos do SPEC, foi escolhido um que tem considerável utilização de memória (MCF). Na coluna de utilização média de memória, este foi o benchmark que mais fez uso deste recurso computacional.

A classificação da carga de trabalho do LAME foi a que representou menor dificuldade para os algoritmos. Este benchmark faz a decodificação de arquivos de áudio para o formato MP3 e possui um comportamento de uso intensivo de processador e E/S. Conforme a arquivo de entrada é processado, o LAME escreve o arquivo MP3 de saída, gerando muitas operações de E/S.

O uso de processador fica mais evidente para todos os benchmarks nas configurações $\mathrm{C} 1$ e C2 devido à presença de apenas um processador. Com a adição de um segundo processador, conforme as configurações C3 e C4, os algoritmos começam a identificar outros perfis de cargas, principalmente do tipo IO (operações intensivas de E/S).

A caracterização do OpenModeller, representando uma classe de aplicações científicas, tem um perfil de muito consumo de processador, com alguma sensibilidade ao consumo de memória e com diversas operações de E/S. Ambos os algoritmos conseguem classificar de forma bastante precisa a carga do OpenModeller, cuja classificação predominante como CPU intensivo é em decorrência das configurações C1 e C2. Entretanto, nas configurações C3 e C4, em que há dois processadores e quantidade de memória suficiente, o OpenModeller é classificado com uma carga predominante de uso intensivo de memória e IO.

A Figura 8 apresenta a classificação dos dois algoritmos no decorrer da execução dos benchmarks e do OpenModeller. O uso dos recursos e a classificação obtida com os algoritmos é colocada de forma sobreposta nas figuras, mostrando como foi o comportamento da carga e sua respectiva classificação. 
Na Figura 8a, que representa a caracterização do OpenModeller na configuração C4, nota-se que as operações de E/S concentram-se no início e no fim da execução, uma vez que esta aplicação recebe um arquivo como entrada, que precisa ser analisado para, em seguida, iniciar uma fase de computação intensiva e, finalmente, retornar os resultados em um arquivo de saída. Entretanto, há atualizações sutis no arquivo de saída no decorrer da execução que fazem com que o arquivo fique em Cache constantemente em tal momento. Mesmo havendo consumo de processador, com bastante oscilação no decorrer da execução, o uso médio fica em torno de $51 \%$, isto é, um dos processadores permanece praticamente ocioso.

A classificação apresentada na Figura 8b é referente ao benchmark SPEC na configuração $\mathrm{C} 1$ e, como esperado, houve um consumo considerável de processador. Apesar de haver algum consumo de memória (experimento que mais consumiu memória comparativamente) a classificação utilizando Naive Bayes foi predominante de CPU e IO intensivo. Já a caracterização utilizando Árvores de Decisão classificou-o como uso intensivo de CPU e MEM. A classificação equivocada do algoritmo Naive Bayes com os índices de memória (classificação predominante de IO intensivo) deve-se ao fato do SPEC ter mantido em memória Cache alguns arquivos quando foi iniciado. O uso de Cache e Buffers são indícios de que a carga possui perfil de IO intensivo. Entretanto, como não houve liberação do Cache, o algoritmo identificou um possível padrão de 10 intensivo.

Por fim, a Figura 8c apresenta a classificação do LAME em uma máquina virtual na configuração C3. O LAME, como discutido anteriormente, não ofereceu dificuldades para os dois algoritmos de classificação avaliados neste trabalho. Os dois gráficos que ilustram o decorrer da caracterização da carga de trabalho são muito similares tanto para o algoritmo Naive Bayes quanto 
para as árvores de decisão.

Figura 8: Caracterização com Naive Bayes e Árvores de Decisão.

(a) Classificação do OpenModeller na Configuração C4.

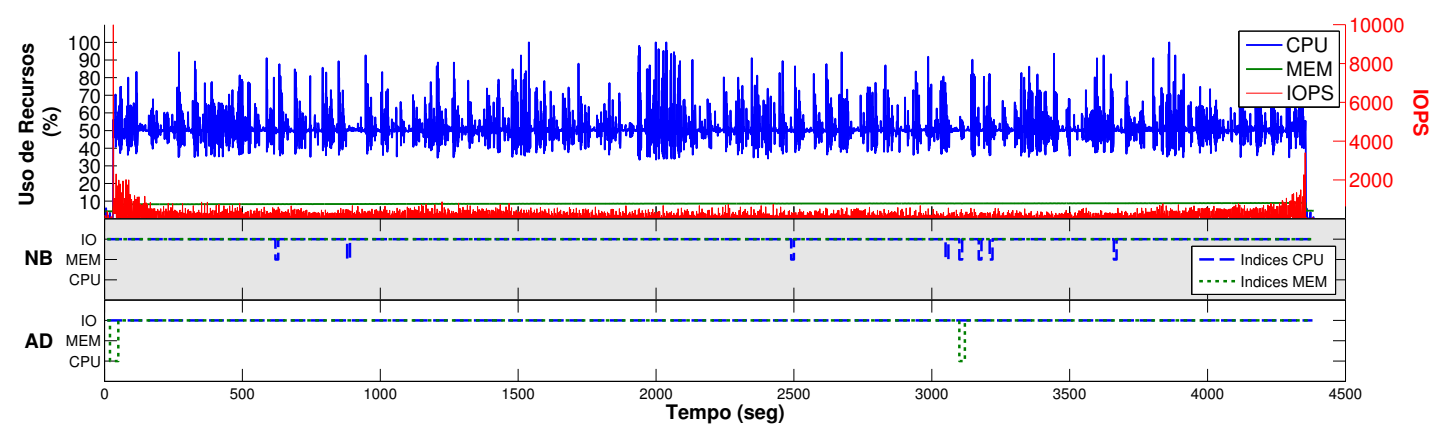

(b) Classificação do SPEC na Configuração C1.

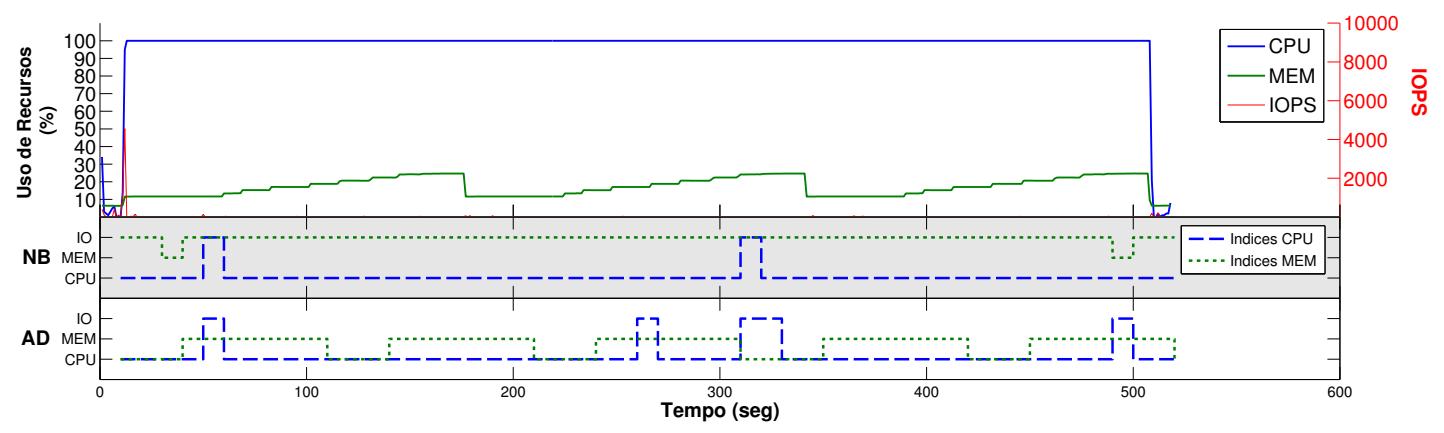

(c) Classificação do LAME na Configuração C3.

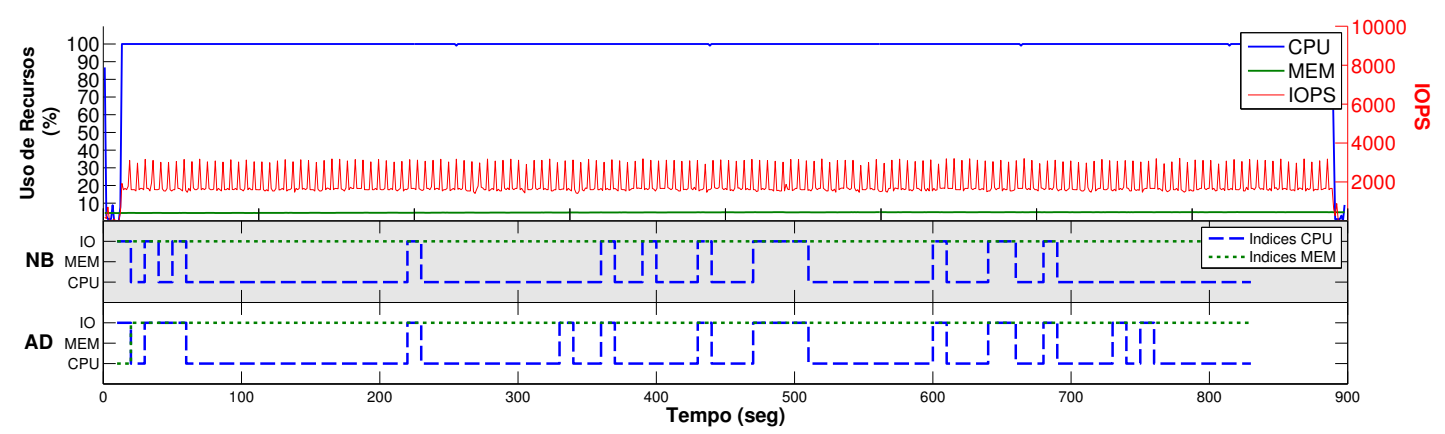

Fonte: Próprio Autor (2015).

Ambos os algoritmos apresentaram um bom desempenho na classificação das cargas de trabalho dos benchmarks e do OpenModeller, representando uma aplicação científica. A caracterização com as Árvores de Decisão possui maior sensibilidade a picos de utilização e sofre maior variação no decorrer da execução das cargas de trabalho. Por outro lado, o algoritmo Naive Bayes tem maior estabilidade por conta do processo de discretização que os dados são submetidos. 
A complexidade assintótica das duas estratégias é linear, o que é de extrema importância para um ambiente de computação na nuvem que pode conter centenas de máquinas virtuais em execução em um dado momento. As Árvores de Decisão tem complexidade dada por $\Theta(i)$, onde $i$ é a quantidade de nós da Árvore de Decisão (desconsiderando os nós folhas). Já no algoritmo Naive Bayes, deve-se contabilizar o processo de discretização e o cálculo das probabilidades, uma vez que a discretização dos índices é apenas uma sequência de comparações que deverá ser feita para cada uma das métricas e, portanto, a complexidade do processo de discretização é de $\Theta(k)$, onde $k$ é a quantidade de índices a serem discretizados. A complexidade para o cálculo das probabilidades é em função da quantidade das classes a serem avaliadas e é dada por $\Theta(n)$, onde $n$ é a quantidade dessas classes. Com isso, a complexidade total do algoritmo Naive Bayes é $\Theta(n+k)$. Ambas as estratégias satisfazem as características discutidas no início da Seção 4.2 e, dessa forma, viabilizam a caracterização em grande escala de máquinas virtuais.

Figura 9: Algoritmos de caracterização e Live Migration.

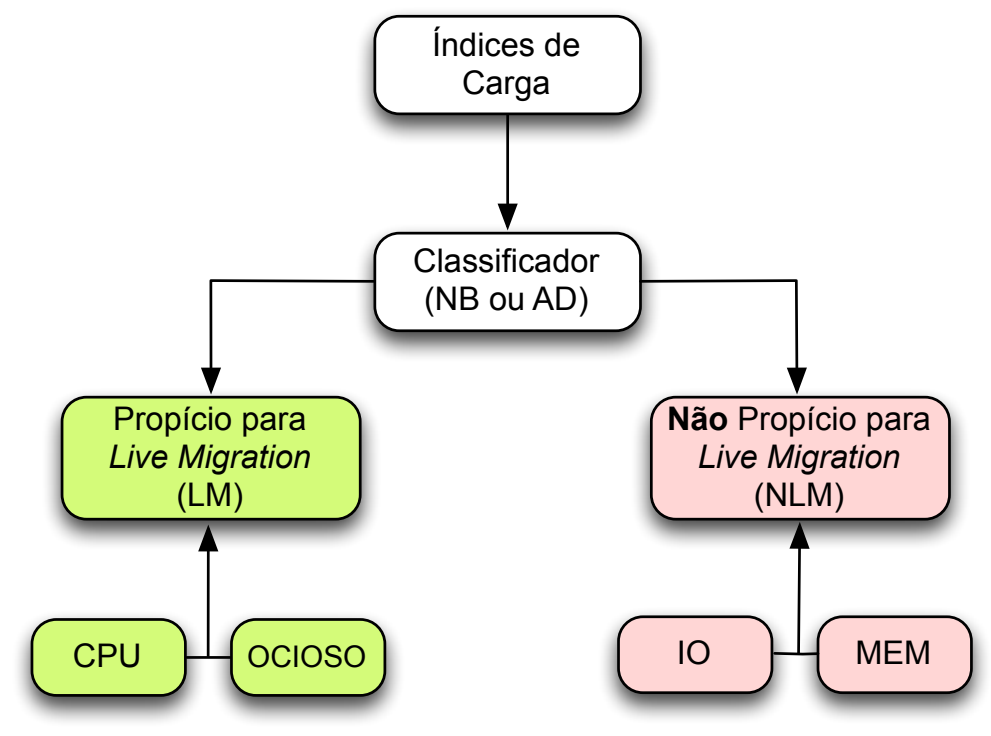

Fonte: Próprio Autor (2015).

Utilizando os algoritmos de caracterização discutidos, torna-se possível identificar quando uma máquina virtual pode ser movimentada entre hospedei- 
ros. Relembrando o capítulo 3, foi mostrado que os algoritmos de Live Migration possuem grande sensibilidade à forma como a memória é utilizada (equações 3.2 e 3.1). Com o uso dos algoritmos de classificação apresentados, pode-se agora verificar qual o tipo de carga predominante em uma máquina virtual e, ao invés de classificar uma carga entre CPU, MEM, IO ou OCIOSA, as cargas serão classificadas como propícias (LM) para serem submetidas ao processo de Live Migration ou como não propícias para o processo de Live Migration (NLM). A Figura 9 apresenta o elo entre os classificadores e o processo de Live Migration. As cargas de uso intensivo de memória e de operações de E/S (IO) são as mais nocivas para a migração de máquinas virtuais, pois possuem constante atualização de memória. Já cargas com predominância de uso de processador ou ociosas são mais favoráveis à migração.

\subsection{Análise Cíclica}

Uma vez que a carga de trabalho é caracterizada como propícia (LM) ou não propícia (NLM) para ser submetida ao processo de migração, pode-se extrair padrões cíclicos, caso existam, das caracterizações realizadas ao longo do tempo. Dado que as classes possíveis para uma carga de trabalho agora foram reduzidas para somente duas (LM ou NLM), pode-se identificar e decompor os ciclos da carga de trabalho.

O processo de extração dos ciclos é feito pela Transformada Rápida de Fourier (TRF) (BERGLAND, 1968). A TRF possui complexidade $O(n \log n)$, onde $n$ é a quantidade de amostras usadas para calcular o ciclo e possibilita converter o tempo (ou espaço) em frequência.

Neste trabalho, um ciclo é definido como um padrão repetitivo da carga de trabalho, que pode ser constituído de diversos períodos, favoráveis ou não 
Figura 10: Composições de um mesmo ciclo

(a) Ciclo A.
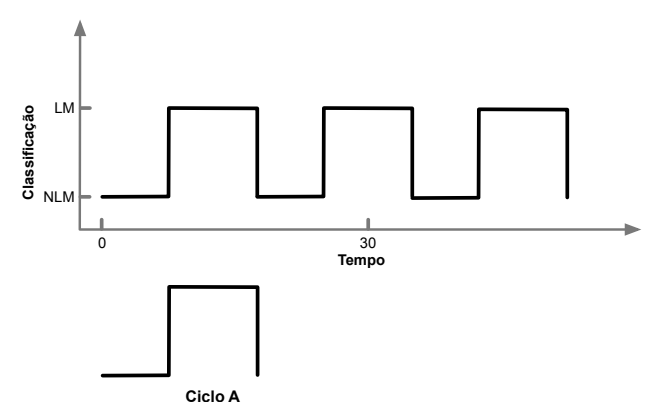

(b) Ciclo A'.

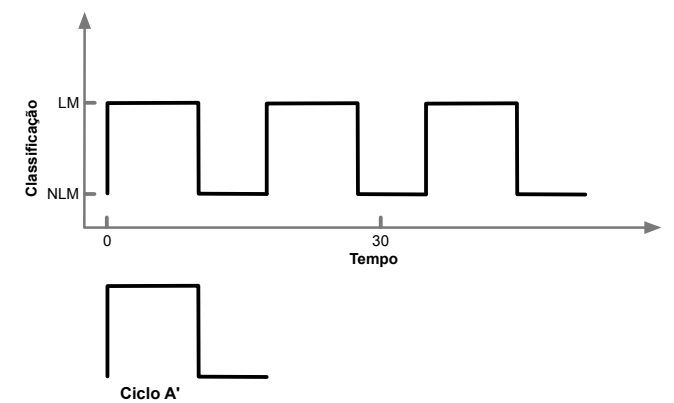

(c) Ciclo A".

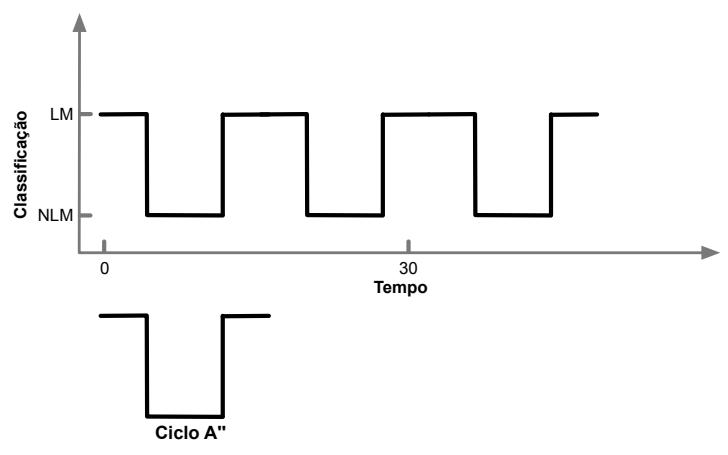

Fonte: Próprio Autor (2015).

para a migração, e um período pode ter qualquer duração de tempo. Adicionalmente, um mesmo ciclo pode possuir diversas composições, como apresentado na Figura 10, em que, a carga de trabalho é considerada cíclica, pois possui um padrão repetitivo no decorrer do tempo. O formato ou composição do ciclo, dependerá do instante inicial. Os ciclos apresentados nas Figuras 10a, 10b e 10c são, essencialmente, o mesmo ciclo, mas iniciando em instantes diferentes. O ciclo terá um formato diferente dependendo do instante em que a coleta dos dados da carga foi iniciada, entretanto, a duração de cada uma das fases e também dos tempo total do ciclo será a mesma.

Além disso, neste trabalho um ciclo pode ser considerado simples ou complexo. Um ciclo simples é aquele que possui até três períodos intercalados, ou a ocorrência de um dos períodos somente uma vez. Ainda na Figura 10, todos são exemplos de ciclos simples. Mesmo no ciclo A", da Figura 10c, observa-se apenas três períodos intercalados (LM, NLM e LM), ou somente a 
Figura 11: Exemplo de ciclo complexo.

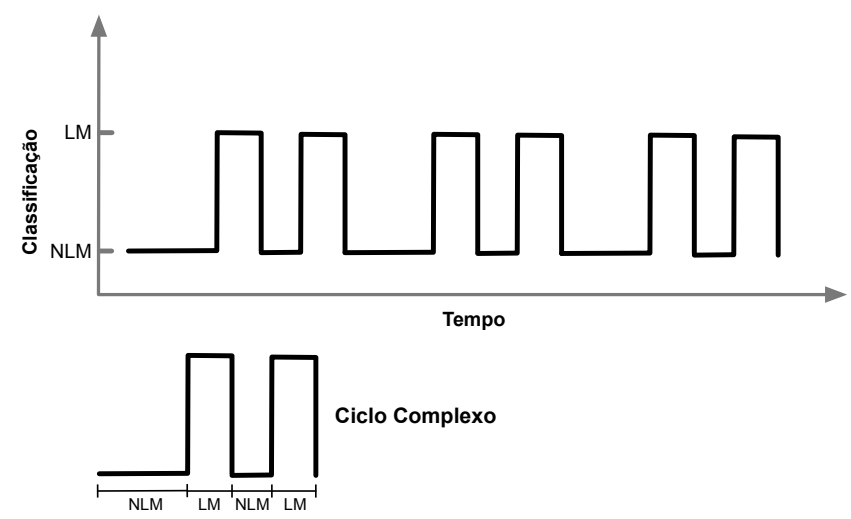

Fonte: Próprio Autor (2015).

ocorrência de um período NLM. A Figura 11 apresenta um exemplo de ciclo complexo, em que se observa que ocorrem dois períodos NLM e dois LM. A facilidade em identificar tanto ciclos simples como ciclos complexos também foi um fator determinante para a escolha do uso da TRF.

Figura 12: Periodograma da carga do benchmark TPC.

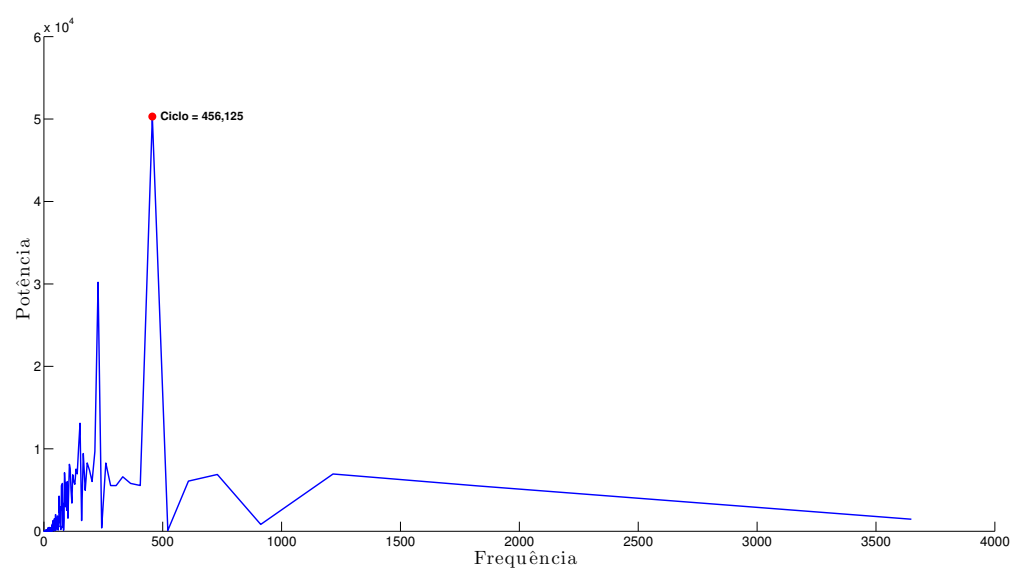

Fonte: Próprio Autor (2015).

Para avaliar a precisão da identificação de ciclos da TRF, foi executado o benchmark TPC (HSU; SMITH; YOUNG, 2001) e, a cada quinze segundos, sua carga foi submetida a um classificador Naive Bayes que a identificou como favorável ou não favorável para a Live Migration. A classificação foi, en- 
tão, submetida à TRF que retornou um ciclo a cada 456,125 segundos ${ }^{1}$, como mostrado no Periodograma gerado da Figura 12.

A classificação da carga do TPC é apresentada na Figura 13. A linha tracejada indica o tamanho do ciclo identificado pela TRF. Além da baixa complexidade da TRF, a precisão para identificar o tamanho do ciclo foi o principal fator que levaram a escolhê-lo. Além disso, quanto maior o histórico das coletas submetidas à TRF, maior será sua precisão.

Figura 13: Identificação de ciclos na carga do benchmark TPC.

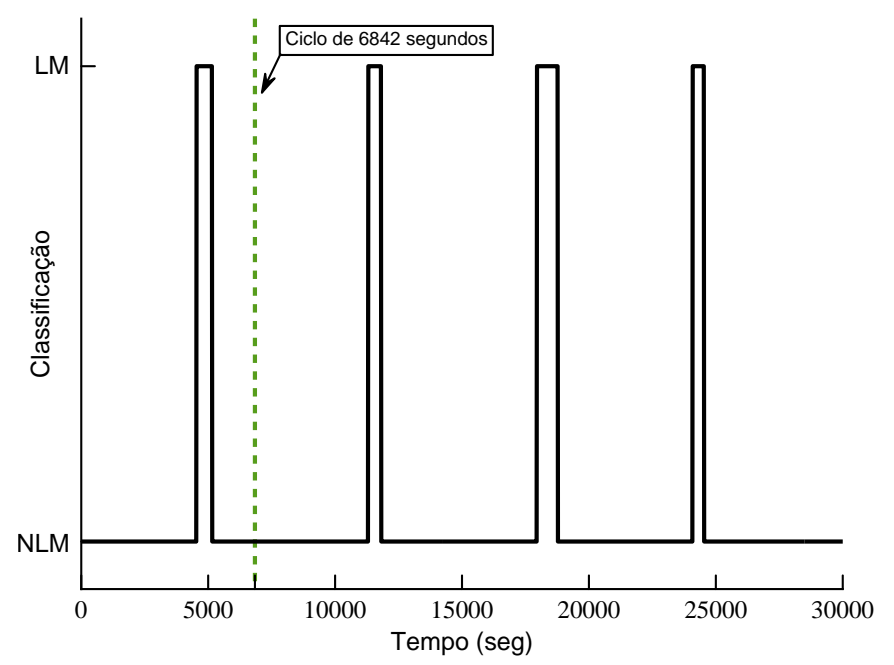

Fonte: Próprio Autor (2015).

\footnotetext{
${ }^{1}$ Este valor deve ser multiplicado por quinze, pois a coleta foi realizada a cada quinze segundos, portanto 6842 segundos.
} 


\section{ORQUESTRAÇÃO DE MIGRAÇÃO DE MÁQUINAS VIRTUAIS BASEADA EM ANÁLISE CÍCLICA}

A migração individual de uma máquina virtual, como visto anteriormente, pode gerar uma quantidade de tráfego de dados, no mínimo, equivalente ao tamanho da memória alocada. Dessa forma, estratégias de consolidação e balanceamento de carga, que podem ativar diversas migrações simultaneamente, podem gerar uma quantidade de tráfego acima da capacidade da rede e, como consequência, gerar congestionamento na rede afetando outras migrações em curso e as aplicações em execução nas máquinas virtuais.

Este capítulo apresenta uma orquestração de migração de máquinas virtuais em que é aplicada a análise cíclica para definir o momento mais propício de migração, independente do algoritmo de migração implementado no monitor de máquinas virtuais (BARUCHI; MIDORIKAWA; SATO, 2015). Para extrair o comportamento cíclico da carga de trabalho, é aplicada a metodologia apresentada no capítulo anterior. Em um primeiro momento, a carga é caracterizada e, em seguida, extraem-se os ciclos da carga de trabalho. Com essas informações é possível definir o melhor momento para submeter a máquina virtual ao processo de migração. No capítulo seguinte, será apresentada a arquitetura ALMA (Application-aware Live Migration Architecture) que é uma implementação da discussão abordada neste ponto. 
Além disso, será apresentada uma métrica para inferir se a migração de uma máquina virtual poderá ou não gerar sobrecarga na aplicação em sua execução. Essa métrica pode ser usada para definir se migrações futuras podem trazer mais custo para a aplicação do que benefícios e, dessa forma, evitar migrações desnecessárias. Será apresentado também um algoritmo cujo desempenho não está associado ao uso de memória pela máquina virtual. Esse algoritmo é um meio termo entre a migração implementada nos monitores de máquinas virtuais e a migração de processos, implementado em ambientes de computação de alto desempenho. Os resultados da métrica de custo de migração e a implementação de um protótipo do algoritmo de migração de máquinas virtuais é apresentado no capítulo 8.

\subsection{Migração Orquestrada}

Ao implementar uma estratégia de balanceamento ou consolidação de máquinas virtuais em um ambiente de computação na nuvem, as migrações ocorrerão de forma imediata, assim que as movimentações necessárias para alcançar um objetivo final, que pode ser a redução do consumo de energia ou a melhora no desempenho de um conjunto de máquinas virtuais de um determinado usuário, estiver calculado. Entretanto, as migrações ocorrerão paralelamente, gerando grande tráfego de rede e que é potencializado quando a migração ocorrer em um instante em que a carga de uma ou mais máquinas virtuais estiver fazendo operações de E/S ou fazendo diversas alterações em memória.

Na Figura 14, são ilustradas duas situações: uma em que a consolidação ou balanceamento de carga faz a migração das três máquinas virtuais imediatamente após o cálculo para definir quais serão as máquinas físicas que as receberão (Figura 14a), e outra situação, em que as máquinas virtuais têm 
suas migrações orquestradas em função da carga de trabalho (Figura 14b). Nesta Figura, os vales representam um período em que a carga de trabalho possui maior potencial de elevar o congestionamento de rede ao ser migrada e os picos são períodos em que a carga não é nociva à rede.

Figura 14: Orquestração de migração de máquinas virtuais utilizando análise cíclica.

(a) Sem Análise Cíclica.

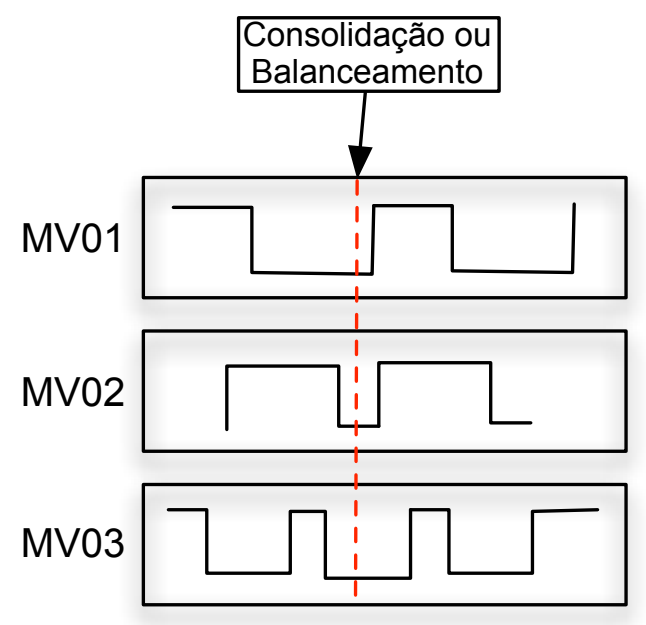

(b) Com Análise Cíclica.

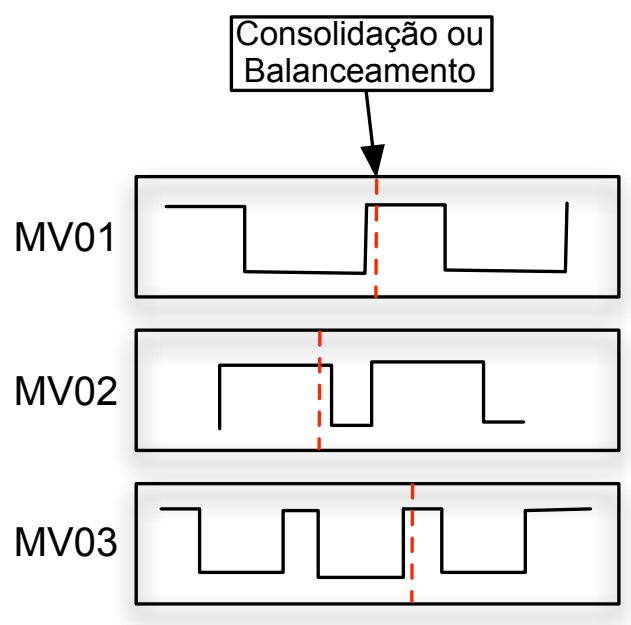

Fonte: Próprio Autor (2015).

Nos casos das máquinas virtuais ilustradas da Figura 14, fica evidente que a migração simultânea causará um tráfego excessivo na rede. Todas as máquinas virtuais da Figura 14a sofrem o processo de migração em um período que não é favorável para tal. Além disso, nota-se que, se a migração fosse adiada em apenas alguns instantes, provavelmente as máquinas virtuais MV01 e MV02 teriam sido migradas em um período mais adequado, sem gerar demasiado tráfego na rede.

O objetivo de aplicar a análise cíclica na carga de trabalho das máquinas virtuais é identificar o padrão de execução da carga e, com isso, adiar migrações com potencial de gerar tráfego de rede para períodos mais favoráveis ao processo de migração. Na Figura 14b, as movimentações das máquinas 
virtuais foram computadas, mas ao invés das migrações terem sido submetidas simultâneamente, elas foram adiadas para períodos mais propícios. Ao orquestrar as migrações de acordo com a carga de trabalho, espera-se observar uma redução no tempo da migração das máquinas virtuais e na quantidade de dados trafegados na rede, eliminando ou, pelo menos, reduzindo de forma considerável o congestionamento na rede.

\subsection{Sinergia entre Análise Cíclica e Estratégias de Migração Massiva}

As estratégias que podem gerar uma quantidade massiva de migração (consolidação ou balanceamento de carga) têm, como discutido anteriormente, a função de otimizar o uso de recursos do data center. Em geral, ao aplicar uma estratégia dessa natureza, o provedor de serviço de computação na nuvem quer reduzir o desperdício de recursos, seja este recurso computacional ou não (como energia elétrica). Para este fim, as estratégias de migração massiva utilizam algoritmos complexos, muitos deles baseados em heurísticas para computar quais máquinas virtuais devem ser movimentadas.

Não é escopo deste trabalho decidir a melhor heurística ou qual estratégia utilizar, mas sim reduzir os efeitos colaterais dessas estratégias. Portanto, para que isso seja possível é necessário que haja uma forma de criar uma sinergia, ou cooperação mútua entre essas estratégias e a orquestração de migração de máquinas virtuais. Uma solução para implementar essa sinergia é interceptar ou receber as movimentações que foram computadas pelas estratégias e, com essa informação, orquestrar as migrações de acordo com o ciclo das cargas de trabalho das máquinas virtuais envolvidas. 
Em uma implementação convencional, as migrações calculadas são passadas diretamente aos monitores de máquinas virtuais, que por sua vez executam as migrações. A ilustração da Figura 15 mostra como seria uma implementação com a orquestração de migração. Antes das solicitações chegarem aos monitores de máquinas virtuais, o orquestrador receberá quais máquinas virtuais serão migradas e para qual máquina física de destino. As migrações ficam, então, represadas no orquestrador que irá executá-las assim que a carga for favorável. Baseando-se no padrão cíclico das máquinas virtuais, o orquestrador tem uma estimativa de quanto tempo ainda resta para que a migração seja submetida. Isso possibilita que sejam feitas configurações como tempo máximo que uma migração pode esperar para ser executada ou ainda se o período favorável está no final e por isso é prudente esperar o próximo período.

Figura 15: Migração Massiva e Orquestração migração de máquinas virtuais.

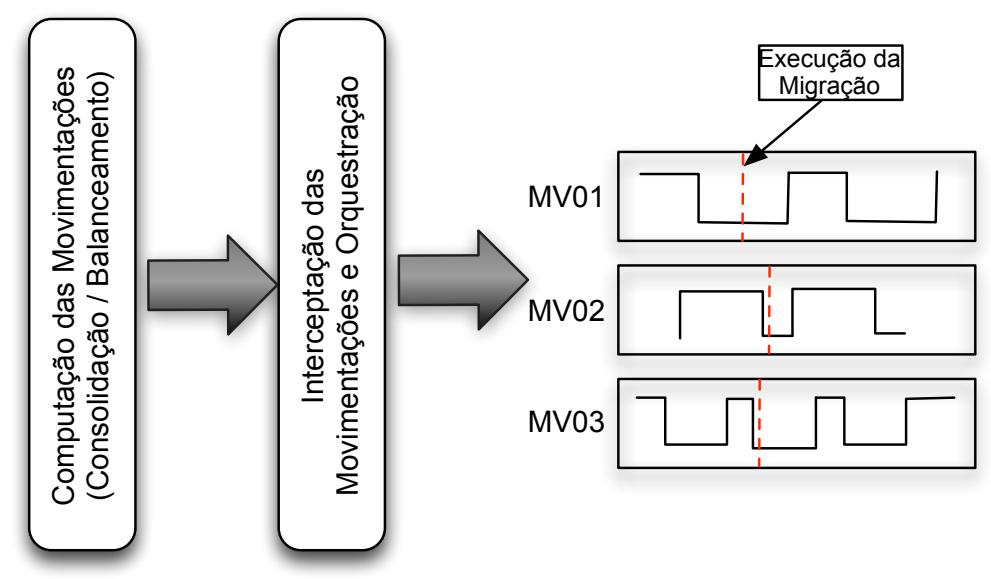

Fonte: Próprio Autor (2015).

Neste modelo, tanto os algoritmos desenvolvidos para a implementação das estratégias de balanceamento ou consolidação como os algoritmos de migração de máquinas virtuais (Pré-cópia ou Pós-cópia) não precisam ser modificados. Na prática, devem ocorrer alterações na implementação das estra- 
tégias de migração em massa, como por exemplo, nas APIs, pois a comunicação não será mais feita diretamente com o monitor de máquinas virtuais. Entretanto, os algoritmos centrais dessas estratégias não precisariam de modificações. O monitor de máquinas virtuais também não sofre alterações, pois neste modelo a ordem de migração é oriunda do orquestrador e não mais das implementações de consolidação ou balanceamento de carga. No capítulo 6 é apresentada a arquitetura ALMA, que implementa as ideias discutidas nesta seção. Os resultados obtidos com esta arquitetura são apresentados no capítulo 7.

\subsection{Migração Individual de Máquinas Virtuais}

Os algoritmos de Live Migration implementados em monitores de máquinas virtuais fazem a movimentação de toda a máquina virtual, levando os processos do usuário e também processos do próprio sistema operacional, sendo que possuem grande sensibilidade em função da taxa de atualização das páginas de memória, como ilustrado na Figura 16a. De acordo com o comportamento de uso da memória alocada pela máquina virtual, a migração sofrerá degradação de desempenho.

Existem também estratégias que fazem a movimentação de apenas um processo especificamente entre duas máquinas, conforme Figura 16b. Em geral, esses mecanismos são implementados em computação distribuída com o objetivo de continuar a computação independentemente de falhas sem que seja necessário reiniciar o processamento (STELLNER, 1996) (GIOIOSA et al., 2005). A proposta do algoritmo de migração de máquinas virtuais apresentada neste trabalho, conforme a Figura 16c, é uma solução intermediária entre os algoritmos tradicionais de Live Migration e os mecanismos de checkpoint/restart usados em ambientes de computação distribuída. 
Neste algoritmo, o principal objetivo é reduzir a dependência da utilização de memória no processo de migração da máquina virtual e uma das estratégias para atingir este objetivo é reduzir a quantidade de dados transferida na rede referente à memória.

Figura 16: Modelos de migração existentes.

(a) Migração Tradicional.

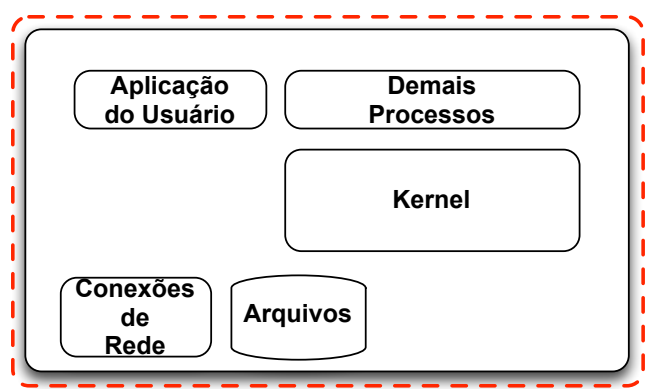

(b) Migração de Processos.

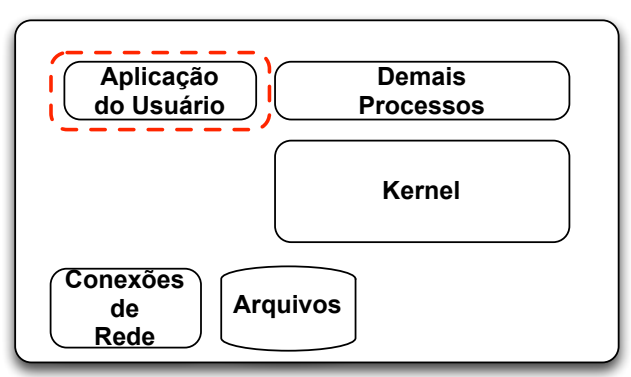

(c) Migração Proposta.

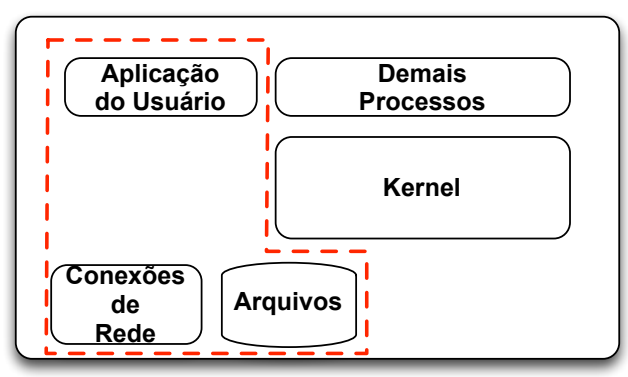

Fonte: Próprio Autor (2015).

O algoritmo consiste em mover o processo do(s) usuário(s), os arquivos que os processos estão usando e manter as conexões de rede ativas no hospedeiro de destino. Esse processo continuaria sendo transparente para o usuário das aplicações, da mesma forma que ocorre com a Live Migration tradicional. Entretanto, a quantidade de dados trafegados seria reduzida e, consequentemente, a indisponibilidade e tempo da migração seriam reduzidos consideravelmente. 


\subsection{Custo da Live Migration}

Neste trabalho é definido o conceito de custo da Live Migration em função da sobrecarga na aplicação. Isto é, uma vez que no decorrer da execução da aplicação em uma determinada máquina virtual houve a ocorrência de uma migração, o tempo adicional (ou reduzido) para que a aplicação termine é o que definirá o custo da Live Migration.

Esta métrica permite quantificar o ganho ou perda de desempenho de uma aplicação na ocorrência de uma Live Migration. Tomando como exemplo a ilustração da Figura 17, observa-se que a aplicação demora um determinado tempo para executar na máquina virtual que está na máquina host A e $25 \%$ a mais do tempo para executar a mesma aplicação, na mesma máquina virtual, mas agora na máquina host B. O caso 1 da Figura 17 é uma situação em que o custo da migração será maior, isto é, no instante $t$ ocorreu uma migração na qual a máquina virtual, originalmente no host $A$, foi para o host $B$. Além do custo intrínseco da migração propriamente dita (parte em vermelho), há a diferença de desempenho entre as duas máquinas. A soma de todos os fatores resulta em uma sobrecarga maior para a aplicação do que tê-la deixado em execução no host $A$.

No caso 2 observa-se a situação oposta, isto é, a mesma aplicação inicia na máquina virtual, mas agora no host $\mathrm{B}$. No mesmo instante $t$ ocorre a migração para o host A. Neste cenário, apesar do custo da movimentação da máquina virtual entre as duas máquinas, ocorre que o desempenho do host A é superior ao do host B. Neste caso, o custo da migração para a aplicação seria positivo pois a aplicação terminaria antes do tempo, caso a migração não tivesse acontecido. 
Figura 17: Representação do custo da Live Migration.

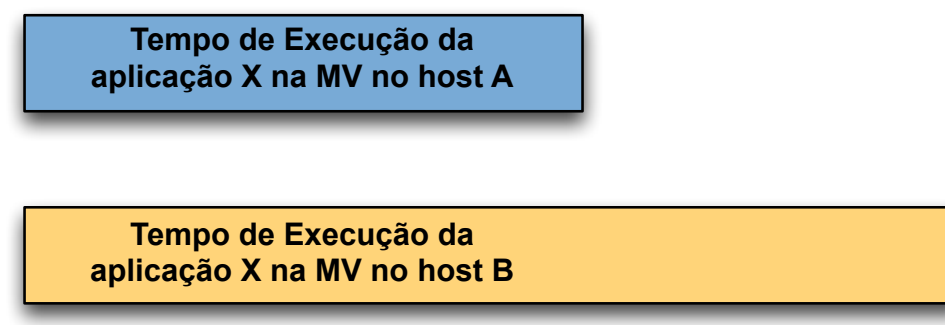

Caso 1: Aplicação que inicia no Host $A$ é migrada para o Host $B$
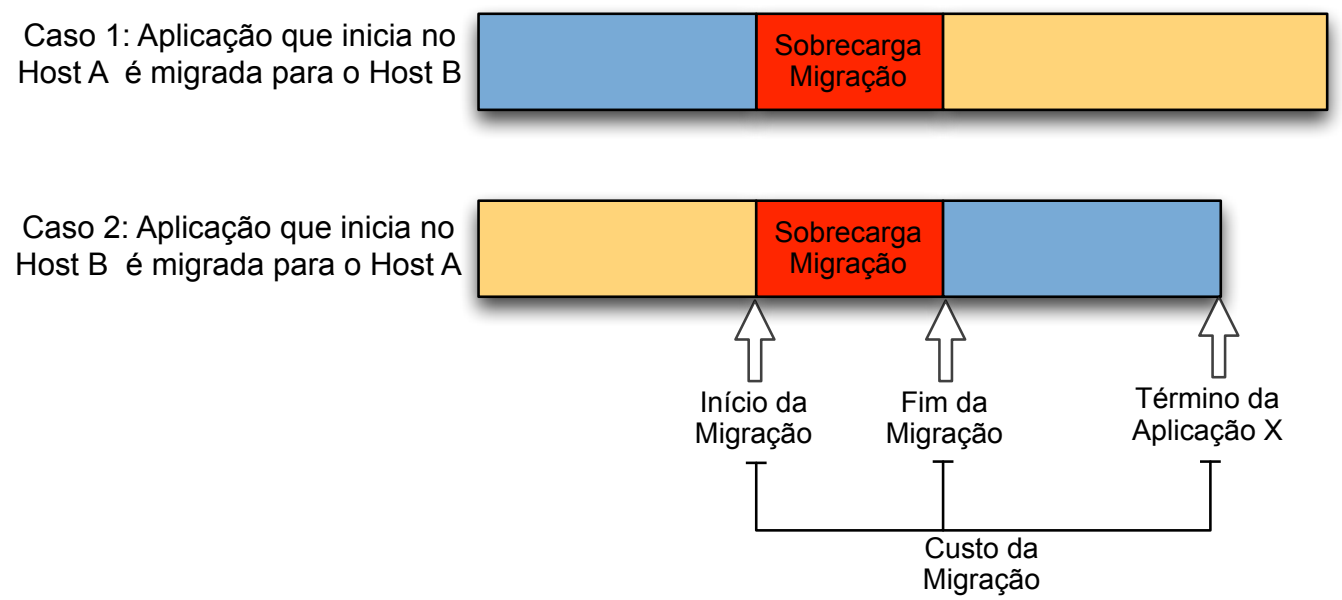

Fonte: Próprio Autor (2015).

Ambos os cenários são factíveis em um ambiente de computação na nuvem, pois apesar da máquina virtual possuir a mesma quantidade de recursos (mesma configuração de software e hardware) independentemente da máquina física, a tecnologia subjacente desta última, ou mesmo parâmetros de otimização, podem ser diferentes e poderiam causar essa situação. Além disso, como observado por Birke et al. (2013) o uso de máquinas com diferentes gerações de tecnologias é o cenário mais comum entre os provedores de computação na nuvem. No capítulo 8 é abordada a utilização dessa métrica. 


\section{ARQUITETURA ALMA}

A análise cíclica, baseada na caracterização de carga de trabalho, pode agora ser utilizada para definir os momentos propícios para a migração de máquinas virtuais, trazendo benefícios para os usuários da nuvem e para o provedor de serviços. Para isso, será proposta uma arquitetura que fará a mediação entre as estratégias de consolidação ou balanceamento de carga ${ }^{1}$ e as máquinas físicas (hospedeiros) do data center.

Além da descrição da arquitetura, neste Capítulo será apresentada uma métrica que indica o custo, ou o impacto, que uma migração terá em uma dada carga de trabalho. Essa métrica, quando bem utilizada, poderá evitar migrações desnecessárias que poderiam gerar sobrecarga na infraestrutra ou ferir contratos de níveis de serviço. No final do Capítulo serão abordados os algoritmos usados para estimar o melhor momento de execução da migração de acordo com o ciclo e da carga de trabalho.

\subsection{Visão Geral da Arquitetura}

Em geral, os esforços para resolver problemas das funções objetivo, que lidam com problemas macro do data center - como consumo de energia ou consumo de recursos computacionais - e problemas relacionados aos algo-

\footnotetext{
${ }^{1}$ Neste capítulo, tanto as estratégias de consolidação como as estratégias de balanceamento de carga serão referenciadas como Função Objetivo.
} 
ritmos de migração de máquinas virtuais - que têm como foco algoritmos de migração menos complexos ou mais eficientes - são tratadas separadamente. A arquitetura proposta, baseando-se na carga de trabalho das máquinas virtuais, faz a mediação entre as duas partes (funções objetivo e algoritmos de migração).

A Figura 18 compara a arquitetura proposta às duas arquiteturas mais tradicionais de um ambiente de computação na nuvem. A Figura 18a é a arquitetura mais comum, em que a migração das máquinas virtuais propriamente dita não possui nenhum controle, isto é, uma vez que a função objetivo tenha definido quais máquinas virtuais serão migradas e para onde, o processo é iniciado e as máquinas virtuais são migradas todas simultaneamente causando congestionamento na rede do provedor de serviços e severas degradações de desempenho nas aplicações hospedadas nas máquinas virtuais (SEKI et al., 2012).

Por outro lado, a arquitetura apresentada na Figura 18b tem algum controle sobre as migrações. Entretanto, esse controle geralmente é feito na camada do monitor de máquinas virtuais e não há uma troca de informações com as estratégias de função objetivo. Em geral, o controle implementado é para reduzir o congestionamento de rede, mas não considera, por exemplo, o perfil da aplicação.

A arquitetura proposta neste trabalho, ilustrada na Figura 18c tem uma abordagem diferente das demais. Uma vez que a função objetivo é computada e, portanto, sabe-se quais máquinas virtuais terão de ser migradas as submissões são interceptadas, que baseado nas informações cíclicas das cargas de trabalho das máquinas virtuais fará a orquestração das migrações. Na arquitetura ALMA (do inglês, Application-aware Live Migration Archtecture) podese implementar uma comunicação de duas vias, isto é, sabendo-se a priori 
Figura 18: Componentes e fluxo de informação nas arquiteturas.

(a) Sem controle de migração.

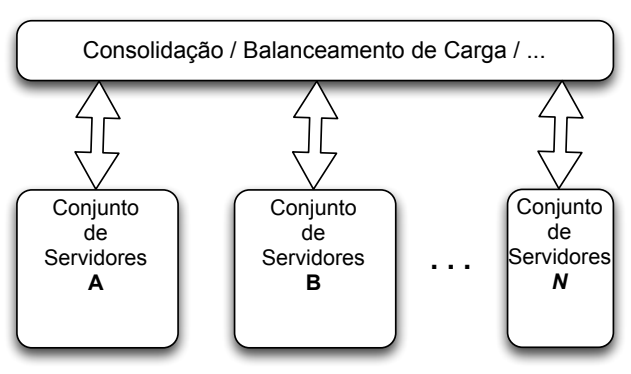

(b) Controle de migração clássico.

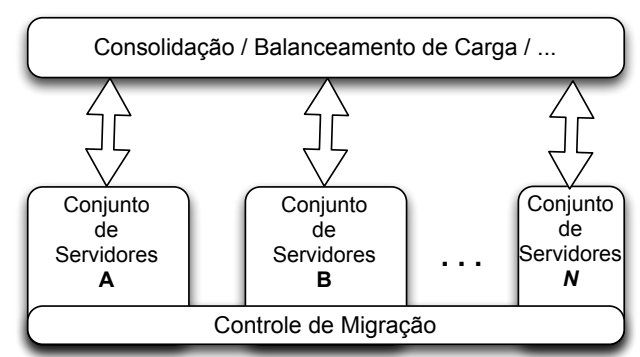

(c) Proposta ALMA.

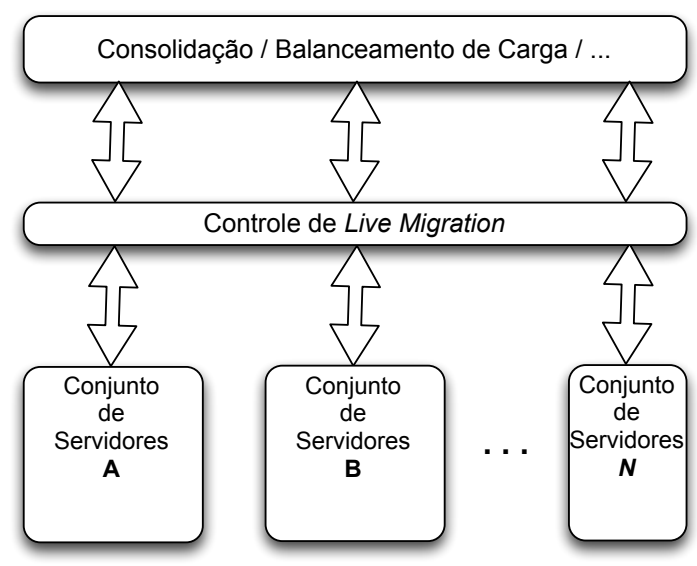

Fonte: Próprio Autor (2015).

quais cargas de trabalho estão mais favoráveis para serem migradas a função objetivo poderia diminuir o escopo da computação a ser feita para decidir as movimentações das máquinas virtuais.

O Módulo de Controle de Live Migration (MCLM) localizado entre as máquinas físicas e o orquestrador das funções objetivo é o responsável por interceptar as solicitações de migrações. Baseado nos dados coletados das máquinas virtuais e nos ciclos das respectivas cargas de trabalho o MCLM, pode adiar ou, caso seja possível, cancelar a migração de uma máquina virtual. O adiamento da migração pode acontecer quando a carga estiver na iminência de entrar em um período propício para ser migrada. Os casos de cancelamento de migração devem ser tratados de forma mais cautelosa, uma situação típica de cancelamento ocorre quando o custo de migrar a máquina virtual incorrerá 
em uma sobrecarga na aplicação desnecessário. Por exemplo, no caso da carga de trabalho já estar terminando ou se a migração implicar em um tempo maior de execução.

A implementação do MCLM poderia ser feita de tal modo a aceitar paramêtros do provedor de serviços e do usuário da nuvem. O provedor pode limitar o tempo máximo que uma máquina virtual pode esperar para ser migrada, o que evitaria que cargas com ciclos muito longos ficassem esperando indefinidamente pelo momento favorável à migração. Um segundo paramêtro, a critério do usuário, é informar o tempo máximo aceitável para a execução da aplicação. Com essa informação e sabendo-se o custo de migrar uma máquina virtual, podem-se criar mecanismos de definir o tempo limite máximo em que uma máquina virtual pode ser migrada.

\subsection{Algoritmos}

Para que a implementação da arquitetura proposta seja viável, foram desenvolvidos dois algoritmos para aplicar as ideias discutidas e apresentadas na Seção 4.3. Classificar e encontrar um padrão cíclico na carga de trabalho é a primeira parte do desafio a ser transposto. A segunda parte, uma vez com o tamanho do ciclo calculado, é verificar quanto tempo ainda resta até que haja um momento favorável para a migração ou, caso a carga esteja no momento favorável, quanto tempo ainda resta para que a migração seja executada.

Os algoritmos poderiam ser abordados como um só, entretanto, a fim de facilitar o entendimento da estratégia, a solução foi dividida em duas partes: (1) decomposição do tipo da carga (LM ou NLM); e (2) verificar em qual instante, em relação ao ciclo, a carga se encontra.

Uma das características da arquitetura proposta é a coleta constante do 
tipo de carga (LM ou NLM) das máquinas virtuais que estão sob a tutela da arquitetura. Essa informação, armazenada em ordem cronológica, será usada como insumo para a entrada do algoritmo 1. A título de exemplo, a Figura 19 representa o vetor $C$, usado como entrada no algoritmo 1 . Supondo que cada posição do vetor tenha uma classificação para a carga da máquina virtual naquele dado instante, em que o instante é a própria posição do vetor, utilizase a Transformada Rápida de Fourier para identificar o tamanho do ciclo para essa carga (linha 2 do algoritmo 1). A partir de então, as análises serão feitas no trecho do vetor $C$ que representa um ciclo completo. Na ilustração da Figura 19, o tamanho do ciclo é de 190 unidades de tempo.

Figura 19: Processo de Decomposição do Ciclo.

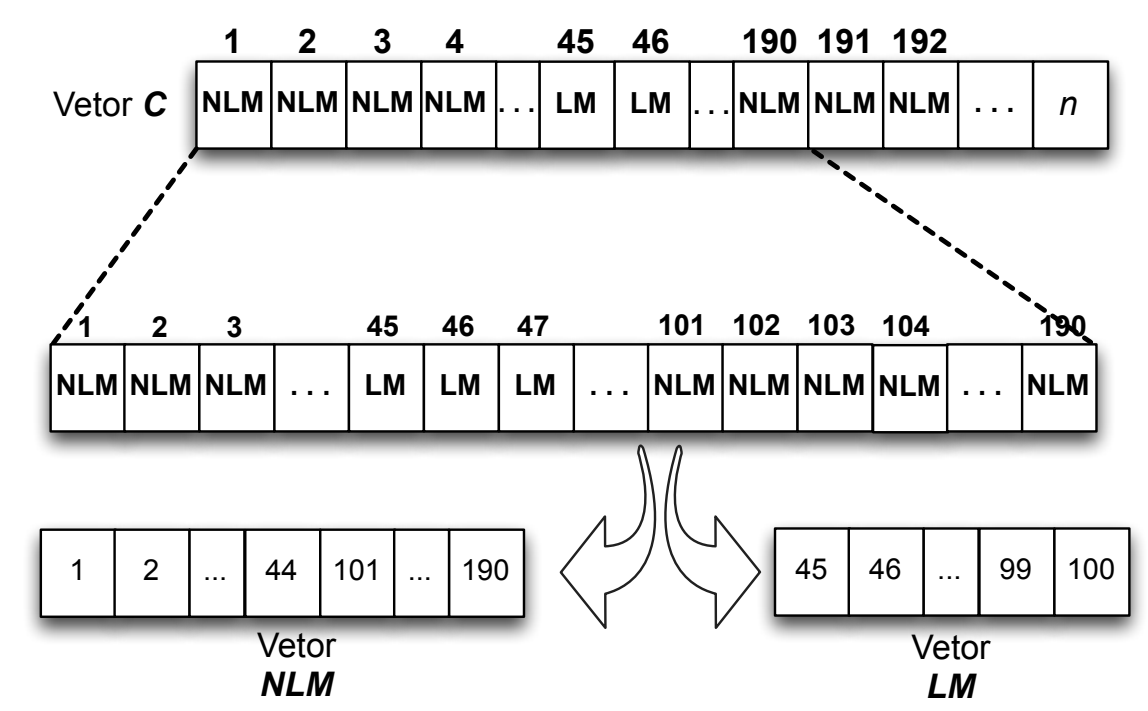

Fonte: Próprio Autor (2015).

O trecho do vetor que representa um ciclo completo da carga de trabalho é então analisado e dividido em dois vetores menores (linhas 5 até a 13 do algoritmo 1). Um vetor armazenará os instantes favoráveis à Live Migration (VetorLM) e o segundo os instantes não favoráveis (VetorNLM). O conteúdo dos vetores será o instante e não a classificação da carga.

O algoritmo 2 tem como objetivo reconhecer o momento corrente (ou presente) em relação ao ciclo. A ilustração da Figura 20 mostra um ciclo de 190 


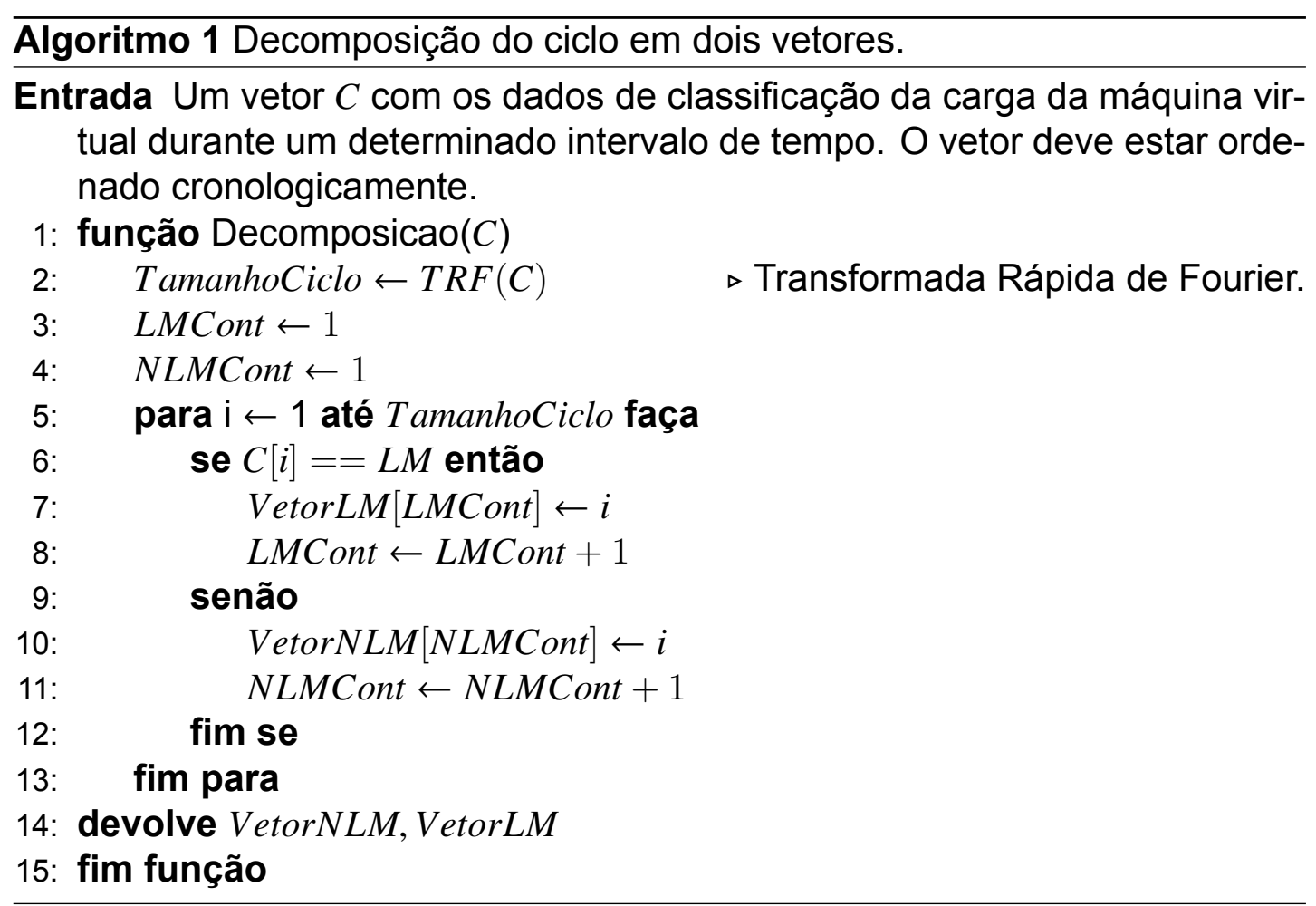

unidades de tempo (calculado pela TRF). Supondo que tenha ocorrido uma solicitação de migração no instante $t=470$, é necessário saber em que momento, em relação ao ciclo, o instante 470 representa. Para isso, calcula-se o resto da divisão entre o momento corrente $\left(M_{\text {presente }}\right)$ e o tamanho do ciclo (TamanhoCiclo), linha 2 do algoritmo 2 e que na Figura 20 é 470 e 190, respectivamente. O resultado da operação é 90 ( $\left.M_{\text {correspondente }}\right)$, isto é, em relação ao ciclo, o instante 470 é análogo ao instante 90.

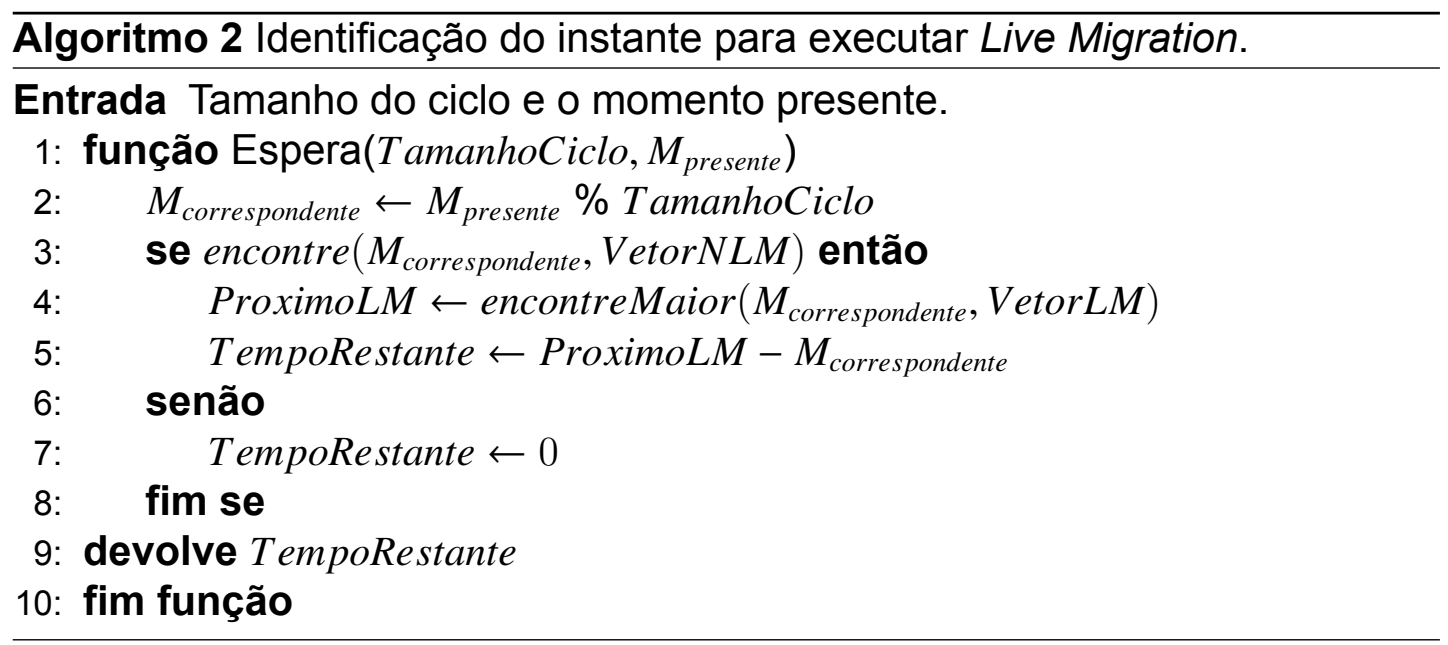


Figura 20: Identificação do momento correspondente ao ciclo.

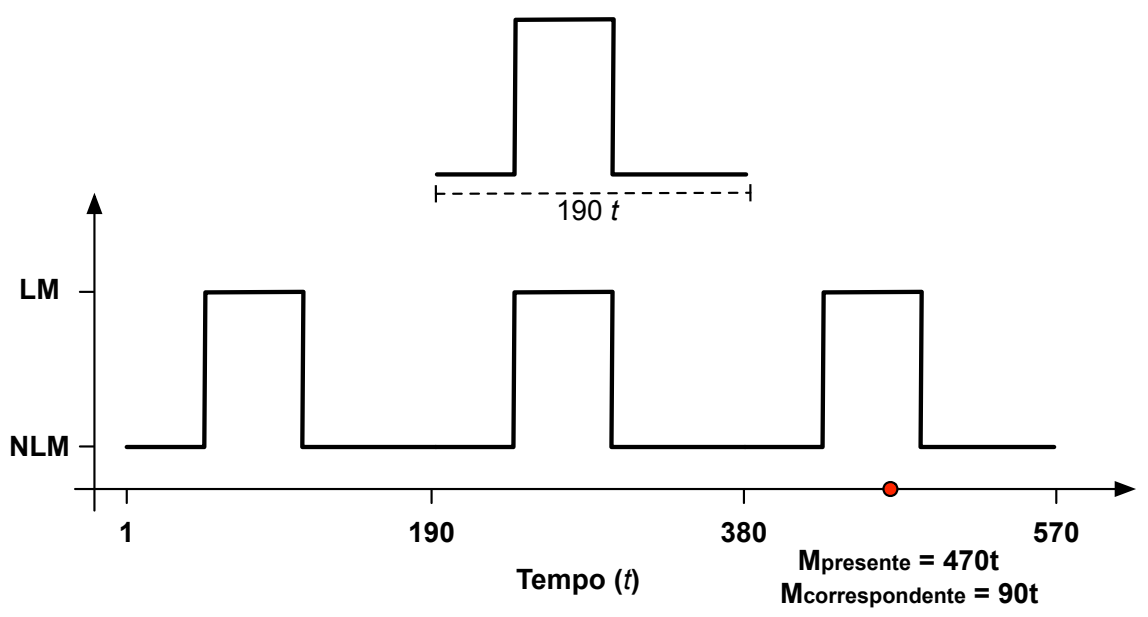

Fonte: Próprio Autor (2105).

O passo seguinte é descobrir se o instante atual é propício ou não para a execução da migração. Agora que já se sabe que o instante corrente representa o instante 90 para o ciclo, busca-se o instante dentro dos vetores gerados pelo algoritmo 1. Caso o instante 90 esteja inserido em algum intervalo do VetorNLM (linha 3 do algoritmo 2), isso indicará que se trata de um instante não propício para a migração e, para saber o tempo restante, basta procurar no VetorLM o próximo instante maior que 90 e verificar a diferença (linhas 4 e 5 do algoritmo 2). No caso do instante 90 estar em algum intervalo compreendido no vetor VetorLM, isso indicará que o momento atual é propício para a migração.

Esses dois algoritmos fazem parte do módulo de controle de migração da arquitetura ALMA e que será avaliado em um próximo Capítulo deste trabaIho. Entretanto, é importante salientar que existem algumas oportunidades de otimização, como uso de algoritmos de busca eficientes (por exemplo: busca binária de complexidade $O(\log n)$ ), uso de estruturas de dados mais eficientes, entre outros.

Um dos principais problemas identificados na abordagem apresentada é uma forma de calcular o comportamento médio do ciclo. A TRF retorna o ta- 
manho do ciclo, porém é necessário escolher um período com o tamanho do ciclo (a partir do instante $t=1$ ) para usar como referência. Apesar do comportamento cíclico, podem acontecer oscilações, mesmo que pequenas, dentro do ciclo. Nos experimentos verificou-se que uma boa escolha é evitar os primeiros ciclos, pois estes ainda podem estar em uma fase de inicialização e, por consequência, sofrer com problemas do tipo cold cache (PATTERSON; GIBSON; SATYANARAYANAN, 1993). A precisão do algoritmo melhorou em média $8 \%( \pm 2)$ quando a escolha pelo ciclo de referência da carga utilizado foi outra, que não os dois primeiros ciclos. 


\section{RESULTADOS E EXPERIMENTOS COM ARQUITETURA ALMA}

O objetivo principal da avaliação exposta neste Capítulo é verificar a precisão com que a arquitetura identifica os momentos propícios de uma dada carga de trabalho e submetê-la à migração e medir a redução da sobrecarga na infra-estrutura ao utilizar a estratégia proposta. Serão avaliadas as métricas referentes ao impacto na infra-estrutura, conforme apresentado no capítulo 3 e também será avaliada a quantidade de dados trafegados no processo da migração. Com isso, as três métricas avaliadas serão:

- Tempo Total de Migração: é o intervalo de tempo entre o início do processo de Live Migration até o reinício da execução da execução da máquina virtual no hospedeiro destino;

- Downtime: intervalo de tempo durante o qual a máquina virtual não está disponível para o usuário;

- Dados Trafegados: quantidade de dados trafegados na rede entre as duas máquinas envolvidas na migração (origem e destino).

Inicialmente será apresentada a metodologia de avaliação, com a topologia e configuração das máquinas. Em seguida, serão apresentados os resultados obtidos com a execução de benchmarks, em que foram criados ciclos artificialmente. Na segunda bateria de testes, foram utilizadas aplicações, variando entre aplicações científicas, aplicações comerciais e aplicações típicas 
de ambientes de nuvem. Por fim, será feita uma análise de escalabilidade da arquitetura, cujo objetivo é averiguar o comportamento em casos de grandes quantidades de máquinas virtuais.

\subsection{Método de Avaliação}

Para a avaliação da estratégia proposta, optou-se por implementar a arquitetura em um ambiente real de nuvem privada. As métricas de avaliação da arquitetura não são encontradas em simuladores de computação na nuvem tradicionais como o CloudSim (CALHEIROS et al., 2011) ou iCanCloud (NUñEZ et al., 2012). Em geral, esses simuladores são voltados para a implementação de escalonadores de máquinas virtuais. Além disso, os resultados de simuladores são aproximações, podendo, em alguns casos, não corresponder com à realidade. Essa configuração de ambiente de testes, também é usada em trabalhos similares (VERMA et al., 2011).

Figura 21: Configuração da Nuvem Privada.

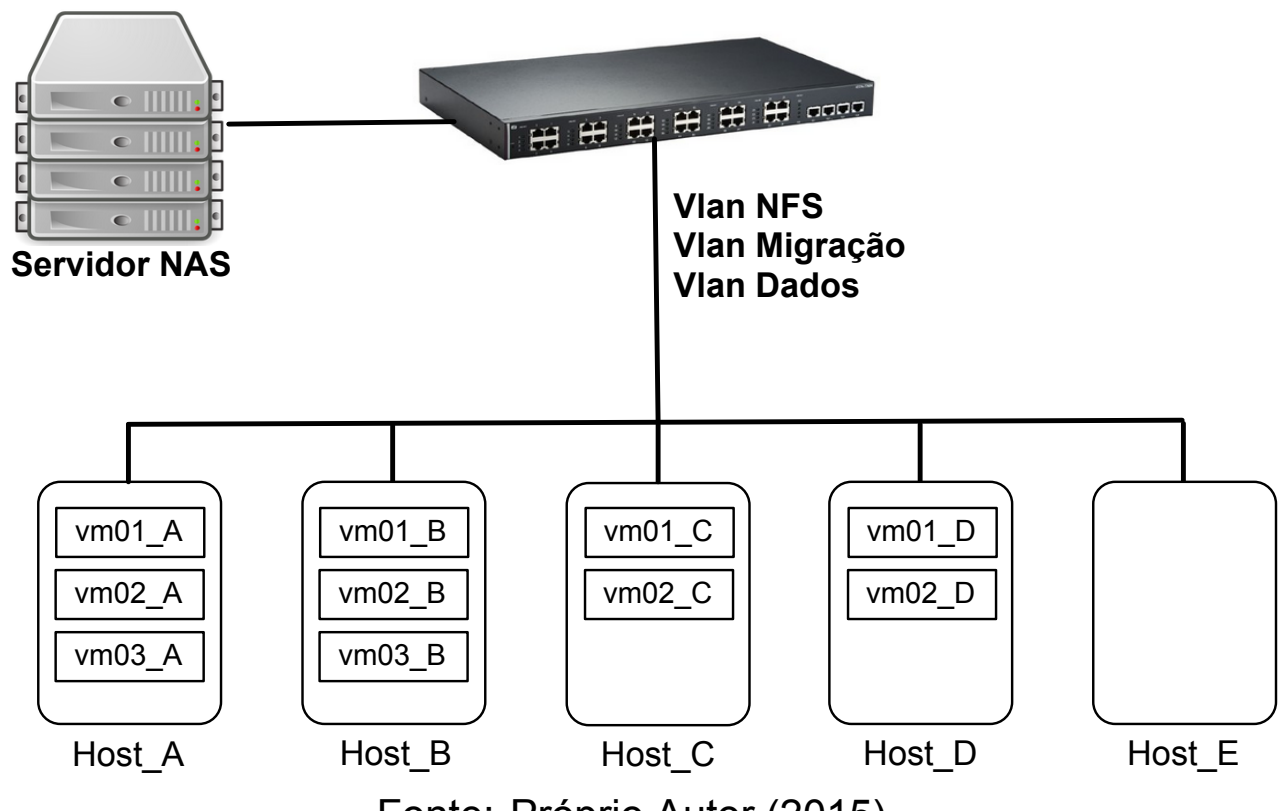

Fonte: Próprio Autor (2015). 
A nuvem privada usada na implementação é composta por cinco servidores físicos, atuando como hospedeiros para as máquinas virtuais e um servidor físico atuando como servidor NAS (do inglês, Network Attached Storage) também onde a implementação da arquitetura foi feita. As máquinas físicas foram instaladas com o openSUSE 12.2 e com o Xen 4.1.6 (kernel 3.4.63-2.44-xen) atuando como monitor de máquinas virtuais e as máquinas virtuais foram instaladas com o CentOS 6.5 (kernel 2.6.32-431.3.1.el6). Todos os componentes são conectados por um switch gerenciável de 24 portas, com segmentação para a rede de dados, administração e migração. Ao todo foram instaladas dez máquinas virtuais e distribuídas de forma homogênea entre as máquinas físicas. A Figura 21 apresenta a visão geral da configuração da nuvem privada usada como ambiente de teste neste trabalho. A configuração do hardware das máquinas físicas é detalhada na Tabela 7 e as máquinas virtuais, instaladas em três configurações diferentes, são descritas na Tabela 8. O core da arquitetura foi implementado em Perl, isto é, o classificador e a análise cíclica baseada nos algoritmos apresentados na seção 6.2. Entretanto, a Transformada Rápida de Fourier foi implementada em $\mathrm{C}^{1}$.

Tabela 7: Configuração das Máquinas Físicas do ambiente de teste.

\begin{tabular}{|c|c|c|}
\hline $\begin{array}{c}\text { Máquina Física } \\
\text { (hostname) }\end{array}$ & \# CPU - Modelo & $\begin{array}{c}\text { Memória Fisica } \\
\text { (GB) }\end{array}$ \\
\hline \hline Host_A & $4 \times 2,66 \mathrm{GHz}-$ Intel 2 Quad & 4 \\
\hline Host_B & $8 \times 2,8 \mathrm{GHz}-$ Intel i7 & 8 \\
\hline Host_C & $4 \times 2,3 \mathrm{GHz}-$ AMD Phenon & 8 \\
\hline Host_D & $4 \times 2,3 \mathrm{GHz}-$ AMD Phenon & 4 \\
\hline Host_E & $8 \times 1,6 \mathrm{GHz}-$ Intel i7 & 16 \\
\hline
\end{tabular}

\footnotetext{
${ }^{1}$ Disponível em: <http://www.fftw.org/>
} 
Figura 22: Nuvem Privada após consolidação em duas máquinas físicas.

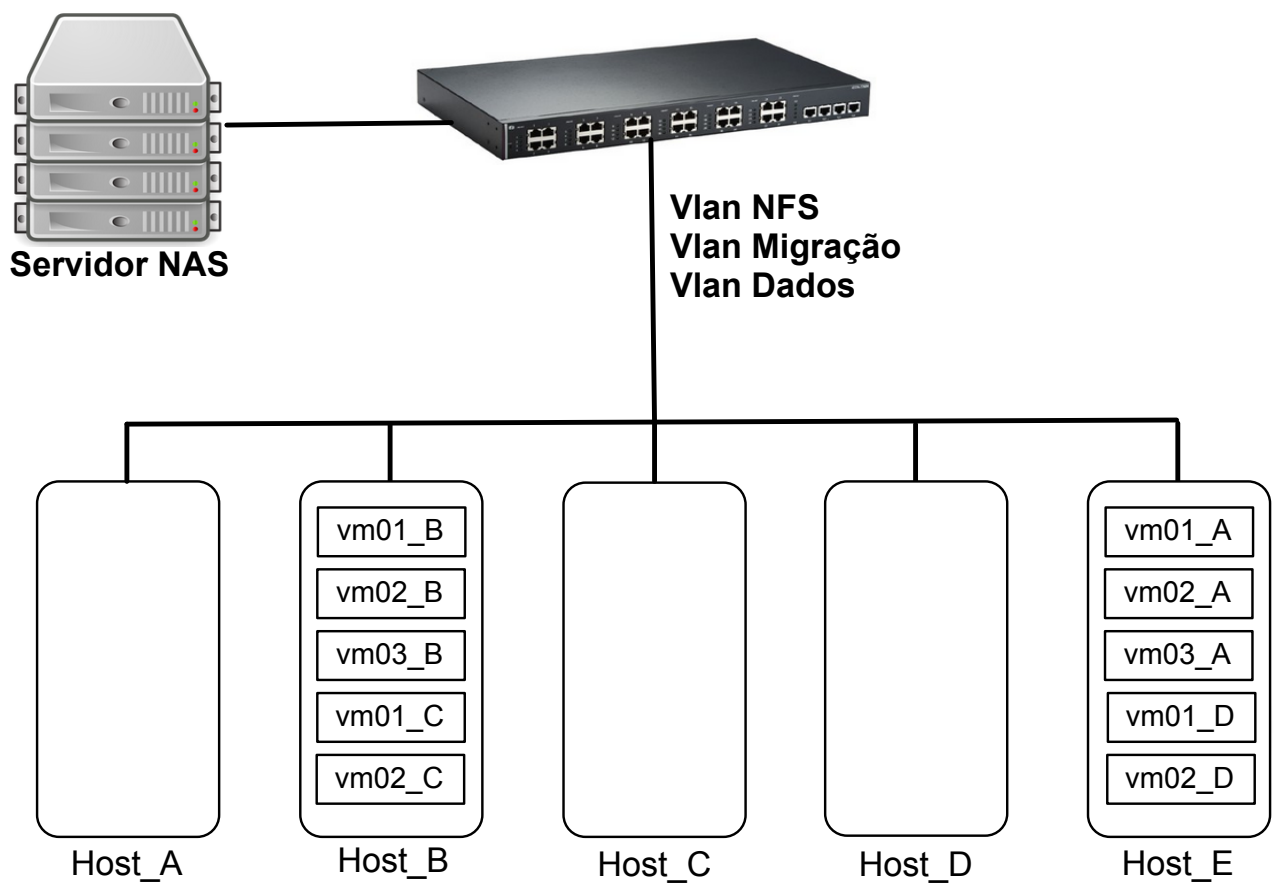

Fonte: Próprio Autor (2015).

Os experimentos conduzidos levaram em conta apenas a consolidação de servidores, isto é, durante a execução da carga de trabalho, as máquinas virtuais eram consolidadas em dois servidores físicos, conforme Figura 22. Os momentos de consolidação foram escolhidos aleatoriamente. Entretanto, como poderá ser observado nas próximas seções, evitaram-se instantes muito próximos um do outro e, como o tempo de execução das cargas de trabalho são diferentes, tiveram preferência momentos em que todas as cargas estavam ativas simultaneamente. O objetivo dessa decisão é aproximar os experimentos o máximo possível da realidade um ambiente de nuvem de produção.

Tabela 8: Configuração das Máquinas Virtuais do ambiente de teste.

\begin{tabular}{|c|c|c|c|}
\hline Configuração & VCPUS & $\begin{array}{c}\text { Memória } \\
\text { (MB) }\end{array}$ & $\begin{array}{c}\text { Máquina Virtual } \\
\text { (hostname) }\end{array}$ \\
\hline \hline Pequena & 1 & 768 & $\begin{array}{c}\text { vm02_A vm03_A } \\
\text { vm01_B vm02_B }\end{array}$ \\
\hline Média & 2 & 1024 & $\begin{array}{c}\text { vm01_A vm01_C } \\
\text { vm01_D vm02_D }\end{array}$ \\
\hline Grande & 2 & 2048 & vm03_B vm02_C \\
\hline
\end{tabular}


Para coletar o tempo total de migração, foi aumentado o nível de detalhamento dos arquivos de registro do Xen. Com esse detalhamento, foi possível verificar exatamente quando a migração foi iniciada e quando foi considerada finalizada pelo monitor de máquinas virtuais. Uma amostra da informação armazenada nesse arquivo é apresentada na Figura 23. A primeira linha mostra o instante em que a solicitação chega ao Xen e a última linha é o instante em que a máquina virtual é totalmente liberada do hospedeiro de origem para iniciar a execução no hospedeiro de destino. No exemplo, o tempo total de migração foi de onze segundos.

Figura 23: Exemplo do registro feito pelo Xen durante o processo de migração.

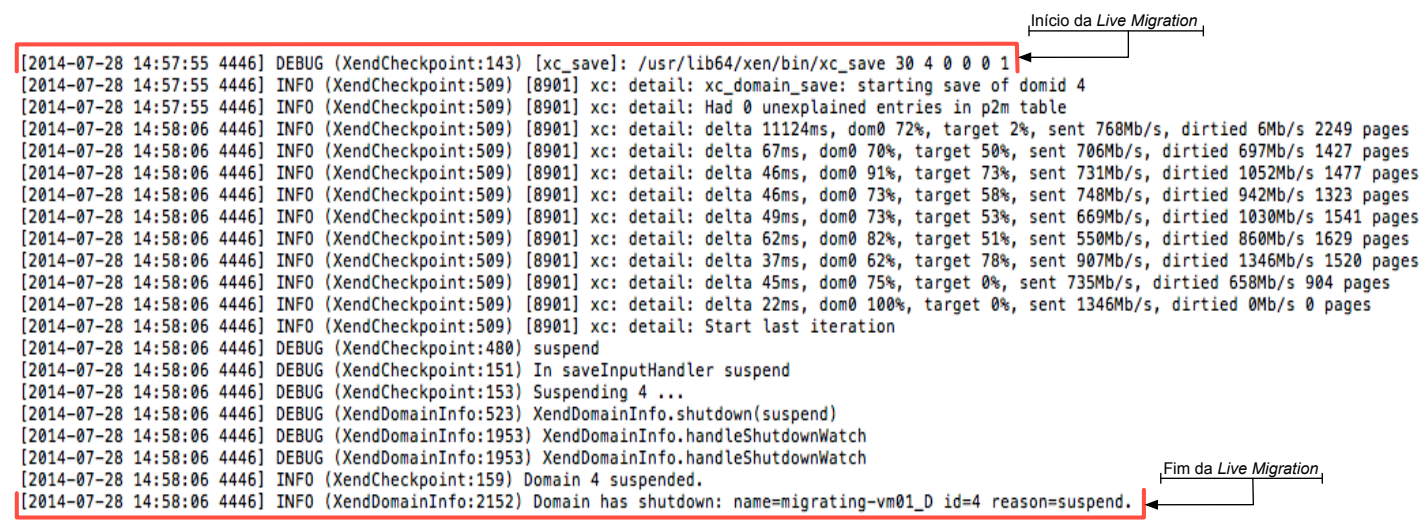

Fonte: Próprio Autor (2015).

O tempo de downtime foi mensurado usando-se o protcolo ICMP (do inglês, Internet Control Message Protocol). Quando a solicitação de Live Migration era executada, um script enviava um pacote ICMP para a máquina virtual e o período em que os pacotes não tiveram uma resposta foi contabilizado como tempo de downtime da máquina virtual. A Figura 24 apresenta um exemplo de saída que o script implementado gera ao identificar um intervalo de tempo sem resposta da máquina virtual. O intervalo é contabilizado a partir do último pacote recebido até o primeiro pacote, após o intervalo, recebido. No caso ilustrado pela Figura 24, o tempo contabilizado de downtime será de onze segundos. 
Figura 24: Saída do script de coleta do período de downtime.

Tue Jul 29 12:24:48 2014 vm01_C is alive (12.9 ms)

Tue Jul 29 12:24:49 2014 vm01_C is alive (26.2 ms)

Tue Jul 29 12:24:50 $2014 \mathrm{vm01}$ C is alive (6.98 ms)

Tue Jul 29 12:24:53 2014 vm01_C is unreachable

Tue Jul 29 12:24:56 2014 vm01_C is unreachable

Tue Jul 29 12:24:59 2014 vm01_C is unreachable

Tue Jul 29 12:25:01 2014 vm01_C is alive (1.97 ms)

Tue Jul 29 12:25:02 2014 vm01_C is alive (2.10 ms)

Tue Jul $2912: 25: 032014$ vm01_C is alive (0.52 ms)

Fonte: Próprio Autor (2015).

Por fim, a quantidade de dados trafegados na rede de migração foi contabilizada coletando-se os dados diretamente do switch via SNMP (do inglês, Simple Network Management Protocol). O switch usado nos experimentos provê uma série de estatísticas a respeito da utilização das portas e a quantidade de pacotes enviadas e recebidas. Todas as vezes que a coleta era feita, os contadores eram zerados para que em uma coleta subsequente os dados coletados fossem condizentes somente com uma migração em particular. Um exemplo da saída gerada pelos scripts usados para esse fim é apresentado na Figura 25.

Figura 25: Saída do script para coleta de dados trafegados.

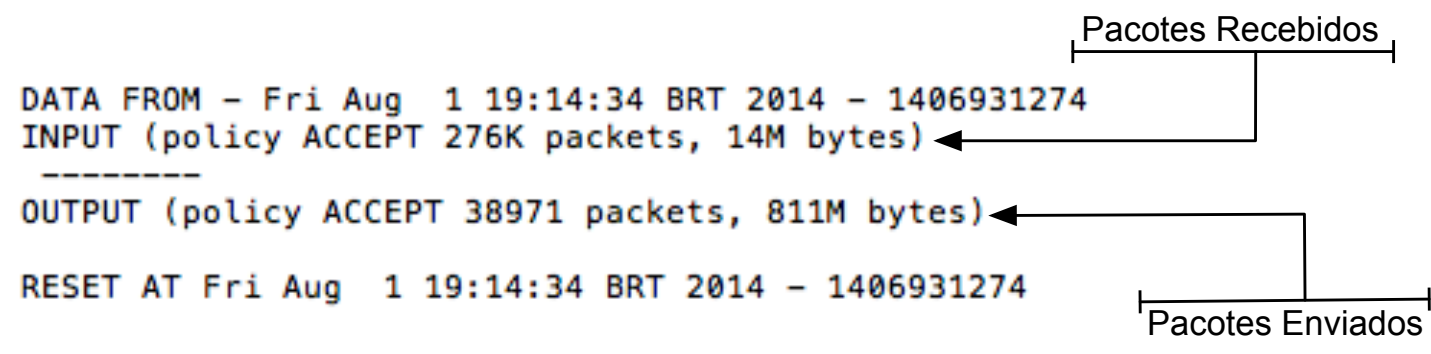

Fonte: Próprio Autor (2015). 


\subsection{Experimentos com Benchmarks}

Os experimentos conduzidos nesta seção são aplicações de benchmarks com comportamento conhecido a priori, como o SPEC, BT, IOZone e Sleep (maiores detalhes vide Tabela 16). As aplicações usadas como benchmarks foram executadas gerando ciclos artificiais, primeiramente em três máquinas virtuais e, em seguida, em quatro máquinas virtuais. Apesar das outras máquinas virtuais estarem ociosas, elas também foram migradas (conforme Figura 22) para gerar ruído na rede. O primeiro experimento visa observar a precisão com que a arquitetura proposta identificou os ciclos e migrou em momentos favoráveis. Para esse objetivo, foi elaborado um diagrama de migração, que é um gráfico que ilustra o comportamento da carga no decorrer do tempo, os instantes que foram submetidas solicitações de consolidação e quando a migração foi executada pela arquitetura.

A Figura 26 apresenta o diagrama de migração elaborado com o propósito de demonstrar a precisão da arquitetura para o experimento em que três máquinas virtuais ( $30 \%$ da nuvem privada) estavam com carga. A linha azul do diagrama é o comportamento da carga no decorrer do tempo, os vales são os períodos de tempo que não são favoráveis à migração (NLM) e os picos os períodos favoráveis (LM). É importante observar que a carga é executada simultaneamente nas três máquinas virtuais. As linhas tracejadas em vermelho indicam os instantes em que a consolidação foi submetida. Quando a carga chega no instante $t$, indicado pela linha tracejada em vermelho, as máquinas virtuais eram consolidadas e a carga de trabalho executada nos hosts físicos até o fim, sem interrupção. Para que fosse possível comparar com a arquitetura proposta, na primeira bateria de testes as máquinas virtuais foram efetivamente migradas nesses instantes (cinco vezes para cada instante, totalizando 50 experimentos). Em uma segunda bateria, a arquitetura foi habilitada e fez a 
interceptação das solicitações, feitas no mesmo instante que a primeira bateria de consolidação, também repetindo-se cinco vezes, totalizando 50 experimentos. Os instantes em que a migração foi submetida pela arquitetura, referentes aos testes da segunda bateria, estão representados por uma linha contínua em cor preta.

Figura 26: Diagrama de migração com três máquinas virtuais executando benchmarks.

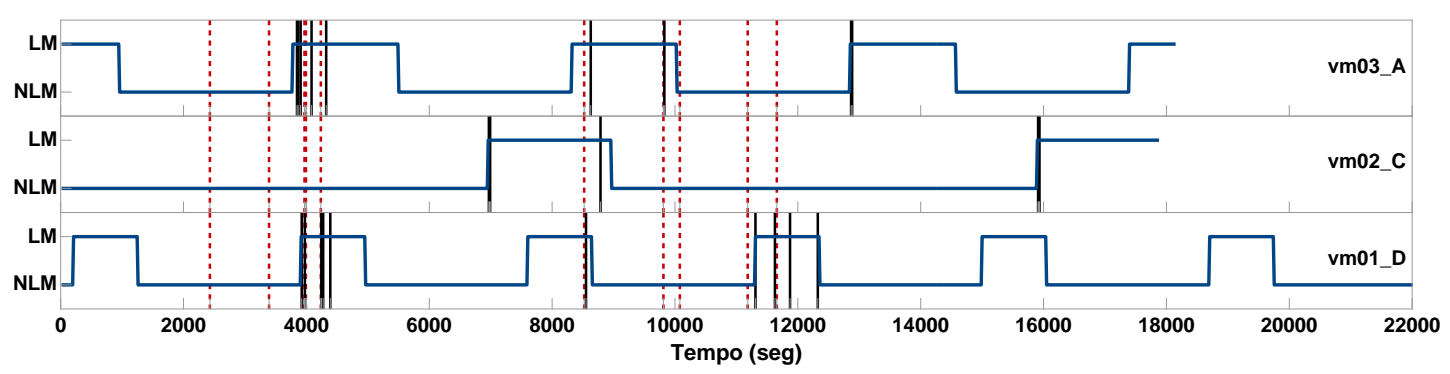

Fonte: Próprio Autor (2015).

O ideal para a arquitetura é que as migrações ocorram sempre nos momentos em que a carga da máquina virtual (linha azul) esteja em período de pico (LM). Neste experimento, pode-se observar que a arquitetura conseguiu atingir o principal objetivo de migrar a carga nos momentos mais favoráveis. Como resultado da precisão apresentada pela arquitetura, as métricas de sobrecarga na infraestrutura foram reduzidas, conforme Figura 27. Os resultados mais expressivos foram observados na redução do tempo de migração, chegando até 61\% na mv02_C. Apesar de terem ocorrido reduções no tempo absoluto de downtime, não há evidências de que houve redução no tempo. Os desvios padrões na comparação dos experimentos estão sobrepostos, como observado na Figura 27a. Adicionalmente, o p-value (WILCOXON, 1945) calculado com confiabilidade de 95\% para a vm03_A e VM01_D são de 0,56 e 1, respectivamente. A vm02_C, com p-value de 0,02 foi a única máquina virtual em que há evidências de que o downtime com a arquitetura ALMA teve piora. A redução da quantidade de dados trafegados na rede foi bastante consistente: em torno de $42 \%$, que representa 5 GigaBytes a menos trafegando na rede (Tabela 9). 
Figura 27: Métricas das três máquinas virtuais executando Benchmark.

(a) Downtime das Máquinas Virtuais.

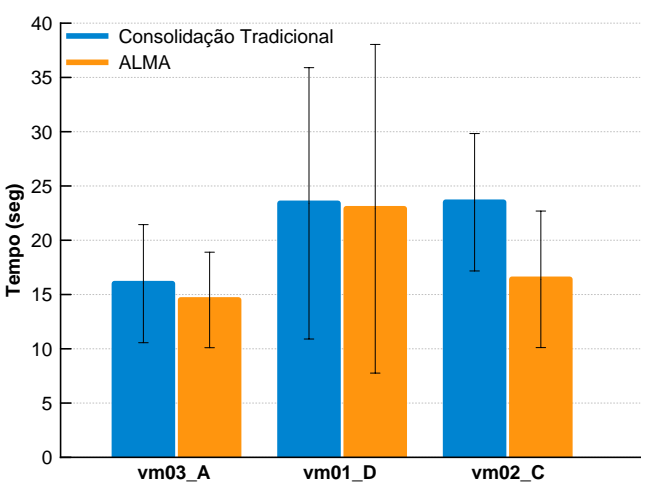

(b) Tempo total de migração.

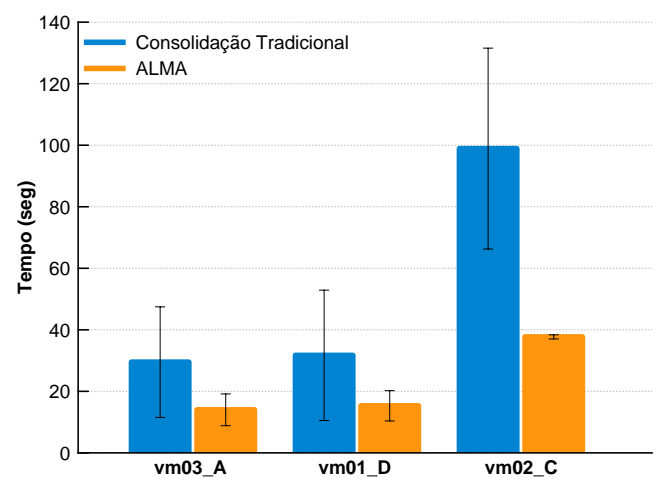

(c) DadosTrafegados.

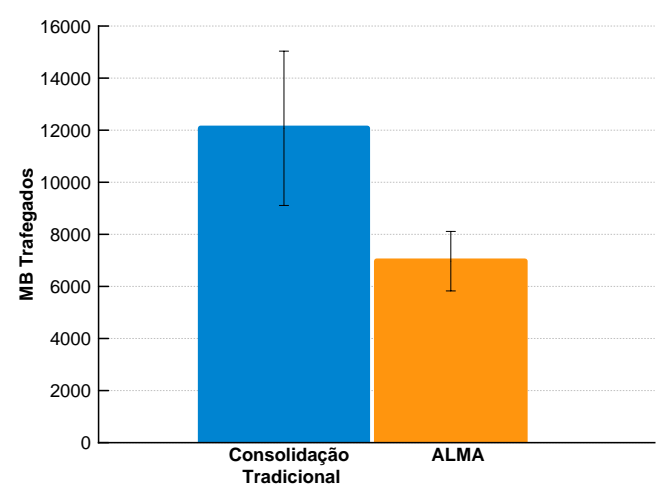

Fonte: Próprio Autor (2015).

O experimento seguinte consiste em usar quatro máquinas virtuais (40\% da nuvem) com carga de trabalho. O diagrama de migração da Figura 28 representa a carga de trabalho das máquinas virtuais com os respectivos instantes em que a consolidação foi executada e os instantes que a arquitetura proposta efetivamente executou a migração da máquina virtual. Novamente, a arquitetura obteve desempenho satisfatório, executando as migrações nos períodos de pico (LM). As migrações solicitadas nos períodos de vale foram adiadas para os períodos mais propícios para a migração. Para o tempo de downtime, não há evidências de que a arquitetura ALMA melhorou ou não esta métrica. O p-value com grau de confiança de 95\% calculado para a vm03_A, vm02_C, vm02_A e vm01_C foram, respectivamente, 0,95, 0,28, 0,43 e 0,73. Entretanto, a redução do tempo de migração chegou a 74\% (mv02_A) e a redução nos dados trafegados foi de $21 \%$ (Tabela 10). 
Tabela 9: Resultados comparativos no experimento com três máquinas virtuais executando Benchmark.

\begin{tabular}{|c|c|c|c|c|}
\hline Métrica & $\begin{array}{l}\text { Máquina } \\
\text { Virtual }\end{array}$ & $\begin{array}{l}\text { Consolidação } \\
\text { Tradicional }\end{array}$ & ALMA & $\begin{array}{c}\text { Redução } \\
\text { (\%) }\end{array}$ \\
\hline \multirow{3}{*}{$\begin{array}{c}\text { Downtime } \\
\text { (seg) }\end{array}$} & vm03_A & 16,00 & 14,50 & 9,38 \\
\hline & vm01_D & 23,40 & 22,90 & 2,14 \\
\hline & vm02_C & 23,50 & 16,40 & 30,21 \\
\hline \multirow{3}{*}{$\begin{array}{l}\text { Tempo de } \\
\text { Migração } \\
\text { (seg) }\end{array}$} & vm03_A & 29,50 & 14,00 & 52,54 \\
\hline & vm01_D & 31,70 & 15,30 & 51,74 \\
\hline & vm02_C & 98,90 & 37,70 & 61,88 \\
\hline \multicolumn{2}{|c|}{$\begin{array}{c}\text { Dados } \\
\text { Trafegados } \\
\text { (MB) }\end{array}$} & 12072,60 & 6969,90 & 42,27 \\
\hline
\end{tabular}

Figura 28: Diagrama de migração com quatro máquinas virtuais executando benchmarks.

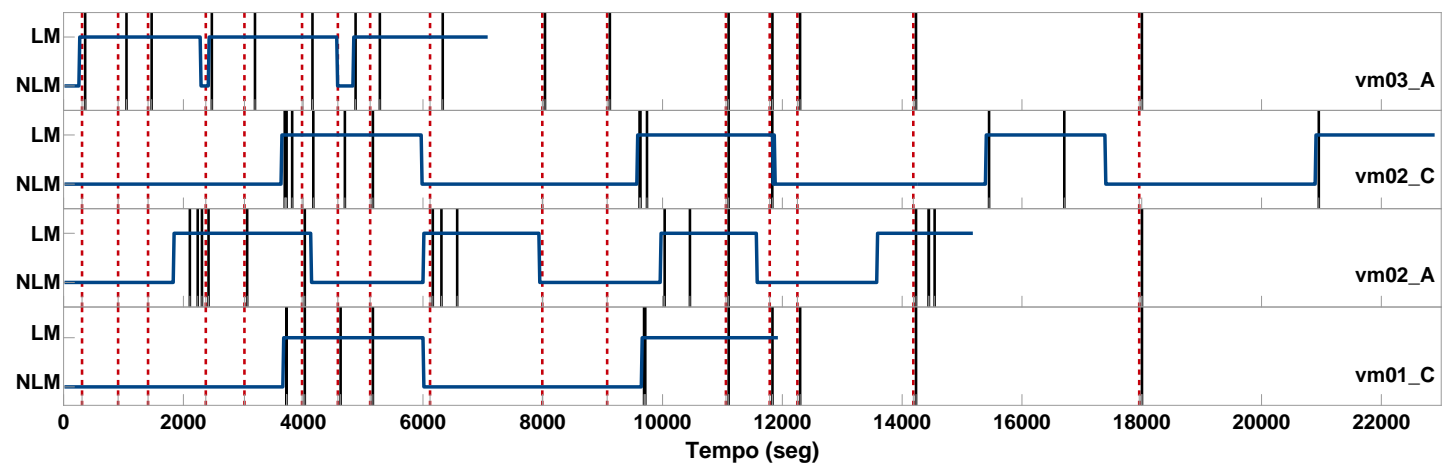

Fonte: Próprio Autor (2015).

Tabela 10: Resultados comparativos no experimento com quatro máquinas virtuais executando Benchmark.

\begin{tabular}{|c|c|c|c|c|}
\hline Métrica & $\begin{array}{l}\text { Máquina } \\
\text { Virtual }\end{array}$ & $\begin{array}{c}\text { Consolidação } \\
\text { Tradicional }\end{array}$ & ALMA & $\begin{array}{c}\text { Redução } \\
\text { (\%) }\end{array}$ \\
\hline \multirow{4}{*}{$\begin{array}{l}\text { Downtime } \\
\text { (seg) }\end{array}$} & vm03_A & 20,06 & 20,44 & $-1,87$ \\
\hline & vm02_C & 18,63 & 17,75 & 4,70 \\
\hline & vm02_A & 20,75 & 23,69 & $-14,16$ \\
\hline & vm01_C & 19,25 & 18,94 & 1,62 \\
\hline \multirow{4}{*}{$\begin{array}{l}\text { Tempo de } \\
\text { Migração } \\
\text { (seg) }\end{array}$} & vm03_A & 28,81 & 12,00 & 58,35 \\
\hline & vm02_C & 87,56 & 42,31 & 51,68 \\
\hline & vm02_A & 43,81 & 11,13 & 74,61 \\
\hline & vm01_C & 54,31 & 26,81 & 50,63 \\
\hline \multicolumn{2}{|c|}{$\begin{array}{l}\text { Dados } \\
\text { Trafegados } \\
\text { (MB) }\end{array}$} & 11557,50 & 9159,60 & 21,56 \\
\hline
\end{tabular}


Figura 29: Métricas das quatro máquinas virtuais executando Benchmark.

(a) Downtime das Máquinas Virtuais.

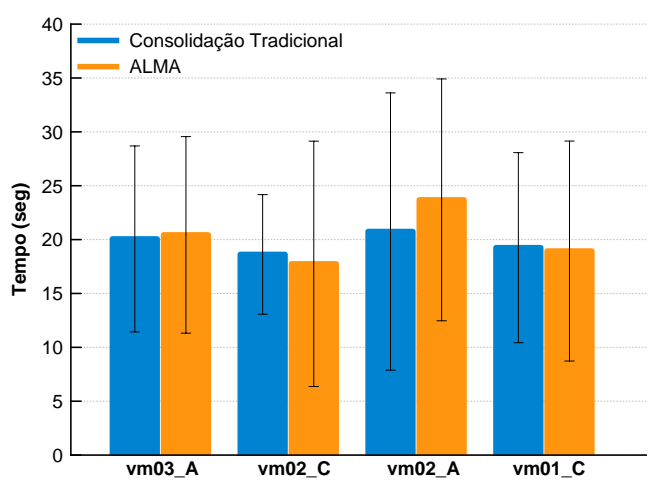

(b) Tempo total de migração

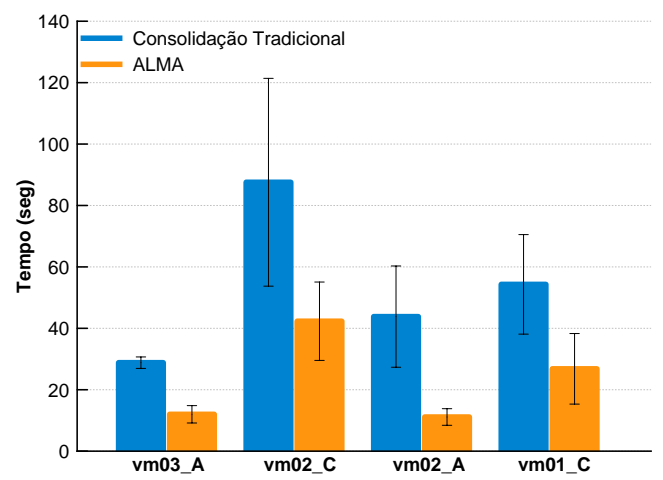

(c) DadosTrafegados.

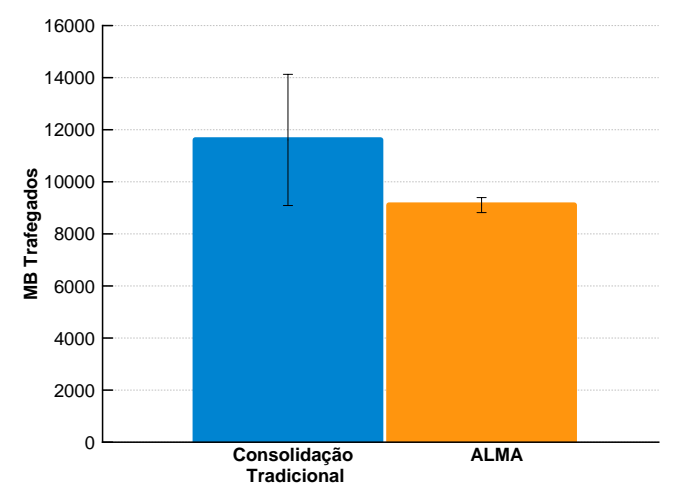

Fonte: Próprio Autor (2015).

Em ambos os experimentos, o tempo de downtime foi a métrica que não se pode afirmar que houve melhora ou piora, devido ao desvio padrão nas comparações apresentadas nos gráficos estarem sobrepostos e o $p$-value calculado. O downtime não é beneficiado na arquitetura porque a infraestrutura de rede criada pelo monitor de máquinas virtuais não é parte do algoritmo de Live Migration, diferentemente, ela é um processo independente da migração que ocorrerá quando a máquina virtual já estiver em execução no hospedeiro de destino. Uma vez que a máquina virtual tenha sido migrada, é necessário que o hospedeiro de destino atualize as tabelas de roteamento e, para isso, é enviado um pacote ICMP para atualizar as tabelas ARP (do inglês, Address Resolution Protocol) dos gateways da rede, indicando que o endereço IP da máquina virtual migrada está agora residente no hospedeiro de destino. Além disso, o downtime é bastante sensível ao algoritmo de controle de congestio- 
namento do protocolo TCP. Os resultados obtidos nesses experimento corroboram o que foi observado por Kikuchi e Matsumoto (2012): quando um pacote não chega ao destino, o remetente fará uma nova tentativa de transmissão do pacote quando o tempo de retransmissão (ou RTO da sigla em inglês - $R e$ transmission Time Out) esgotar. O tempo de retransmissão é calculado em função do tempo de round-trip dos pacotes transmitidos entre as máquinas e começa com um tempo inicial de três segundos. A cada vez que ocorre uma retransmissão o RTO é dobrado, aumentando o tempo de Downtime.

\subsection{Experimentos com Aplicações}

Nesta seção serão apresentados os resultados obtidos ao utilizar aplicações como carga de trabalho para as máquinas virtuais. As aplicações utilizadas, descritas na Tabela 11, foram escolhidas com o objetivo de simular cargas científicas (BRAMS e OpenModeller) e também aplicações comerciais (TPC-H) e aplicações de uso rotineiro em nuvens (MapReduce).

Tabela 11: Aplicações utilizadas para gerar a carga de trabalho nas máquinas virtuais.

\begin{tabular}{|c|l|c|}
\hline Aplicação & \multicolumn{1}{c|}{$\begin{array}{c}\text { Descrição } \\
\text { Virtuais }\end{array}$} \\
\hline \hline $\begin{array}{c}\text { TeraSort } \\
\text { (MapReduce) } \\
\text { (DEAN; GHEMAWAT, 2008) }\end{array}$ & $\begin{array}{l}\text { Algoritmo padrão de ordenação que utiliza uma lista ordenada de N-1 } \\
\text { exemplares de chaves que definem um intervalo para cada Reduce. }\end{array}$ & $\begin{array}{l}\text { vm01_B } \\
\text { vm02_A } \\
\text { vm01_C }\end{array}$ \\
\hline $\begin{array}{c}\text { BRAMS } \\
\text { (FREITAS et al., 2009) }\end{array}$ & Modelo do sistema atmosférico brasileiro, usado na previsão de tempo. & vm02_C \\
\hline $\begin{array}{c}\text { TPC-H }{ }^{2} \\
\text { (KANDASWAMY; KNIGHTEN, 2000) }\end{array}$ & $\begin{array}{l}\text { Simula um sistema de suporte à decisão (BI). É composto de 22 } \\
\text { queries que acessam um grande volume de dados. }\end{array}$ & vm01_D \\
\hline $\begin{array}{c}\text { OpenModeller } \\
\text { (MUñOZ et al., 2011) }\end{array}$ & $\begin{array}{l}\text { É uma aplicação científica utilizada na Biologia. Faz a modelagem de } \\
\text { distribuição de espécies baseado em pré-requisitos ecológicos. }\end{array}$ & vm03_A \\
\hline
\end{tabular}

Na Figura 30 é apresentada a carga de trabalho das aplicações. Uma característica das aplicações foi a ausência de grandes períodos favoráveis a migração. Entretanto, mesmo em situações como essa a arquitetura proposta pode identificar e postergar a submissão de migração para os períodos favo-

\footnotetext{
${ }^{2}$ Esta aplicação foi usada somente no experimento com três máquinas virtuais.
} 
ráveis com sucesso. Nas métricas, apresentadas na Figura 31, foi possível obter reduções no tempo de migração de até $63 \%$ na máquina vm01_D e redução de $20 \%$ na quantidade de dados trafegados. O tempo de downtime teve o mesmo comportamento dos experimentos com benchmarks, sem alterações estatísticas relevantes para ser possível afirmar a ocorrência de melhora ou piora nesta métrica. Os $p$-values calculados para o downtime com confiabialidade de $95 \%$ foram de 0,95, 0,28,0,43 e 0,73 para as máquinas virtuais vm03_A, vm02_C, vm02_A e vm01_C, respectivamente.

Figura 30: Diagrama de migração com três máquinas virtuais executando aplicações.

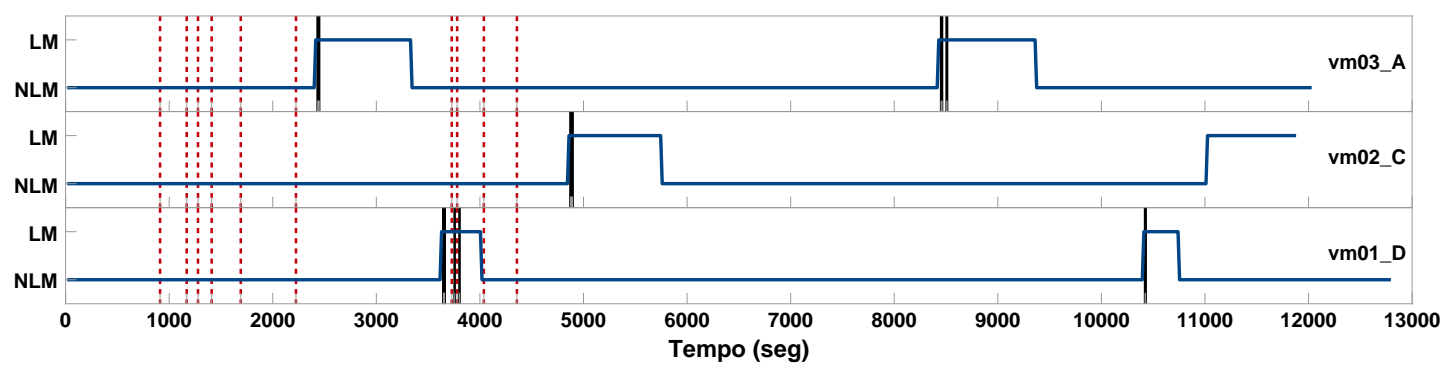

Fonte: Próprio Autor (2015).

Tabela 12: Resultados comparativos no experimento com três máquinas virtuais executando Aplicações.

\begin{tabular}{|c|l|c|c|c|}
\hline \multirow{2}{*}{ Métrica } & $\begin{array}{c}\text { Máquina } \\
\text { Virtual }\end{array}$ & $\begin{array}{c}\text { Consolidação } \\
\text { Tradicional }\end{array}$ & ALMA & $\begin{array}{c}\text { Redução } \\
\mathbf{( \% )}\end{array}$ \\
\hline \hline \multirow{2}{*}{$\begin{array}{c}\text { Downtime } \\
\text { (seg) }\end{array}$} & vm03_A & 19,10 & 16,80 & 12,04 \\
\cline { 2 - 5 } & vm01_D & 19,00 & 20,30 & $-6,84$ \\
\cline { 2 - 5 } & vm02_C & 20,10 & 22,50 & $-11,94$ \\
\hline $\begin{array}{c}\text { Tempo de } \\
\text { Migração } \\
\text { (seg) }\end{array}$ & vm03_A & 28,70 & 10,60 & 63,07 \\
\cline { 2 - 5 } & vm01_D & 27,30 & 9,90 & 63,74 \\
\hline \multicolumn{2}{|c|}{$\begin{array}{c}\text { Dados_C } \\
\text { Trafegados } \\
\text { (MB) }\end{array}$} & 43,20 & 36,30 & 15,97 \\
\hline \multicolumn{2}{|c}{} & 11557,50 & 9159,60 & 20,75 \\
\hline
\end{tabular}

O experimento seguinte consiste na execução dos teste com cinco máquinas virtuais. O cluster Hadoop é composto por três máquinas virtuais (vm01_B, vm02_A e vm01_C). Entretanto, a máquina vm01_B não é migrada para nenhum hospedeiro, pois já está em um dos hospedeiros usados para consolida- 
Figura 31: Métricas das três máquinas virtuais executando aplicações.

(a) Downtime das Máquinas Virtuais.

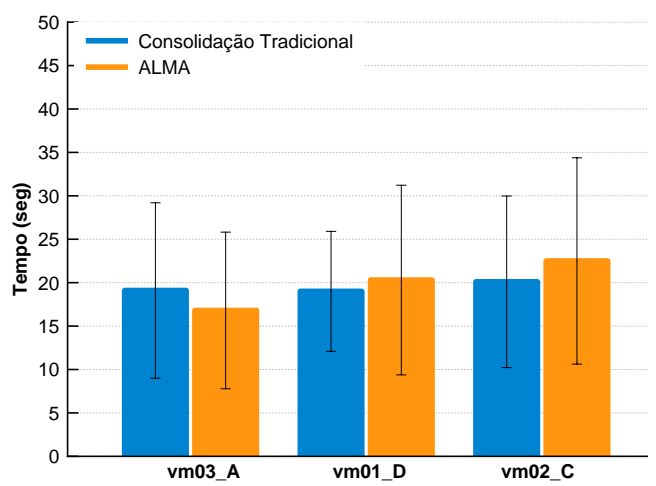

(b) Tempo total de migração.

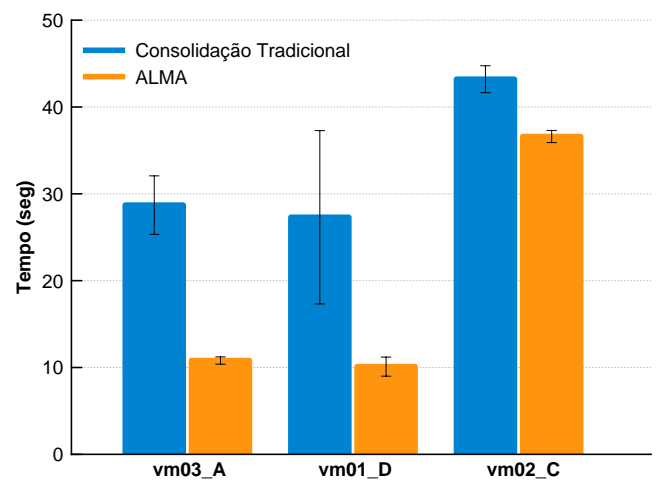

(c) DadosTrafegados.

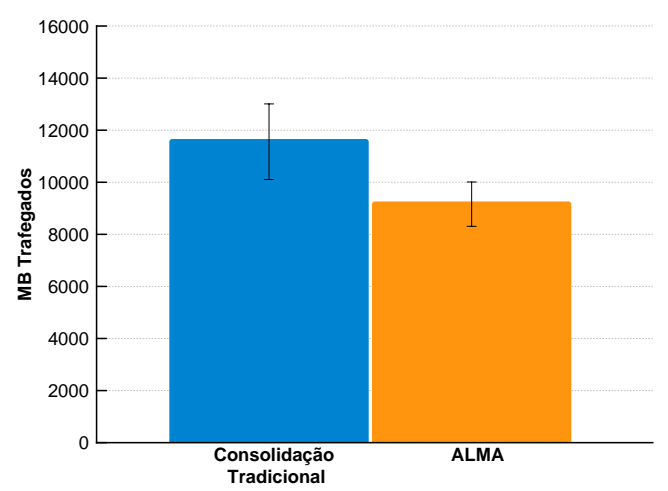

Fonte: Próprio Autor (2015).

ção (Host_B, conforme Figura 22). Assim, as métricas dessa máquina virtual e os instantes de migração foram suprimidos dos resultados deste trabalho.

No diagrama de migração apresentado na Figura 32, observa-se um comportamento bastante peculiar das aplicações. Algumas cargas possuem longos períodos favoráveis para a migração, como a vm01_C, longos períodos não favoráveis, como a vm03_A, e cargas com ciclos um pouco mais complexos, como apresentado pela máquina virtual vm01_D. Mesmo com cargas possuindo ciclos diferenciados, a arquitetura obteve resultados adequados, fazendo a migração nos períodos mais propícios.

A redução no tempo de migração das máquinas virtuais e na quantidade de dados trafegados para este experimento foi bastante expressiva quando comparado aos experimentos anteriores. Isso se deve principalmente por conta do 
Figura 32: Diagrama de migração com quatro máquinas virtuais executando aplicações.

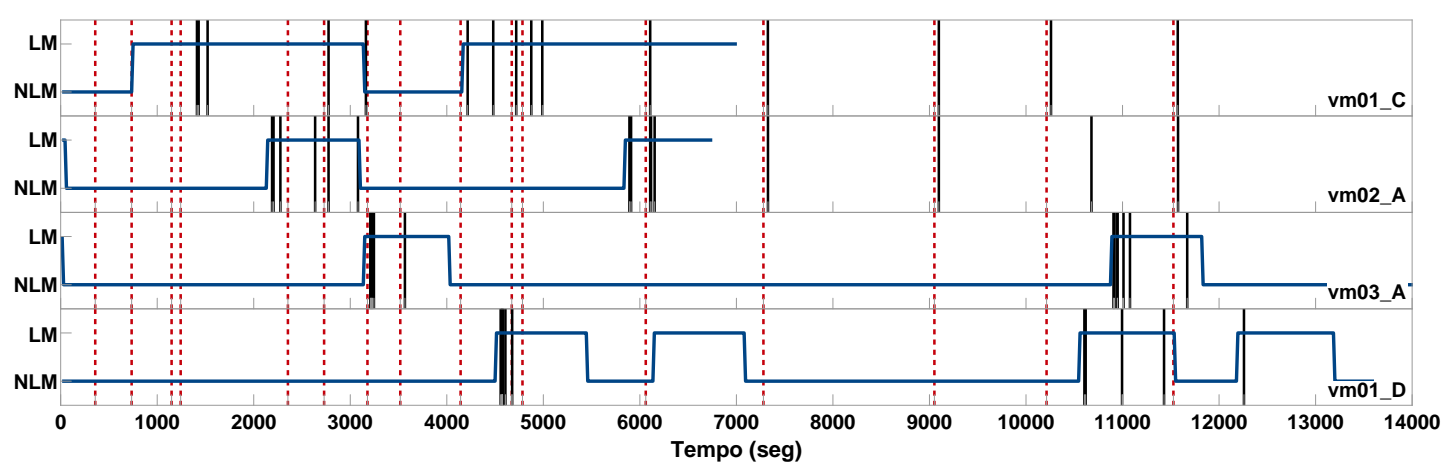

Fonte: Próprio Autor (2015).

cluster Hadoop que movimenta uma grande quantidade de dados localmente e pela rede, devido à comunicação inerente dos nós que o compõe. Essa aplicação, particularmente, se beneficiou bastante da arquitetura, como pode ser observado no gráfico da Figura 33b, em que as máquinas virtuais que obtiveram maior redução no tempo de migração foram a vm01_C e a vm02_A.

Figura 33: Métricas das quatro máquinas virtuais executando aplicações.

(a) Downtime das Máquinas Virtuais.

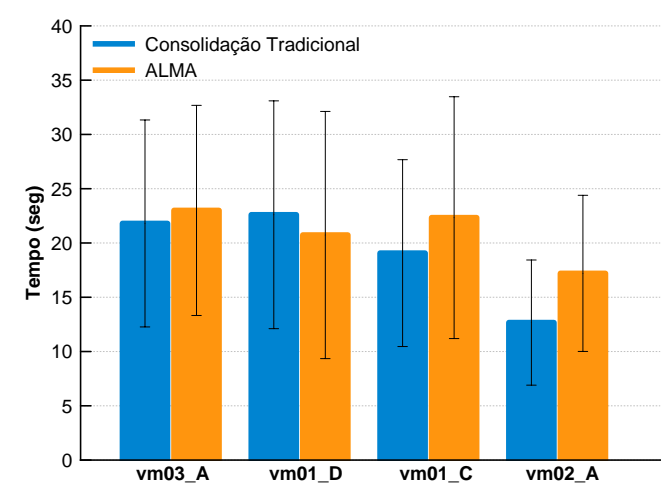

(b) Tempo total de migração.

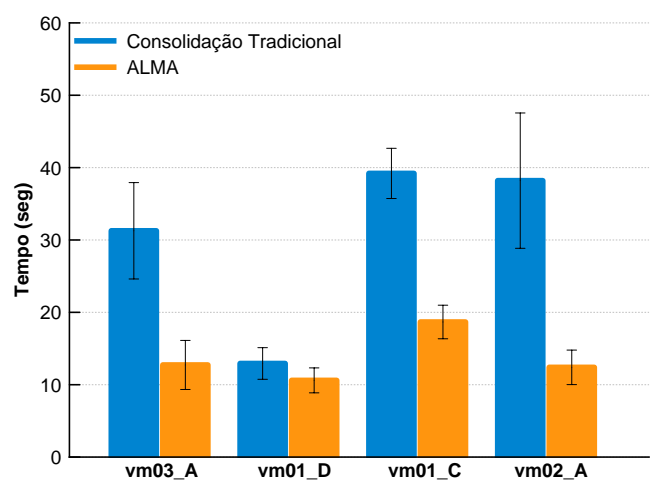

(c) DadosTrafegados.

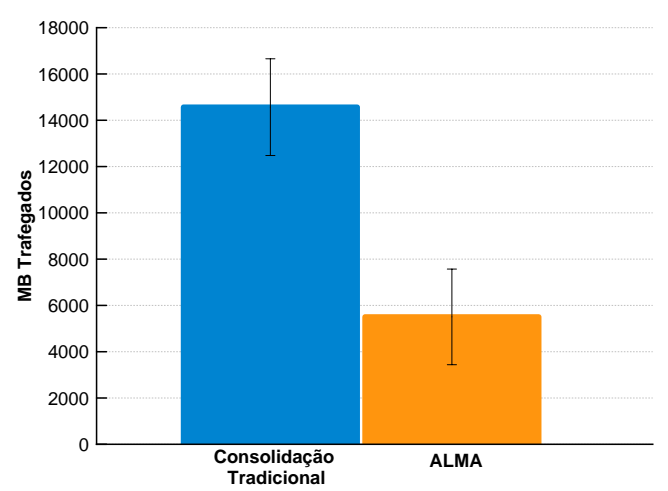

Fonte: Próprio Autor (2015). 
Os experimentos com aplicações foram particularmente satisfatórios, pois além de representarem um desafio para a análise cíclica em si, também são desafiadores para as estratégias de classificação, pois o comportamento das aplicações não é conhecido a priori e é sensível aos parâmetros recebidos como entrada, como arquivos ou queries. Entretanto, mesmo com a adversidade imposta pelas aplicações, a arquitetura classificou as cargas de trabalho corretamente e os momentos escolhidos para executar as migrações foram precisos. Os resultados foram reduções significativas no tempo de migração e na quantidade de dados trafegados na rede. No tempo de downtime o comportamento repetiu-se, não havendo evidências de que há melhora ou piora nesta métrica ao utilizar a arquitetura ALMA. Os valores de p-value com grau de confiança de 95\% calculados para a vm03_A, vm01_D, vm01_C e vm02_A, respectivamente, são 0,77, 0,54, 0,53 e 0,06.

Tabela 13: Resultados comparativos no experimento com quatro máquinas virtuais executando Aplicações.

\begin{tabular}{|c|c|c|c|c|}
\hline Métrica & $\begin{array}{l}\text { Máquina } \\
\text { Virtual }\end{array}$ & $\begin{array}{c}\text { Consolidação } \\
\text { Tradicional }\end{array}$ & ALMA & $\begin{array}{c}\text { Redução } \\
(\%)\end{array}$ \\
\hline \multirow{4}{*}{$\begin{array}{c}\text { Downtime } \\
\text { (seg) }\end{array}$} & vm03_A & 21,80 & 23,00 & $-5,50$ \\
\hline & vm01_D & 22,60 & 20,73 & 8,26 \\
\hline & vm01_C & 19,07 & 22,33 & $-17,13$ \\
\hline & vm02_A & 12,67 & 17,20 & $-35,79$ \\
\hline \multirow{4}{*}{$\begin{array}{l}\text { Tempo de } \\
\text { Migração } \\
\text { (seg) }\end{array}$} & vm03_A & 31,27 & 12,73 & 59,28 \\
\hline & vm01_D & 12,93 & 10,60 & 18,04 \\
\hline & vm01_C & 39,20 & 18,67 & 52,38 \\
\hline & vm02_A & 38,20 & 12,40 & 67,54 \\
\hline \multicolumn{2}{|c|}{$\begin{array}{l}\text { Dados } \\
\text { Trafegados } \\
\text { (MB) }\end{array}$} & 14566,47 & 5504,98 & 62,21 \\
\hline
\end{tabular}

Quando as aplicações foram executadas sob a arquitetura ALMA, observou-se uma redução na quantidade de páginas alteradas (Dirty Pages) por iteração de cópia ${ }^{3}$, conforme apresentado na Figura 34 e na Tabela 14. Ao submeter a migração em períodos em que não ocorrem muitas alterações em

\footnotetext{
${ }^{3}$ Vide estágio 2, Pré-Cópia Iterativa do algoritmo Pré-Cópia apresentado na seção 3.1
} 
páginas de memória, a quantidade de iterações que devem ser executadas para copiar a máquina virtual e a quantidade de páginas copiadas em cada uma das iterações são reduzidas. A taxa de Dirty Pages por iteração sofreu uma redução média de $34 \%$ com o uso da arquitetura ALMA, em alguns casos chegando a até $70 \%$ como verificado na Figura 34b. O caso da máquina virtual vm03_A é bem expressivo, pois os períodos não favoráveis para a migração são predominantes em sua carga de trabalho.

Com a arquitetura ALMA, foi possível reduzir, em média, $51 \%$ a quantidade de iterações de cópia que são necessárias para realizar a Live Migration das máquinas virtuais. Quando uma máquina virtual é migrada em um momento em que muitas páginas estão sendo atualizadas, foram necessárias diversas iterações de cópia e, em alguns casos, chegou-se a 30 iterações. Além disso, a baixa quantidade de iterações de cópia é o principal motivo da redução do tempo de migração observado nos experimentos.

Tabela 14: Taxa de Dirty Pages por Iteração.

\begin{tabular}{|c|c|c|c|}
\hline $\begin{array}{c}\text { Máquina } \\
\text { Virtual }\end{array}$ & $\begin{array}{c}\text { Dirty Pages/lteração } \\
\text { Consolidação Tradicional }\end{array}$ & $\begin{array}{c}\text { Dirty Pages/Iteração } \\
\text { Consolidação ALMA }\end{array}$ & $\begin{array}{c}\text { Redução } \\
\text { (\%) }\end{array}$ \\
\hline \hline vm02_A & 1600,48 & 1287,52 & 19,55 \\
\hline vm03_A & 4210,72 & 1229,27 & 70,81 \\
\hline vm01_D & 1785,51 & 1341,08 & 24,89 \\
\hline vm01_C & 1434,93 & 1125,30 & 21,58 \\
\hline
\end{tabular}

\subsection{Análise de Escalabilidade}

O fator de escalabilidade é de grande importância quando se trata de ambientes de computação na nuvem. Uma das principais características de ambientes de computação na nuvem é a elasticidade dos recursos que são provisionados de acordo com a demanda do usuário (ARMBRUST et al., 2009). Um usuário pode adicionar ou remover máquinas virtuais com grande facilidade 
Figura 34: Taxa de Dirty Pages por Iteração.

(a) Taxa na vm02_A.

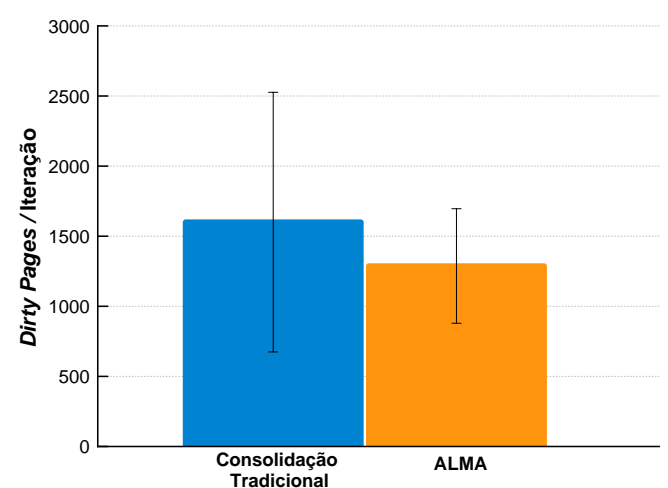

(c) Taxa na vm01_D.

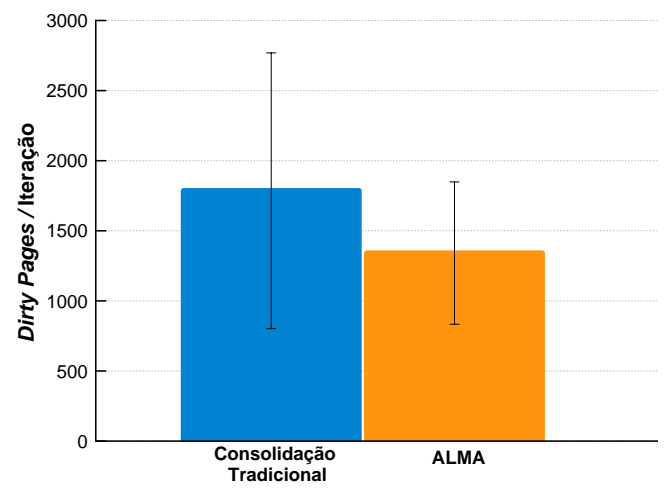

(b) Taxa na vm03_A.

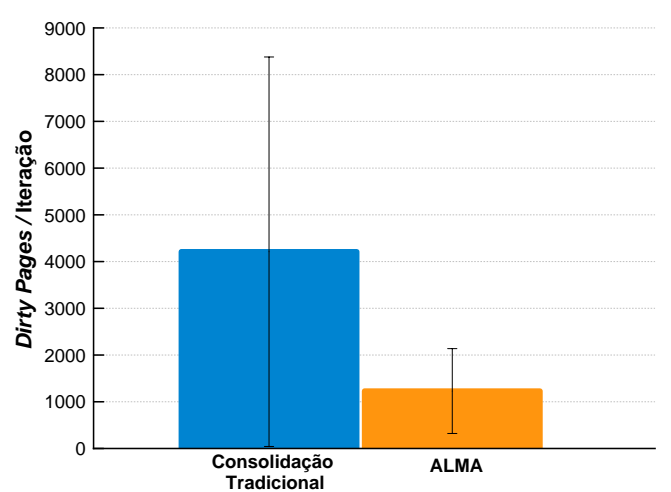

(d) Taxa na vm01_C.

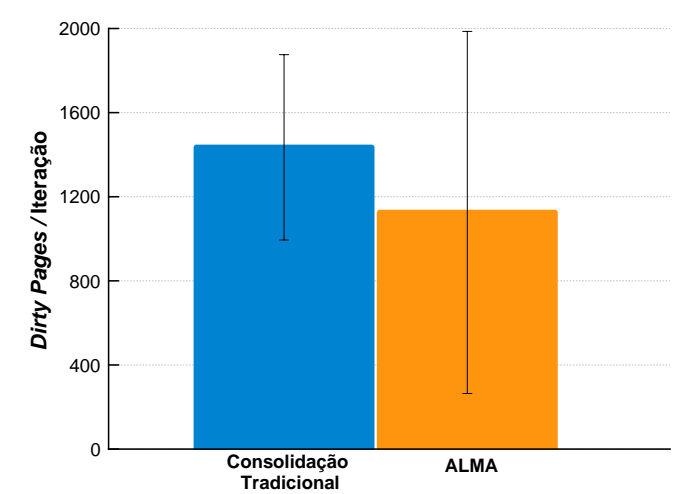

Fonte: Próprio Autor (2015).

de acordo com a demanda e isso torna o ambiente especialmente sensível a soluções com baixa capacidade de escalabilidade.

Nesta seção, será apresentada uma análise de escalabilidade na arquitetura ALMA. Apesar dos experimentos das seções 7.2 e 7.3 terem sido conduzidos em um ambiente real, os experimentos dessa seção foram executados a partir de simulação da arquitetura. Para isso, foram gerados traces das cargas de trabalho das aplicações usadas na seção 7.3 e submetidas ao crivo do Módulo de Controle de Live Migration (MCLM) da arquitetura ALMA. O objetivo é mensurar a sobrecarga de processamento causado pelo (MCLM), responsável por classificar e decidir o melhor momento para realizar a migração.

O baseline é o tempo de compilação do Kernel do Linux sem nenhum processo em execução. Em seguida, foram submetidos os traces e o tempo adici- 
onal de compilação foi contabilizado como a sobrecarga causada pelo MCLM. Conforme a Figura 35, para cada máquina virtual um processo é criado dentro do MCLM, responsável por classificar, calcular o tamanho do ciclo e fazer a análise cíclica para definir os momentos propícios de migração para aquela máquina virtual. A simulação iniciou com cinco máquinas virtuais, aumentando gradativamente até mil máquinas virtuais (Tabela 15).

Figura 35: Estrutura dos processos dentro do MCLM.

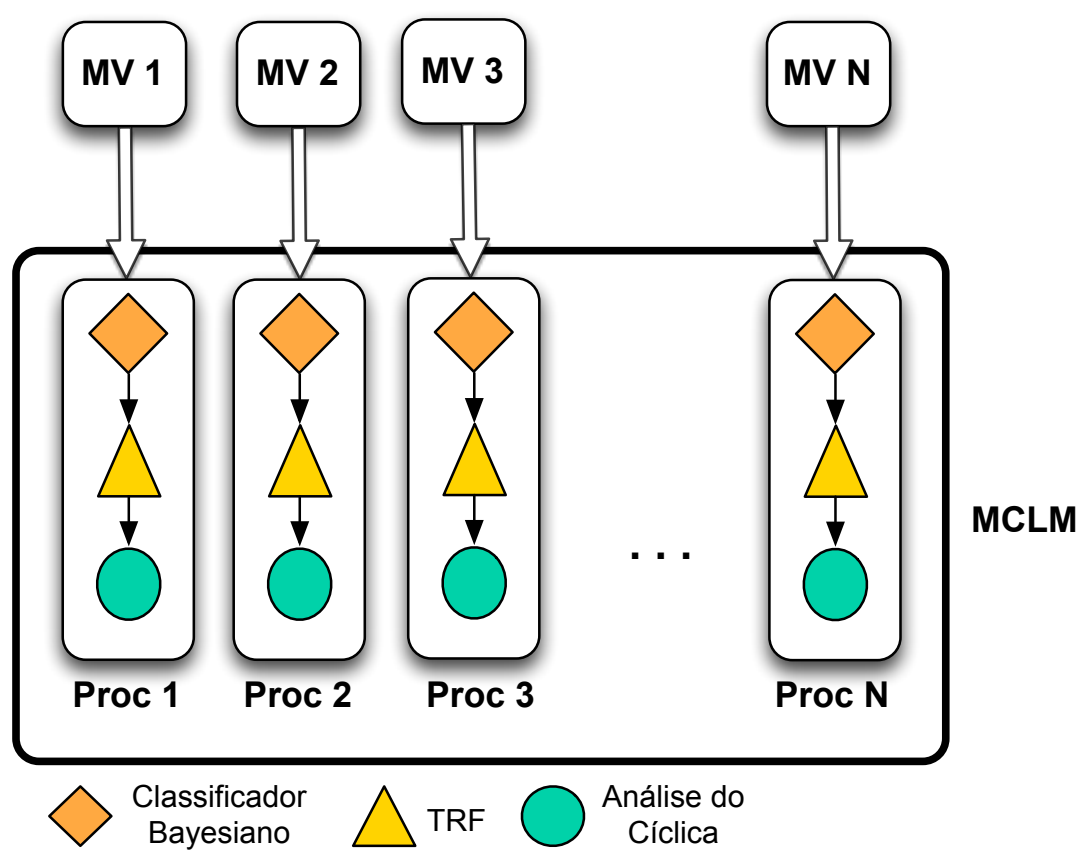

Fonte: Próprio Autor (2015).

O gráfico da Figura 36 apresenta o resultado obtido com a simulação. Para cada quantidade de máquina virtual, o experimento foi repetido dez vezes. A partir dos resultados obtidos, verificou-se a tendência da sobrecarga (linha em vermelho) e, apesar da ligeira curvatura apresentada da linha, a sobrecarga do MCLM tem um comportamento bem próximo do linear, aumentando de forma proporcional a medida que novas máquinas virtuais são adicionadas. Em média, para cada cinco máquinas virtuais, há uma sobrecarga de 0,21\%. Na configuração utilizada e, de acordo com os resultados obtidos, a saturação do MCLM seria atingida com algo em torno de 1800 máquinas virtuais. 
Figura 36: Sobrecarga do MCLM com até mil máquinas virtuais.

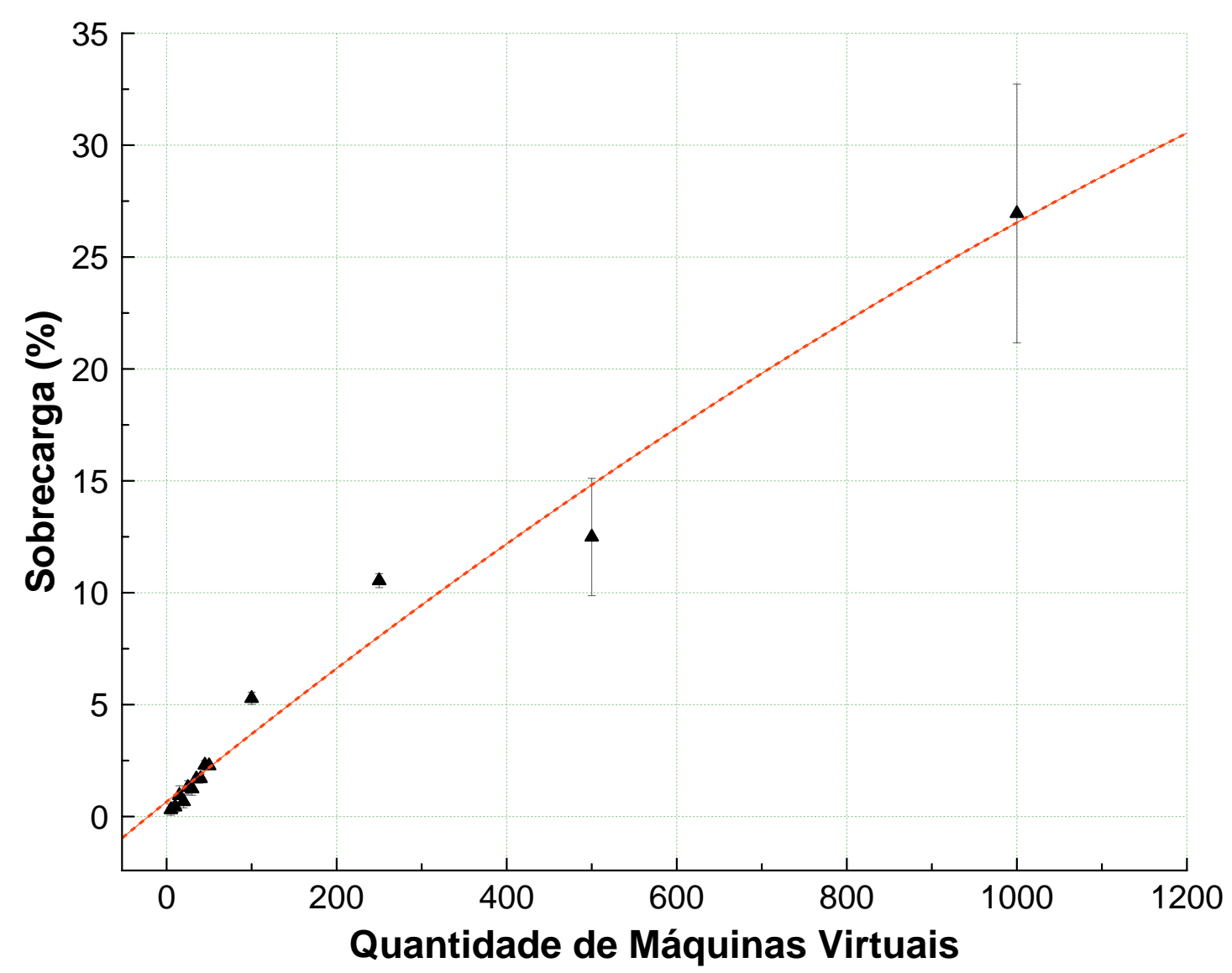

Fonte: Próprio Autor (2015).

É importante ressaltar que o MCLM pode ser distribuído em diversas máquinas pelo ambiente, segmentado por usuário ou por um conjunto de máquinas físicas. Mesmo com os resultados satisfatórios da escalabilidade, a segmentação das máquinas gerenciadas pelo MCLM aumentaria ainda a mais a capacidade de escalar da arquitetura proposta.

Tabela 15: Resultados obtidos no experimento de escalabilidate.

\begin{tabular}{|c|c|c|c|}
\hline \# Máquinas Virtuais & $\begin{array}{c}\text { Sobrecarga } \\
\mathbf{( \% )}\end{array}$ & \# Máquinas Virtuais & $\begin{array}{c}\text { Sobrecarga } \\
\mathbf{( \% )}\end{array}$ \\
\hline \hline 5 & 0,31 & 40 & 1,70 \\
\hline 10 & 0,43 & 45 & 2,30 \\
\hline 15 & 0,94 & 50 & 2,27 \\
\hline 20 & 0,67 & 100 & 5,28 \\
\hline 25 & 1,30 & 250 & 10,54 \\
\hline 30 & 1,24 & 500 & 12,49 \\
\hline 35 & 1,68 & 1000 & 26,95 \\
\hline
\end{tabular}




\subsubsection{Sobrecarga nas Máquinas Virtuais}

Um aspecto importante a ser tratado é a sobrecarga da coleta dos índices de carga nas máquinas virtuais. Na implementação realizada neste trabalho, os índices foram coletados via SNMPv2, recomenda-se que para obter maior segurança seja utilizado a versão 3 do SNMP. Cada requisição de SNMP gerava a execução de um script em Shell que retorna os índices de carga apresentados na seção 4.1.1 (Tabelas 1 e 2).

Figura 37: Sobrecarga nas Máquinas Virtuais.

(a) Um processador.

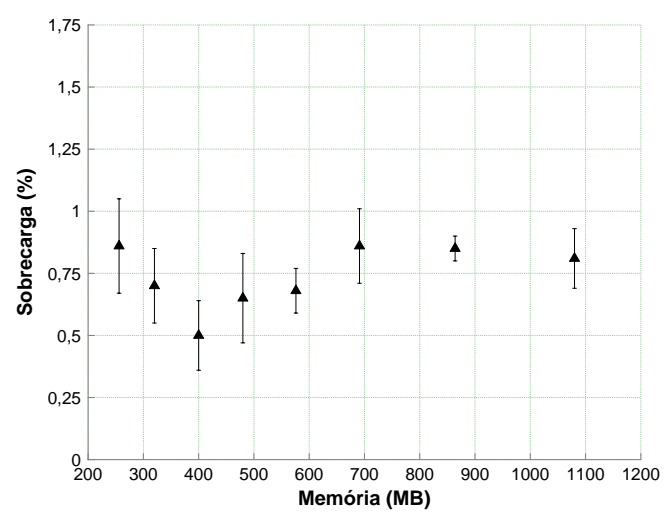

(b) Dois processadores.

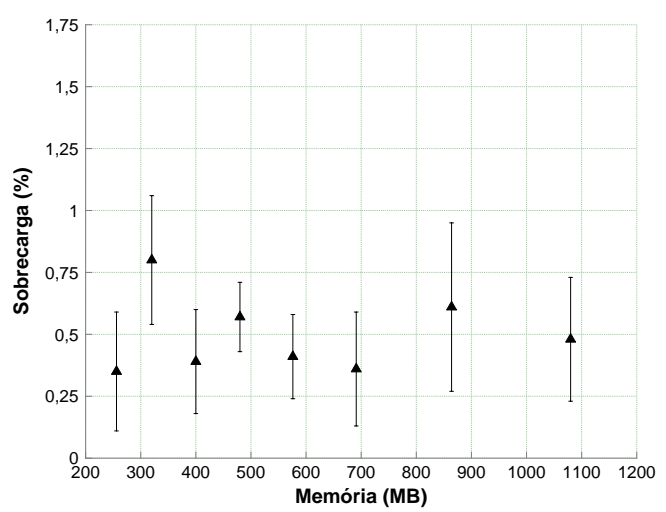

Fonte: Próprio Autor (2015).

O processo de avaliação da sobrecarga conduzido nas máquinas virtuais também foi baseado na compilação do Kernel do Linux. As variações foram feitas na configuração das máquinas virtuais (processador e memória). O objetivo é mensurar a sobrecarga causada pela coleta das métricas de acordo com a quantidade de recursos disponível na máquina virtual.

Foram configuradas máquinas virtuais com um processador e com dois processadores. A memória inicial de 256 MegaBytes foi aumentada gradativamente até 1080 MegaBytes. Os resultados apresentados na Figura 37 indicam uma sobrecarga desprezível, em torno de $0,75 \%$ e $0,5 \%$ para maquinas virtuais com um e dois processadores, respectivamente. 


\section{MIGRAÇÃO INDIVIDUAL DE MÁQUINAS VIRTUAIS}

A arquitetura ALMA apresenta uma solução para orquestração de migração de máquinas virtuais em ambientes de computação na nuvem. Nesse tipo de ambiente, diversas máquinas podem estar sendo migradas em um dado momento, em decorrência de estratégias de consolidação ou balanceamento de carga. Entretanto, neste capítulo, o enfoque é na migração de uma única máquina virtual. É discutida uma métrica que avalia o impacto da migração em uma aplicação dada a ocorrência de uma migração durante a execução que pode ser usada para adiar a migração de máquinas virtuais, cuja carga de trabalho não apresenta um comportamento cíclico, ou para evitar penalidades contratuais por ferir acordos de níveis de serviço.

Além disso, neste capítulo é apresentado um algoritmo cujo desempenho não é dependente da utilização de memória. A idéia principal deste algoritmo é migrar o ambiente de execução da máquina virtual, que seria um meio termo entre a migração da uma máquina inteira e a migração de um único processo. Esta estratégia permite que a migração tenha um comportamento determinístico e, dessa forma, o algoritmo pode ser usado para migrações de máquinas virtuais cujas cargas de trabalho não possuam um padrão cíclico. 


\subsection{Custo da Live Migration}

Como apresentado no capítulo 5, a migração de uma máquina virtual é um processo que causará uma sobrecarga na aplicação. Durante o processo de migração, a aplicação será parada por um intervalo de tempo que irá variar de acordo com diversos fatores, tais como vazão de rede, poder computacional das máquinas físicas envolvidas, taxa de atualização da memória, entre outros. Esta métrica tem como objetivo identificar o custo das migrações subsequentes de uma máquina virtual. De acordo com ela, pode-se inferir se a migração em um dado instante trará ou não benefícios para a aplicação em execução na máquina virtual.

\subsubsection{Formalização}

Como descrito anteriormente, o custo da Live Migration é a soma de fatores como a sobrecarga da migração propriamente dita, isto é, a movimentação da máquina virtual entre as máquinas físicas e o desempenho da aplicação nas máquinas envolvidas. Portanto, pode-se definir o custo de migrar uma máquina virtual entre o host $\mathrm{A}$ e o host $\mathrm{B}\left(C_{A \rightarrow B}\right)$ como:

$$
C_{A \rightarrow B}=C_{m i g}+D_{a p l_{B}}
$$

Onde:

$C_{\text {mig }}$ : Sobrecarga intrínseca da movimentação da máquina virtual;

$D_{a p l_{B}}$ : Desempenho da aplicação no hospedeiro destino.

É importante salientar que para realizar o cálculo do custo da migração sobre a aplicação é necessário que, ao menos uma vez, ela tenha sido executada em ambos os hospedeiros (de origem e destino) e que tenha ocorrido, também, ao menos uma vez, uma migração entre esses mesmos hospedeiros. Apesar 
de um ambiente de computação na nuvem ser constituído de centenas de máquinas físicas, é comum que as máquinas virtuais sejam migradas sempre para os mesmos hospedeiros (BIRKE et al., 2013). Isso se deve principalmente a restrições comerciais impostos pelos usuários, como não compartilhar os mesmos recursos com concorrentes em potencial, ou restrições técnicas como a impossibilidade de migrar uma máquina virtual para outro data center. Além disso, o objetivo deste trabalho é modelar o custo de tal forma que seja possível estimar o custo para a aplicação de migrar a máquina virtual em futuras solicitações de Live Migration. Com essas informações é possível estimar $C_{m i g}$ da seguinte forma:

$$
C_{m i g}=\left[\left(T_{m_{A \rightarrow B}}-t_{A}\right)+t_{T B}\right]-T_{B}
$$

Onde:

$T_{m_{A \rightarrow B}}$ : tempo médio de execução da aplicação na ocorrência de uma migração entre o hospedeiro A e o hospedeiro B;

$t_{A}$ : tempo que a aplicação ficou em execução no hospedeiro A;

$t_{T B}$ : tempo que a aplicação ficou em execução no hospedeiro A, mas transformado para o tempo de execução do hospedeiro B;

$T_{B}$ : tempo médio da execução da aplicação no hospedeiro $\mathrm{B}$, sem a ocorrência de migração.

O termo $t_{T B}$ da equação 8.2 é uma normalização entre as máquinas físicas envolvidas no processo de Live Migration. Uma vez que o tempo de processamento de um mesmo trecho de código é diferente nos dois hospedeiros, a idéia desse termo é aferir qual seria a situação da aplicação no hospedeiro de destino, caso a aplicação estivesse sendo executada naquela máquina física.

A segunda parte da equação 8.1 , o termo $D_{a p l_{B}}$, refere-se ao tempo que ainda resta de processamento da aplicação, mas na máquina de destino. $O$ cálculo deste termo também considera a normalização mencionada anterior- 
mente e é calculada conforme a seguir:

$$
D_{a p l_{B}}=T_{B}-t_{T B}
$$

Onde:

$T_{B}$ : tempo médio da execução da aplicação no hospedeiro $\mathrm{B}$, sem a ocorrência de migração;

$t_{T B}$ : tempo que a aplicação ficou em execução no hospedeiro A, mas transformado para o tempo de execução do hospedeiro B.

Dessa forma, substituindo os termos da equação 8.1 pelas equações 8.2 e 8.3, já fazendo as simplificações necessárias, temos que:

$$
C_{A \rightarrow B}=T_{m_{A \rightarrow B}}-t_{A}
$$

\subsubsection{Experimento}

Para avaliar o modelo apresentado para calcular o custo da Live Migration foram utilizados três benchmarks que fazem uso intensivo de um determinado recurso computacional, conforme apresentado na Tabela 16. Os benchmarks foram executados em uma sequência diferente para cada uma das quatro máquinas virtuais configuradas (Tabela 17).

Tabela 16: Benchmarks utilizados para simular carga nas máquinas virtuais.

\begin{tabular}{|c|c|}
\hline Benchmark & Comportamento \\
\hline $\begin{array}{c}\text { SPEC } \\
\text { (SAIR; CHARNEY, 2000) }\end{array}$ & CPU \\
\hline $\begin{array}{c}\text { BT (NPB) } \\
\text { (BAILEY et al., 1991) }\end{array}$ & MEM \\
\hline $\begin{array}{c}\text { IOZONE } \\
\text { (TARASOV et al., 2011) }\end{array}$ & IO \\
\hline sleep $^{1}$ & OCl (ocioso) \\
\hline
\end{tabular}

O experimento consiste em submeter as máquinas virtuais ao processo

\footnotetext{
${ }^{1}$ Disponível em: <http://man7.org/linux/man-pages/man3/sleep.3.html>
} 
de migração em momentos aleatórios durante a execução dos benchmarks e medir o tempo de execução. Em seguida, foram feitas estimativas do tempo de execução utilizando o modelo apresentado anteriormente. Os resultados são apresentados na Figura 38.

Tabela 17: Configuração das máquinas virtuais e sequência de benchmarks executados.

\begin{tabular}{|c|c|c|}
\hline Máquina Virtual & $\begin{array}{c}\text { Configuração } \\
\text { (vcpu / memória) }\end{array}$ & $\begin{array}{c}\text { Sequência de } \\
\text { Execução }\end{array}$ \\
\hline \hline VM01 & $2 \mathrm{vcpu} / 1048 \mathrm{MB}$ & MEM-OCI-CPU-MEM-OCI-CPU \\
\hline VM02 & $1 \mathrm{vcpu} / 512 \mathrm{MB}$ & MEM-CPU-CPU-MEM-CPU-CPU-MEM-CPU-CPU-MEM-CPU-CPU \\
\hline VM03 & $2 \mathrm{vcpu} / 2048 \mathrm{MB}$ & MEM-OCI-CPU-MEM-OCI-CPU-MEM-OCI-CPU-MEM-OCI-CPU \\
\hline VM04 & $1 \mathrm{vcpu} / 512 \mathrm{MB}$ & IO-CPU-CPU-IO-CPU-CPU-IO-CPU-CPU \\
\hline
\end{tabular}

Figura 38: Comparação entre execução real e estimativas.

(a) Estimativa de execução na má- (b) Estimativa de execução na máquina virtual VM01.

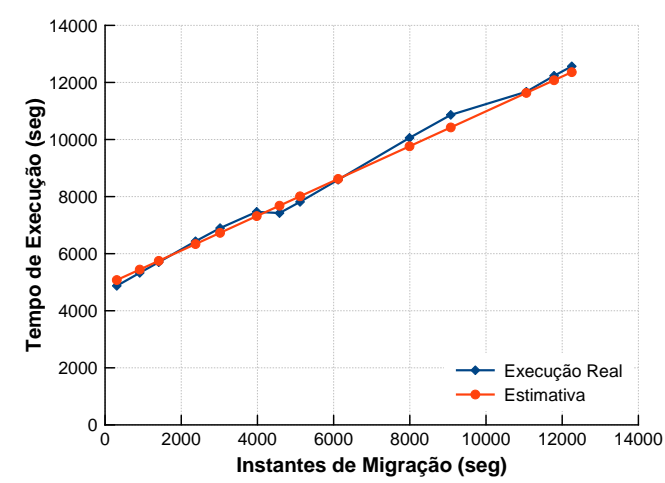

(c) Estimativa de execução na máquina virtual VM03.

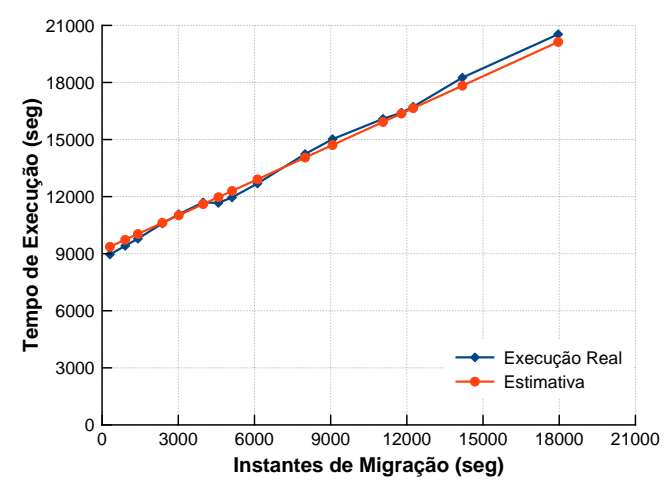
quina virtual VM02.

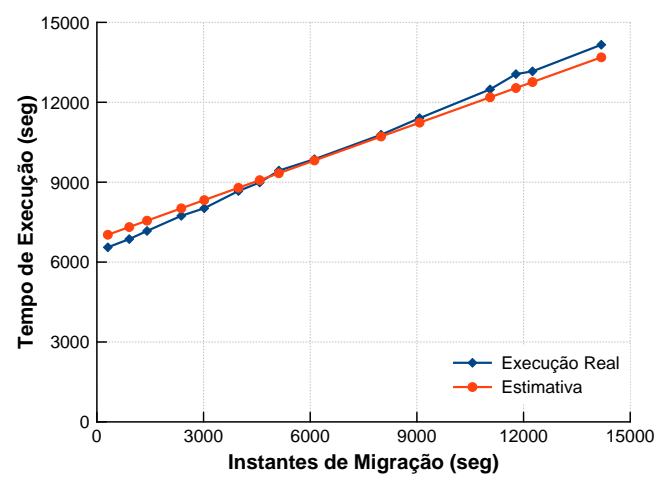

(d) Estimativa de execução na máquina virtual VM04.

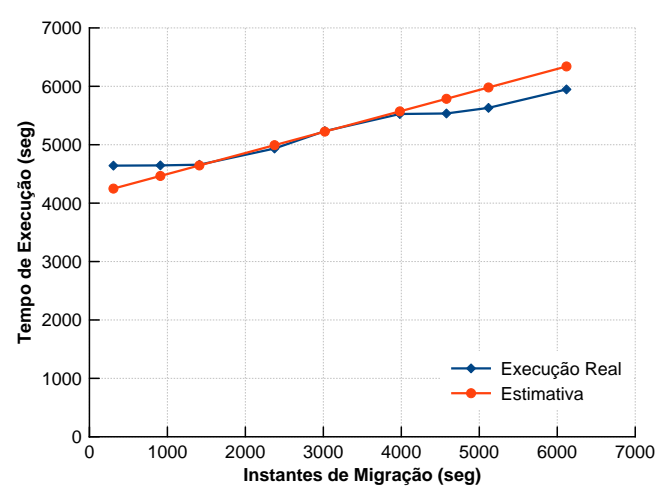

Fonte: Próprio Autor (2015).

O erro médio da estimativa foi em torno $3 \%( \pm 1)$. A carga que apresentou maior erro médio foi da VM04, apresentada na Figura 38d, com erro médio de $4 \%( \pm 3)$. A natureza não determinística de operações de E/S reduzem a preci- 
são do modelo proposto. As requisições de E/S da máquina virtual podem ser atendidas em momentos totalmente diferentes, que dependem de uma série de variáveis, como o consumo do cache e buffer, entre outros. As cargas de trabalho com maior predominância de uso de processador e memória são mais precisas, com erro em torno de $2 \%( \pm 1)$.

\subsection{Protótipo do Algoritmo de Live Migration In- dependente do Uso de Memória}

Nesta seção será apresentado um protótipo do algoritmo de Live Migration proposto que tem como principal característica a migração somente do ambiente de execução da aplicação e não de toda a máquina a virtual, como ocorre nos algoritmos tradicionais de Live Migration. Para verificar sua viabilidade, foi implementado um protótipo que executa os passos do algoritmo utilizando diferentes ferramentas já implementadas por terceiros, mas com algumas alterações.

A primeira ação do algoritmo, ao receber uma solicitação de migração, é criar um checkpoint dos processos do usuário. Em paralelo à criação do checkpoint, enquanto os processos estão congelados, é gerado também um snapshot dos sistemas de arquivos que os processos estão acessando. Assim que o checkpoint termina, os processos podem continuar com a execução. O checkpoint e o snapshot são, então, enviados para o hospedeiro de destino que poderá recriar os processos e os dados a partir do momento que o checkpoint foi realizado. As conexões de rede podem ser redirecionadas e mantidas usando-se SDN (do inglês, Software Defined Network) (GHORBANI et al., 2014).

Uma ilustração do processo de migração é apresentada na Figura 39, em 
Figura 39: Fases do Algoritmo.

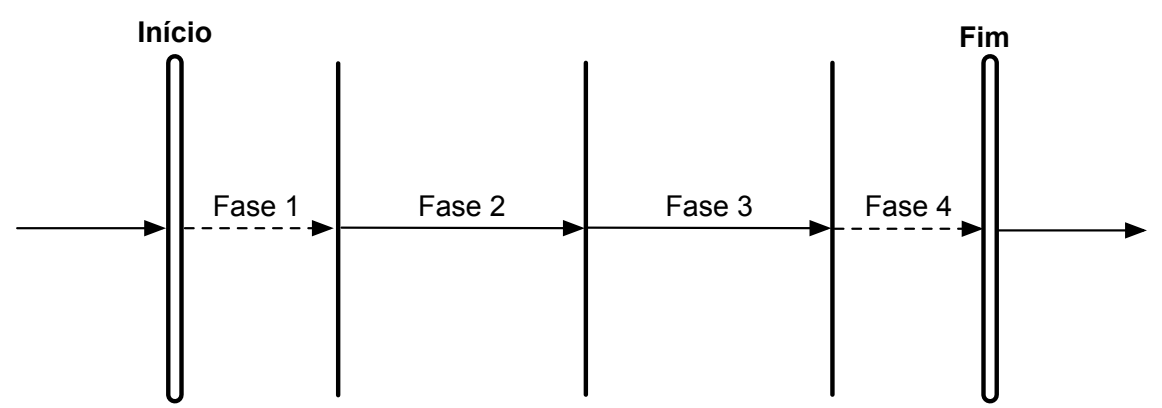

Fonte: Próprio Autor (2015).

que as setas pontilhadas representam o downtime do processo e as setas em linha contínua representam o processo em execução. A Fase 1 inclui a realização do checkpoint do processo e, ao mesmo tempo, a criação do snapshot dos sistemas de arquivos que o processo está acessando. A Fase 2 representa a criação de um backup dos arquivos a partir do snapshot gerado. Em seguida, a Fase 3 é iniciada e consiste na transferência dos arquivos de checkpoint (com as informações necessárias para recriar os processos do(s) usuário(s)) e o backup criado na Fase 2. Por fim, a Fase 4 é a parada do processo na máquina virtual de origem e a inicialização do processo na máquina virtual de destino. Neste momento, ocorre o segundo congelamento do processo e, em seguida, o processo continua a execução normalmente.

\subsubsection{Análise do Algoritmo}

Os algoritmos de migração abordados anteriormente (Pré-Cópia e PósCópia) foram analisados de acordo com o tempo de downtime e o tempo da migração, nas inequações 3.2 e 3.1 do Capítulo 3. Por esse motivo, os mesmos critérios serão usados para a análise do algoritmo apresentado.

Para a análise do algoritmo, serão usadas as seguintes denominações:

$T_{C H P}$ : Tempo para realizar o checkpoint;

$T_{S N A P}$ : Tempo para realizar o snapshot; 
$T_{B K P}$ : Tempo para realizar a cópia dos arquivos acessados pelo processo (backup);

$A_{C H P}$ : Tamanho do arquivo de checkpoint;

$A_{B K P}$ : Tamanho do arquivo de backup;

$T_{R E S T A}$ : Tempo para reiniciar o processo (restart);

$T_{\text {RESTO }}$ : Tempo para realizar o restore dos arquivos copiados e a conexão de rede;

$t_{m i g}:$ Tempo de migração;

$t_{\text {down }}$ : Tempo de downtime;

$B$ : Banda de rede entre os hospedeiros de origem e de destino.

A primeira análise a ser realizada é em relação ao tempo de migração, considerando que o melhor cenário ocorre quando o processo a ser migrado não tem arquivos abertos no momento da migração e não depende de conexões de rede para a execução (como processos batch). Nesse caso, será necessário realizar apenas o checkpoint do processo, sem necessidade de criar o snapshot nem o backup dos arquivos. Assim, o melhor cenário seria:

$$
\text { MelhorCaso }=T_{C H P}+\frac{A_{C H P}}{B}+T_{R E S T A}
$$

O pior caso para o tempo de migração é quando o processo possui arquivos abertos e conexões de rede estabelecidas que deverão ser migradas. Nesse cenário, o tempo de migração poderia ser contabilizado como:

$$
\text { PiorCaso }=T_{C H P}+T_{S N A P}+\frac{A_{C H P}+A_{B K P}}{B}+T_{R E S T A}+T_{R E S T O}
$$

Portanto, podem-se definir os limites inferiores e superiores do tempo de 
migração do algoritmo proposto como:

$$
T_{C H P}+\frac{A_{C H P}}{B}+T_{R E S T A} \leq \mathbf{t}_{\mathbf{m i g}} \leq T_{C H P}+T_{S N A P}+\frac{A_{C H P}+A_{B K P}}{B}+T_{R E S T A}+T_{R E S T O}
$$

Na avaliação do tempo de downtime, os mesmos cenários foram considerados. O melhor caso é quando o processo não possui arquivos ou conexões de rede abertas e o pior caso é considerado o processo com arquivos abertos e conexões de rede estabelecidas. O melhor caso pode ser descrito como:

$$
\text { MelhorCaso }=T_{C H P}+T_{R E S T A}
$$

O downtime para o pior cenário é:

$$
\text { PiorCaso }=T_{C H P}+T_{S N A P}+T_{R E S T A}+T_{R E S T O}
$$

Portanto, os limites inferiores e superiores para o tempo de downtime do algoritmo proposto será:

$$
T_{C H P}+T_{R E S T A} \leq \mathbf{t}_{\text {down }} \leq T_{C H P}+T_{S N A P}+T_{R E S T A}+T_{R E S T O}
$$

Esta análise mostra que o tempo de migração poderá ser maior em comparação com os demais algoritmos, pois dependendo da quantidade de arquivos abertos de um processo ou do tamanho dos arquivos, a quantidade de dados a ser enviada pela rede pode ser superior ao tamanho da memória alocada para a máquina virtual. $\mathrm{O}$ algoritmo sempre terá vantagem no tempo de migração se $A_{C H P}+A_{B K P}$ for menor que o tamanho da memória alocada para a máquina virtual, pois o algoritmo de migração Pré-cópia sempre irá transferir, pelo menos, uma quantidade de dados igual ao tamanho da memória alocado para a máquina virtual (limite inferior da equação 3.1). Entretanto, sabendose a priori a quantidade e o tamanho dos arquivos abertos e o tamanho dos 
processos em memória, é possível saber a quantidade de dados trafegados e, por consequência, o tempo de migração. O tempo de downtime do algoritmo é sensível ao tempo necessário para realizar o checkpoint e o restart do processo e, no pior caso, o tempo para se reestabelecer as conexões de rede e os arquivos abertos pelo processo.

\subsubsection{Protótipo e Resultados}

Para fins de comparação com o algoritmo de Pré-Cópia foi criado um protótipo do algoritmo apresentado. A Tabela 18 apresenta as ferramentas que foram utilizadas para implementar o protótipo. A comparação realizada tem como objetivo verificar a quantidade de dados trafegados na rede com dois benchmarks. Um de uso intensivo de memória e outro que realiza muitas operações de leitura e escrita (NPB e IOZone, ambos descritos na Tabela 16).

Tabela 18: Ferramentas e linguagens utilizadas na implementação do protótipo.

\begin{tabular}{|l|c|c|}
\hline \multicolumn{1}{|c|}{ Função } & Ferramenta / Projeto & Linguagem \\
\hline \hline \multirow{2}{*}{ Checkpoint / Restart } & BLCR & C \\
& (CORNWELL; KONGMUNVATTANA, 2011) & C \\
\hline Snapshot & ZFS (fuse) $)^{1}$ & Perl / Python \\
\hline Conexão de Rede & SDN $^{2}$ & (C) \\
\hline
\end{tabular}

Para a realização do Checkpoint/Restart (CR) dos processos foi utilizado o Berkley Lab Checkpoint Restart (BLCR). O BLCR faz o CR na camada do sistema operacional, isto é, não há necessidade de alterar as aplicações dos usuários para a realização do CR. Outra vantagem do BLCR é a implementação como device driver o que evita alterações no Kernel do Linux.

O snapshot é uma característica que pode ser implementada na camada do Gerenciador de Volumes Lógicos (do inglês, Logical Volume Manager - LVM).

\footnotetext{
${ }^{1}$ Disponível em: <http://zfsonlinux.org/>

2Disponível em: <https://www.opennetworking.org/>
} 
Na implementação do protótipo, foi usado o ZFS (do inglês, Zettabyte File System), que possui boas funcionalidades de snapshot. No Linux, o ZFS ainda é implementado como FUSE, que é um sistema de arquivos na camada do usuário, que facilita alterações no código fonte e possui uma biblioteca de programação mais completa. Para a migração das conexões de rede, utiliza-se o OpenFlow, uma das várias implementações de Software Defined Network (SDN). O SDN permite que os fluxos de rede sejam direcionados de forma dinâmica e distribuída nos próprios dispositivos de rede.

Os resultados obtidos com o algoritmo de uso intensivo de leitura e escrita são apresentados na Tabela 19. A primeira coluna é o instante em que a migração ocorreu a partir do instante de inicio do benchmark. A segunda e a terceira coluna mostram o tamanho do processo e a quantidade de dados referentes a arquivos abertos que foram transmitidos. Portanto, a quantidade total de dados trafegados usando o algoritmo proposto é a soma da segunda e terceira coluna. A quarta coluna é a quantidade de dados trafegados usando o algoritmo Pré-Cópia e, por fim, a última coluna é a redução obtida ao utilizar o algoritmo proposto.

Na comparação usando o benchmark de leitura e escrita intensivo, o tamanho do processo, isto é, a quantidade de memória que ele ocupa na máquina virtual, é constante. Os tamanhos dos dados sofrem comparações consideráveis no decorrer do teste, e isso se deve ao fato de que num dado instante o benchmark pode estar com diversos arquivos abertos ou nenhum (como no caso do instante em que a migração ocorreu após 119 segundos do início do benchmark).

Os resultados obtidos com o algoritmo sob uma carga de uso intensivo de memória são apresentados na Tabela 20. O comportamento deste benchmark é mais determinístico que o benchmark, anterior pois não possui arquivos 
Tabela 19: Comparação entre os algoritmos com benchmark de leitura e escrita intensiva.

\begin{tabular}{|c|c|c|c|c|}
\hline $\begin{array}{c}\text { Momento da } \\
\text { Migração } \\
\text { (seg) }\end{array}$ & $\begin{array}{c}|c| \\
\text { Algoritmo Proposto }\end{array}$ & $\begin{array}{c}\text { Pré-Cópia } \\
\text { (MB) }\end{array}$ & $\begin{array}{c}\text { Redução } \\
\text { (\%) }\end{array}$ \\
\cline { 2 - 3 } (MB) & $\begin{array}{c}\text { Tamanho Processo } \\
\text { (MB) }\end{array}$ & $\begin{array}{c}\text { Tamanho Dados } \\
\text { (MBnnn}\end{array}$ & & \\
\hline \hline 268 & 103 & 252 & 1270 & 72,06 \\
\hline 257 & 103 & 659 & 1605 & 52,53 \\
\hline 246 & 103 & 1026 & 8837 & 87,23 \\
\hline 239 & 103 & 831 & 5345 & 82,52 \\
\hline 236 & 103 & 1026 & 5519 & 79,55 \\
\hline 221 & 103 & 274 & 5239 & 92,80 \\
\hline 214 & 103 & 832 & 5265 & 82,24 \\
\hline 159 & 103 & 1026 & 3582 & 68,49 \\
\hline 147 & 103 & 624 & 7168 & 89,86 \\
\hline 128 & 103 & 278 & 7896 & 95,17 \\
\hline 119 & 103 & 0 & 2881 & 96,42 \\
\hline 104 & 103 & 1026 & 2790 & 59,54 \\
\hline 94 & 103 & 829 & 8408 & 88,91 \\
\hline 82 & 103 & 646 & 13312 & 94,37 \\
\hline 73 & 103 & 383 & 2785 & 82,55 \\
\hline
\end{tabular}

de entrada e saída. O processo ocupa maior espaço em memória (685 MegaBytes), mas pelo fato de não haver arquivos abertos a quantidade de dados trafegados entre as máquinas envolvidas é menor. A redução para esse experimento ficou em $40 \%$.

Tabela 20: Comparação entre os algoritmos com benchmark de memória.

\begin{tabular}{|c|c|c|c|}
\hline $\begin{array}{c}\text { Momento da } \\
\text { Migração }\end{array}$ & $\begin{array}{c}\text { Algoritmo Proposto } \\
\text { (MB) }\end{array}$ & $\begin{array}{c}\text { Pré-Cópia } \\
\text { (MB) }\end{array}$ & $\begin{array}{c}\text { Redução } \\
\text { (\%) }\end{array}$ \\
\hline \hline 268 & 685 & 1153 & 40,59 \\
\hline 257 & 685 & 1154 & 40,64 \\
\hline 246 & 685 & 1152 & 40,54 \\
\hline 239 & 685 & 1151 & 40,49 \\
\hline 236 & 685 & 1153 & 40,59 \\
\hline 221 & 685 & 1152 & 40,54 \\
\hline 214 & 685 & 1151 & 40,49 \\
\hline 159 & 685 & 1156 & 40,74 \\
\hline 147 & 685 & 1154 & 40,64 \\
\hline 128 & 685 & 1155 & 40,69 \\
\hline 119 & 685 & 1158 & 40,85 \\
\hline 104 & 685 & 1157 & 40,80 \\
\hline 94 & 685 & 1144 & 40,12 \\
\hline 82 & 685 & 1160 & 40,95 \\
\hline 73 & 685 & 1161 & 41,00 \\
\hline
\end{tabular}


O algoritmo apresentou redução de tráfego de dados nos experimentos conduzidos e um comportamento mais estável quando comparado com o algoritmo de Pré-Cópia. Ainda existem desafios a serem transpostos para a sua implementação, como a criação da máquina virtual no hospedeiro de destino. Entretanto, a idéia de movimentar somente os dados necessários para a continuidade da execução e o uso de SDN tornam a proposta do algoritmo promissora para ambientes com a banda de rede limitada, situação típica para migrações entre data centers distribuídos. 


\section{CONCLUSÕES E TRABALHOS FUTUROS}

Neste trabalho foi analisado como reduzir a sobrecarga imposta pelo processo de migração de máquinas virtuais tirando proveito dos comportamentos cíclicos presentes em uma vasta gama de aplicações. Outros trabalhos mostraram que as cargas de trabalho mais nocivas para a migração são aquelas com altas taxas de atualização de páginas. Entretanto, esses períodos podem não ser constantes no decorrer da execução da aplicação, variando de acordo com o horário, dia da semana, período do ano ou mesmo de acordo com os parâmetros de entrada da aplicação. O desafio, então, é identificar cargas que tenham este comportamento e, dado que o comportamento cíclico foi identificado, como evitar que as migrações ocorram nos períodos em que a aplicação mais atualiza a memória.

A identificação do tipo de carga de trabalho, apresentada no capítulo 4, é feita a partir de índices de carga que captam a utilização do processador e da memória. Esses índices são submetidos a um classificador (que pode ser um classificador Bayesiano ou uma Árvore de Decisão) que dirá o comportamento da carga de trabalho no decorrer do tempo. Essa classificação é então submetida à Transformada de Fourier que retornará o tamanho do ciclo daquela carga.

Com essas informações, foram elaborados dois algoritmos, abordados no capítulo 6, capazes de identificar o tempo que resta até um período propício 
para iniciar a migração da máquina virtual ou, caso a máquina virtual ainda esteja em um período favorável para a migração, quanto tempo ainda resta para que a migração seja submetida. Os experimentos, apresentados no capítulo 7 , conduzidos em uma nuvem privada real e com cargas de trabalhos sintéticas e aplicações reais, indicaram reduções no tempo de migração da ordem de $60 \%$ nos melhores casos, e de até $62 \%$ na quantidade de dados trafegados. Não foi possível identificar reduções ou aumentos significativos estatisticamente para o tempo de downtime para nos experimentos realizados. Além disso, os experimentos de escalabilidade mostraram que a arquitetura proposta possui grande potencial de escalabilidade. Uma máquina com dois processadores e com 6 GigaBytes de memória é capaz de gerenciar mais de 1800 máquinas virtuais. Além disso, a arquitetura pode ser distribuída entre diversas máquinas, sem a necessidade de um controle centralizado.

Outro problema abordado nesta tese é o custo, ou sobrecarga, que é imposta na carga de trabalho quando há a ocorrência de uma migração em plena execução da carga de trabalho, problema que é particularmente interessante para definir se uma migração implicará em ganho de desempenho ou não. Caso a sobrecarga imposta pela migração somada ao tempo restante de processamento seja muito superior ao tempo de processamento sem a migração, pode-se cancelar a migração. Os resultados obtidos com a métrica do custo da migração, apresentados no capítulo 8, leva em conta as diferentes gerações de processadores, comuns em ambientes de nuvem, mostraram que o modelo tem uma precisão bastante satisfatória em diversos tipos de cargas de trabalho.

Por fim, no capítulo 5 foi proposto um algoritmo agnóstico à carga de trabalho, isto é, independentemente da carga de trabalho, a variação de dados transmitidos entre os hospedeiros é minima. Os resultados obtidos com a im- 
plementação de um protótipo foi de até $96 \%$ em uma carga de trabalho de escrita e leitura intensiva e até $41 \%$ em cargas de uso intensivo de memória.

Os resultados obtidos neste trabalho indicam que escolhendo o momento mais favorável para realizar a migração da máquina virtual, tem-se uma redução do congestionamento de rede e também do tempo de migração das máquinas virtuais, confirmando a hipótese deste trabalho.

\subsection{Contribuições}

Tem-se as seguintes contribuições deste trabalho:

- O desenvolvimento de uma metodologia para classificar cargas de trabaIho que sejam favoráveis ou não para o processo de migração baseado na extração de índices de carga de memória e processador. Os índices são submetidos a um classificador Bayesiano que caracteriza a carga de trabalho em favorável ou não favorável para ser submetida ao processo de migração;

- Elaboração de método para a extração de padrões repetitivos em uma carga de trabalho baseada na Transformada Rápida de Fourier. A partir dessa extração é possível inferir o tempo de duração dos instantes propícios para a migração, bem como o tempo que falta para que a carga de trabalho entre em um período propício;

- Desenvolvimento de um modelo para estimar a sobrecarga imposta à aplicação pelo processo de migração. Através desse modelo, os provedores de serviço podem deduzir se uma migração pode ser vantajosa para obter ganhos de desempenho ou, no caso oposto, se a migração poderá implicar em penalidades contratuais por ferir cláusulas de quali- 
dade de serviço e/ou disponibilidade;

- Desenvolvimento de um algoritmo de migração de máquinas virtuais cujo desempenho não é afetado pela carga de trabalho da máquina virtual. Neste algoritmo, é migrado apenas o ambiente de execução do usuário (processos, arquivos abertos, conexões de rede, entre outros), reduzindo o footprint de memória da máquina virtual e, consequentemente, a quantidade de dados trafegados na rede.

\subsection{Trabalhos Futuros}

A redução da sobrecarga causada pela Live Migration em data centers é um problema que transcende a camada de virtualização e que pode ser abordado em diversas outras camadas, como de rede, sistema operacional e, até mesmo, na própria camada da aplicação. A pesquisa conduzida neste trabalho abre caminho para estudos direcionados a aplicações conscientes da virtualização (ou virtualization-aware), isto é, aplicações que, na sua concepção, abrem espaços para serem migradas, por exemplo, reduzindo consideravelmente o consumo de rede ou de memória, ou que sejam capazes de se candidatar ao processo de migração ao serem solicitadas.

Do ponto de vista da arquitetura ALMA, algumas pesquisas voltadas à expansão da arquitetura podem ser conduzidas no futuro, como:

- Conjunto de Máquinas: Criação de uma estratégia que possa identificar ciclos de um conjunto de máquinas (ou clusters) para aplicações que sejam dependentes (ou multi-tier) entre si. Através de correlações poder-se-ia inferir a existência de períodos favoráveis em comum de um conjunto de máquinas virtuais; 
- Cargas de Trabalho Acíclicas: O escopo da pesquisa neste trabalho foram aplicações que apresentem uma repetição no comportamento da carga de trabalho. Uma expansão do estudo seria o tratamento de cargas acíclicas.

Por fim, o acoplamento da arquitetura em orquestradores de nuvem pode ser avaliado. Alguns orquestradores possuem plugins para a implementação de escalonadores. A implementação de uma estratégia de escalonamento com a arquitetura ALMA poderiam trazer reduções ainda mais significativas na sobrecarga imposta pela Live Migration. 


\section{REFERÊNCIAS}

AHMAD, I. Easy and efficient disk i/o workload characterization in vmware esx server. In: Proceedings of the 2007 IEEE 10th International Symposium on Workload Characterization. Washington, DC, USA: IEEE Computer Society, 2007. (IISWC '07), p. 149-158. ISBN 978-1-4244-1561-8. Disponível em: <http://dx.doi.org/10.1109/IISWC.2007.4362191>.

AMSTADT, B.; JOHNSON, M. K. Wine. v. 4, p. 3-3, ago. 1994. ISSN 1075-3583 (print), 1938-3827 (electronic).

ARMBRUST, M. et al. Above the Clouds: A Berkeley View of Cloud Computing. [S.I.], 2009. Disponível em: <http://www.eecs.berkeley.edu/Pubs/TechRpts/ 2009/EECS-2009-28.html>.

ARTHI, T.; HAMEAD, H. Energy aware cloud service provisioning approach for green computing environment. In: Energy Efficient Technologies for Sustainability (ICEETS), 2013 International Conference on. [S.I.: s.n.], 2013. p. 139-144.

BAILEY, D. H. et al. The nas parallel benchmarks\&mdash;summary and preliminary results. In: Proceedings of the 1991 ACM/IEEE Conference on Supercomputing. New York, NY, USA: ACM, 1991. (Supercomputing '91), p. 158-165. ISBN 0-89791-459-7. Disponível em: <http://doi.acm.org/10.1145/ 125826.125925>.

BARHAM, P. et al. Xen and the art of virtualization. SIGOPS Oper. Syst. Rev., ACM, New York, NY, USA, v. 37, n. 5, p. 164-177, out. 2003. ISSN 0163-5980. Disponível em: <http://doi.acm.org/10.1145/1165389.945462>.

BARUCHI, A.; MIDORIKAWA, E. Análise de duas estratégias de caracterização para computação na nuvem. In: Anais do XIV Simpósio em Sistemas Computacionais (WSCAD-SSC). [S.I.]: Sociedade Brasileira de Computação (SBC), 2013.

BARUCHI, A.; MIDORIKAWA, E.; NETTO, M. A. S. Improving virtual machine live migration via application-level workload analysis. In: 10th International Conference on Network and Service Management 2014 (CNSM 2014). Rio de Janeiro, Brazil: [s.n.], 2014.

BARUCHI, A.; MIDORIKAWA, E.; SATO, L. Reducing virtual machine live migration overhead via workload analysis. IEEE Latin America Transactions, IEEE Press, Piscataway, NJ, USA, v. 12, n. 4, p. 1178-1187, abr. 2015. ISSN 1548-0992. 
BARUCHI, A.; MIDORIKAWA, E. T. Hypervisor agnostic workload characterization of virtual machines. In: PRESS, A. (Ed.). 16th Parallel and Distributed Computing and Systems (PDCS'12). [S.I.: s.n.], 2012. (Software Engineering and Applications), p. 62-69.

BELOGLAZOV, A.; BUYYA, R. Managing overloaded hosts for dynamic consolidation of virtual machines in cloud data centers under quality of service constraints. IEEE Trans. Parallel Distrib. Syst., IEEE Press, Piscataway, NJ, USA, v. 24, n. 7, p. 1366-1379, jul. 2013. ISSN 1045-9219. Disponível em: <http://dx.doi.org/10.1109/TPDS.2012.240>.

BERGLAND, G. D. Numerical analysis: A fast fourier transform algorithm for real-valued series. Commun. ACM, ACM, New York, NY, USA, v. 11, n. 10, p. 703-710, out. 1968. ISSN 0001-0782. Disponível em: <http://doi.acm.org/10. 1145/364096.364118>.

BIRKE, R. et al. State-of-the-practice in data center virtualization: Toward a better understanding of vm usage. In: Dependable Systems and Networks (DSN), 2013 43rd Annual IEEE/IFIP International Conference on. [S.I.: s.n.], 2013. p. 1-12. ISSN 1530-0889.

BRANCO, K. R. L. J. C. Índices de carga e desempenho em ambientes paralelos/distribuídos - modelagem e métricas. Tese (Doutorado) - Instituto de Ciências Matemáticas e de Computação, Universidade de São Paulo, 2004. Tese de Doutorado em Ciências de Computação e Matemática Computacional.

BUYYA, R.; BROBERG, J.; GOSCINSKI, A. M. Cloud Computing Principles and Paradigms. [S.I.]: Wiley Publishing, 2011. ISBN 9780470887998.

CALHEIROS, R. N. et al. Cloudsim: A toolkit for modeling and simulation of cloud computing environments and evaluation of resource provisioning algorithms. Softw. Pract. Exper., John Wiley \& Sons, Inc., New York, NY, USA, v. 41, n. 1, p. 23-50, jan. 2011. ISSN 0038-0644. Disponível em: <http: //dx.doi.org/10.1002/spe.995>.

CHEN, W. et al. Design and implementation of server cluster dynamic load balancing in virtualization environment based on openflow. In: Proceedings of The Ninth International Conference on Future Internet Technologies. New York, NY, USA: ACM, 2014. (CFI '14), p. 9:1-9:6. ISBN 978-1-4503-2942-2. Disponível em: <http://doi.acm.org/10.1145/2619287.2619288>.

CORNWELL, J.; KONGMUNVATTANA, A. Efficient system-level remote checkpointing technique for blcr. In: Proceedings of the 2011 Eighth International Conference on Information Technology: New Generations. Washington, DC, USA: IEEE Computer Society, 2011. (ITNG '11), p. 1002-1007. ISBN 978-07695-4367-3. Disponível em: <http://dx.doi.org/10.1109/ITNG.2011.172>.

DEAN, J.; GHEMAWAT, S. Mapreduce: Simplified data processing on large clusters. Commun. ACM, ACM, New York, NY, USA, v. 51, n. 1, p. 107-113, jan. 
2008. ISSN 0001-0782. Disponível em: <http://doi.acm.org/10.1145/1327452. 1327492>.

DOMANAL, S.; REDDY, G. Optimal load balancing in cloud computing by efficient utilization of virtual machines. In: Communication Systems and Networks (COMSNETS), 2014 Sixth International Conference on. [S.I.: s.n.], 2014. p. 1-4.

DU, J.; SEHRAWAT, N.; ZWAENEPOEL, W. Performance profiling of virtual machines. SIGPLAN Not., ACM, New York, NY, USA, v. 46, n. 7, p. 3-14, mar. 2011. ISSN 0362-1340. Disponível em: <http://doi.acm.org/10.1145/2007477. 1952686>.

FELLER, E.; MORIN, C.; ESNAULT, A. A case for fully decentralized dynamic vm consolidation in clouds. In: Cloud Computing Technology and Science (CloudCom), 2012 IEEE 4th International Conference on. [S.I.: s.n.], 2012. p. 26-33.

FERRETO, T. C. et al. Server consolidation with migration control for virtualized data centers. Future Gener. Comput. Syst., Elsevier Science Publishers B. V., Amsterdam, The Netherlands, The Netherlands, v. 27, n. 8, p. 1027-1034, out. 2011. ISSN 0167-739X. Disponível em: <http://dx.doi.org/10.1016/j.future. 2011.04.016>.

FREITAS, S. R. et al. The coupled aerosol and tracer transport model to the brazilian developments on the regional atmospheric modeling system (cattbrams)" part 1: Model description and evaluation. Atmospheric Chemistry and Physics, v. 9, n. 8, p. 2843-2861, 2009. Disponível em: <http://www. atmos-chem-phys.net/9/2843/2009/>.

GARFINKEL, T.; ROSENBLUM, M. When virtual is harder than real: Security challenges in virtual machine based computing environments. In: Proceedings of the 10th Conference on Hot Topics in Operating Systems - Volume 10. Berkeley, CA, USA: USENIX Association, 2005. (HOTOS'05), p. 20-20. Disponível em: <http://dl.acm.org/citation.cfm?id=1251123.1251143>.

GHORBANI, S. et al. Transparent, live migration of a software-defined network. In: Proceedings of the ACM Symposium on Cloud Computing. New York, NY, USA: ACM, 2014. (SOCC '14), p. 3:1-3:14. ISBN 978-1-4503-3252-1. Disponível em: <http://doi.acm.org/10.1145/2670979.2670982>.

GIOIOSA, R. et al. Transparent, incremental checkpointing at kernel level: a foundation for fault tolerance for parallel computers. In: Supercomputing, 2005. Proceedings of the ACM/IEEE SC 2005 Conference. [S.I.: s.n.], 2005. p. 9-9.

GOLDBERG, R. P. Survey of virtual machine research. Computer, IEEE Computer Society Press, Los Alamitos, CA, USA, v. 7, n. 9, p. 34-45, set. 1974. ISSN 0018-9162. Disponível em: <http://dx.doi.org/10.1109/MC.1974. 6323581>. 
GULATI, A.; AHMAD, I.; WALDSPURGER, C. A. Parda: Proportional allocation of resources for distributed storage access. In: Proccedings of the 7th Conference on File and Storage Technologies. Berkeley, CA, USA: USENIX Association, 2009. (FAST '09), p. 85-98. Disponível em: <http://dl.acm.org/citation. cfm? id $=1525908.1525915>$.

GUPTA, A. et al. The who, what, why and how of high performance computing applications in the cloud. In: Proceedings of the 5th IEEE International Conference on Cloud Computing Technology and Science. [S.I.: s.n.], 2013. (CloudCom '13).

HALFHILL, T. R. Transmeta breaks x86 low-power barrier. Microprocessor Report, 2000.

HALL, M. et al. The weka data mining software: An update. SIGKDD Explor. Newsl., ACM, New York, NY, USA, v. 11, n. 1, p. 10-18, nov. 2009. ISSN 19310145. Disponível em: <http://doi.acm.org/10.1145/1656274.1656278>.

HERMENIER, F. et al. Entropy: A consolidation manager for clusters. In: Proceedings of the 2009 ACM SIGPLAN/SIGOPS International Conference on Virtual Execution Environments. New York, NY, USA: ACM, 2009. (VEE '09), p. 41-50. ISBN 978-1-60558-375-4. Disponível em: < http://doi.acm.org/10.1145/ 1508293.1508300>.

HINES, M. R.; GOPALAN, K. Post-copy based live virtual machine migration using adaptive pre-paging and dynamic self-ballooning. In: Proceedings of the 2009 ACM SIGPLAN/SIGOPS International Conference on Virtual Execution Environments. New York, NY, USA: ACM, 2009. (VEE '09), p. 51-60. ISBN 978-1-60558-375-4. Disponível em: <http://doi.acm.org/10.1145/ 1508293.1508301>.

HSU, W. W.; SMITH, A. J.; YOUNG, H. C. I/o reference behavior of production database workloads and the tpc benchmarks\&mdash; an analysis at the logical level. ACM Trans. Database Syst., ACM, New York, NY, USA, v. 26, n. 1, p. 96-143, mar. 2001. ISSN 0362-5915. Disponível em: < http://doi.acm.org/10. 1145/383734.383737>.

JOHNSTON, J.; FERREIRA, A. Sum-difference stereo transform coding. In: Acoustics, Speech, and Signal Processing, 1992. ICASSP-92., 1992 IEEE International Conference on. [S.I.: s.n.], 1992. v. 2, p. 569-572 vol.2. ISSN 15206149.

KANDASWAMY, M. A.; KNIGHTEN, R. L. I/o phase characterization of tpc$\mathrm{h}$ query operations. In: Proceedings of the 4th International Computer Performance and Dependability Symposium. Washington, DC, USA: IEEE Computer Society, 2000. (IPDS '00), p. 81-. ISBN 0-7695-0553-8. Disponível em: <http://dl.acm.org/citation.cfm?id=857196.857846>.

KIKUCHI, S.; MATSUMOTO, Y. Impact of live migration on multi-tier application performance in clouds. In: Cloud Computing (CLOUD), 2012 IEEE 5th International Conference on. [S.I.: s.n.], 2012. p. 261-268. ISSN 2159-6182. 
LINDHOLM, T.; YELLIN, F. Java Virtual Machine Specification. 2nd. ed. Boston, MA, USA: Addison-Wesley Longman Publishing Co., Inc., 1999. ISBN 0201432943.

MENESES, E. et al. Using migratable objects to enhance fault tolerance schemes in supercomputers. IEEE Transactions on Parallel and Distributed Systems, IEEE Computer Society, Los Alamitos, CA, USA, v. 99, n. PrePrints, p. 1, 2014. ISSN 1045-9219.

MUñOZ, M. S. et al. openModeller: a generic approach to species' potential distribution modelling. Geolnformatica, Springer US, v. 15, n. 1, p. 111-135, jan. 2011. ISSN 1384-6175. Disponível em: <http://dx.doi.org/10. 1007/s10707-009-0090-7>.

NAGIN, K. et al. Inter-cloud mobility of virtual machines. In: Proceedings of the 4th Annual International Conference on Systems and Storage. New York, NY, USA: ACM, 2011. (SYSTOR '11), p. 3:1-3:12. ISBN 978-1-4503-0773-4. Disponível em: <http://doi.acm.org/10.1145/1987816.1987820>.

NUAIMI, K. et al. A survey of load balancing in cloud computing: Challenges and algorithms. In: Network Cloud Computing and Applications (NCCA), 2012 Second Symposium on. [S.I.: s.n.], 2012. p. 137-142.

NUñEZ, A. et al. icancloud: A flexible and scalable cloud infrastructure simulator. J. Grid Comput., Springer-Verlag New York, Inc., Secaucus, NJ, USA, v. 10, n. 1, p. 185-209, mar. 2012. ISSN 1570-7873. Disponível em: <http: //dx.doi.org/10.1007/s10723-012-9208-5>.

PARKHILL, D. The Challenge of the Computer Utility. [S.I.]: Addison-Wesley Publishing Company, 1966. (The Challenge of the Computer Utility, p. 246).

PATTERSON, R. H.; GIBSON, G. A.; SATYANARAYANAN, M. A status report on research in transparent informed prefetching. SIGOPS Oper. Syst. Rev., ACM, New York, NY, USA, v. 27, n. 2, p. 21-34, abr. 1993. ISSN 0163-5980. Disponível em: <http://doi.acm.org/10.1145/155848.155855>.

RAHMAWAN, H.; GONDOKARYONO, Y. The simulation of static load balancing algorithms. In: Electrical Engineering and Informatics, 2009. ICEEI '09. International Conference on. [S.I.: s.n.], 2009. v. 02, p. 640-645.

RANDLES, M.; LAMB, D.; TALEB-BENDIAB, A. A comparative study into distributed load balancing algorithms for cloud computing. In: Advanced Information Networking and Applications Workshops (WAINA), 2010 IEEE 24th International Conference on. [S.I.: s.n.], 2010. p. 551-556.

RIMAL, B. P.; CHOI, E.; LUMB, I. A taxonomy and survey of cloud computing systems. In: Proceedings of the 2009 Fifth International Joint Conference on INC, IMS and IDC. Washington, DC, USA: IEEE Computer Society, 2009. (NCM '09), p. 44-51. ISBN 978-0-7695-3769-6. Disponível em: <http://dx.doi.org/10. 1109/NCM.2009.218>. 
ROYTMAN, A. et al. Pacman: Performance aware virtual machine consolidation. In: Proceedings of the 10th International Conference on Autonomic Computing (ICAC 13). San Jose, CA: USENIX, 2013. p. 83-94. ISBN 9781-931971-02-7. Disponível em: <https://www.usenix.org/conference/icac13/ technical-sessions/presentation/roytman>.

RUSSELL, S.; NORVIG, P. Artificial Intelligence: A Modern Approach. 3rd. ed. Upper Saddle River, NJ, USA: Prentice Hall Press, 2009. ISBN 0136042597, 9780136042594.

SAIR, S.; CHARNEY, M. Memory Behavior of the SPEC2000 Benchmark Suite. [S.I.], 2000.

SEKI, M. et al. Selfish virtual machine live migration causes network instability. In: Information and Telecommunication Technologies (APSITT), 2012 9th AsiaPacific Symposium on. [S.I.: s.n.], 2012. p. 1-6.

SMITH, J.; NAIR, R. Virtual Machines: Versatile Platforms for Systems and Processes (The Morgan Kaufmann Series in Computer Architecture and Design). San Francisco, CA, USA: Morgan Kaufmann Publishers Inc., 2005. ISBN 1558609105.

SONI, G.; KALRA, M. A novel approach for load balancing in cloud data center. In: Advance Computing Conference (IACC), 2014 IEEE International. [S.I.: s.n.], 2014. p. 807-812.

SRIKANTAIAH, S.; KANSAL, A.; ZHAO, F. Energy aware consolidation for cloud computing. In: Proceedings of the 2008 Conference on Power Aware Computing and Systems. Berkeley, CA, USA: USENIX Association, 2008. (HotPower'08), p. 10-10. Disponível em: <http://dl.acm.org/citation.cfm?id= 1855610.1855620>.

STAGE, A.; SETZER, T. Network-aware migration control and scheduling of differentiated virtual machine workloads. In: Software Engineering Challenges of Cloud Computing, 2009. CLOUD '09. ICSE Workshop on. [S.I.: s.n.], 2009. p. 9-14.

STELLNER, G. Cocheck: Checkpointing and process migration for mpi. In: IN PROCEEDINGS OF THE 10TH INTERNATIONAL PARALLEL PROCESSING SYMPOSIUM (IPPS '96. [S.I.: s.n.], 1996. p. 526-531.

STRUNK, A. Costs of virtual machine live migration: A survey. In: Services (SERVICES), 2012 IEEE Eighth World Congress on. [S.I.: s.n.], 2012. p. 323-329.

TAN, P.-N.; STEINBACH, M.; KUMAR, V. Introduction to Data Mining, (First Edition). Boston, MA, USA: Addison-Wesley Longman Publishing Co., Inc., 2005. ISBN 0321321367. 
TARASOV, V. et al. Benchmarking file system benchmarking: It *is* rocket science. In: Proceedings of the 13th USENIX Conference on Hot Topics in Operating Systems. Berkeley, CA, USA: USENIX Association, 2011. (HotOS'13), p. 9-9. Disponível em: <http://dl.acm.org/citation.cfm?id=1991596.1991609>.

THEIMER, M. M.; LANTZ, K. A.; CHERITON, D. R. Preemptable remote execution facilities for the v-system. SIGOPS Oper. Syst. Rev., ACM, New York, NY, USA, v. 19, n. 5, p. 2-12, dez. 1985. ISSN 0163-5980. Disponível em: <http://doi.acm.org/10.1145/323627.323629>.

TSAI, L.; LIAO, W. Cost-aware workload consolidation in green cloud datacenter. In: Cloud Networking (CLOUDNET), 2012 IEEE 1st International Conference on. [S.I.: s.n.], 2012. p. 29-34.

TZIRITAS, N. et al. Application-aware workload consolidation to minimize both energy consumption and network load in cloud environments. In: Proceedings of the 2013 42Nd International Conference on Parallel Processing. Washington, DC, USA: IEEE Computer Society, 2013. (ICPP '13), p. 449-457. ISBN 978-07695-5117-3. Disponível em: <http://dx.doi.org/10.1109/ICPP.2013.54>.

VENKATARAMAN, A. et al. Softmap: On minimizing software costs using vm consolidation. In: Proceedings of the 5th IBM Collaborative Academia Research Exchange Workshop. New York, NY, USA: ACM, 2013. (I-CARE '13), p. 12:1-12:4. ISBN 978-1-4503-2320-8. Disponível em: <http://doi.acm.org/10. $1145 / 2528228.2528241>$.

VERMA, A.; AHUJA, P.; NEOGI, A. pmapper: Power and migration cost aware application placement in virtualized systems. In: Proceedings of the 9th ACM/IFIP/USENIX International Conference on Middleware. New York, NY, USA: Springer-Verlag New York, Inc., 2008. (Middleware '08), p. 243-264. ISBN 3-540-89855-7. Disponível em: <http://dl.acm.org/citation. cfm?id=1496950.1496966>.

VERMA, A. et al. Cosmig: Modeling the impact of reconfiguration in a cloud. In: Proceedings of the 2011 IEEE 19th Annual International Symposium on Modelling, Analysis, and Simulation of Computer and Telecommunication Systems. Washington, DC, USA: IEEE Computer Society, 2011. (MASCOTS '11), p. 3-11. ISBN 978-0-7695-4430-4. Disponível em: <http://dx.doi.org/10.1109/ MASCOTS.2011.37>.

WALDSPURGER, C. A. Memory resource management in vmware esx server. SIGOPS Oper. Syst. Rev., ACM, New York, NY, USA, v. 36, n. SI, p. 181-194, dez. 2002. ISSN 0163-5980. Disponível em: <http://doi.acm.org/10. 1145/844128.844146>.

WANG, L.; WANG, T. Green computing wanted: Electricity consumptions in the it industry and by household computers in five major chinese cities. In: Green Computing and Communications (GreenCom), 2011 IEEE/ACM International Conference on. [S.I.: s.n.], 2011. p. 226-229. 
WILCOXON, F. Individual Comparisons by Ranking Methods. Biometrics Bulletin, International Biometric Society, v. 1, n. 6, p. 80-83, dez. 1945. ISSN 00994987. Disponível em: <http://dx.doi.org/10.2307/3001968>.

WITTEN, I. H.; FRANK, E.; HALL, M. A. Data Mining: Practical Machine Learning Tools and Techniques. 3rd. ed. San Francisco, CA, USA: Morgan Kaufmann Publishers Inc., 2011. ISBN 0123748569, 9780123748560.

WU, J.-J.; LIU, P.; YANG, J.-S. Workload characteristics-aware virtual machine consolidation algorithms. In: Proceedings of the 2012 IEEE 4th International Conference on Cloud Computing Technology and Science (CloudCom). Washington, DC, USA: IEEE Computer Society, 2012. (CLOUDCOM '12), p. 42-49. ISBN 978-1-4673-4511-8. Disponível em: <http://dx.doi.org/10.1109/ CloudCom.2012.6427540>.

$\mathrm{XU}, \mathrm{F}$. et al. iaware: Making live migration of virtual machines interferenceaware in the cloud. IEEE Transactions on Computers, IEEE Computer Society, Los Alamitos, CA, USA, v. 99, n. PrePrints, p. 1, 2013. ISSN 0018-9340.

$\mathrm{YE}, \mathrm{K}$. et al. Vc-migration: Live migration of virtual clusters in the cloud. In: Proceedings of the 2012 ACM/IEEE 13th International Conference on Grid Computing. Washington, DC, USA: IEEE Computer Society, 2012. (GRID '12), p. 209-218. ISBN 978-0-7695-4815-9. Disponível em: <http://dx.doi.org/10. 1109/Grid.2012.27>.

ZUO, X.-D.; JIA, H.-M. An energy saving heuristic algorithm based on consolidation of virtual machines. In: Machine Learning and Cybernetics (ICMLC), 2013 International Conference on. [S.I.: s.n.], 2013. v. 04, p. 1578-1583. 


\section{APÊNDICE A - ÁRVORES DE DECISÃO}

Abaixo são apresentadas as duas Árvores de Decisão geradas com o software WEKA. A Figura 40a apresenta a árvore construída utilizando-se os índices de carga relativos à memória. A árvore da Figura 40b foi construída com os índices do processador.

Figura 40: Árvores de Decisão.

(a) Índices de Memória.

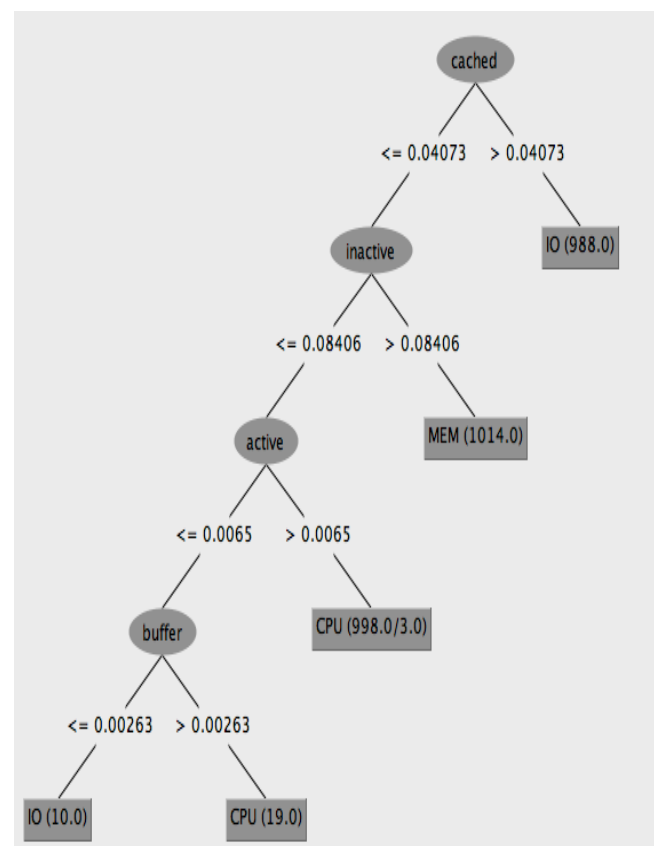

(b) Índices de Processador.

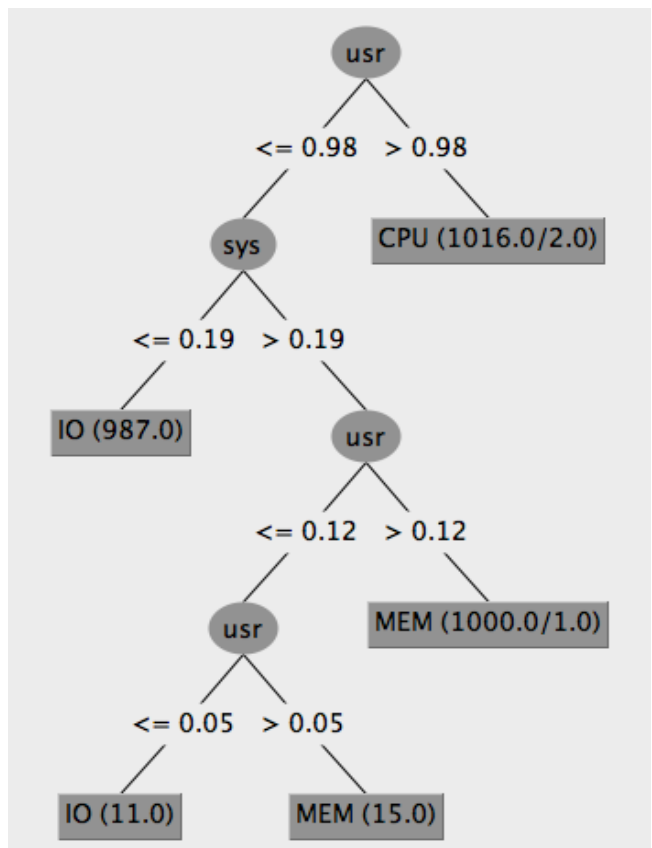

Fonte: Próprio Autor (2015). 


\section{APÊNDICE B - NAIVE BAYES}

A seguir, apresenta-se a saída obtida com o software WEKA ao submeter os índices de carga ao Naive Bayes. A saída contempla a parte da discretização entrópica, discutida na seção 4.2.1 e suas respectivas probabilidades. No final, há também uma matriz de confusão gerada pelo WEKA com alguns testes realizados sobre a amostra da fase de aprendizagem. 
Classifier Model

Naive Bayes Classifier

$\begin{array}{lrr} & \text { Class } & \\ \text { Attribute } & \text { LM } & \text { NLM } \\ & (0.45) & (0.55)\end{array}$

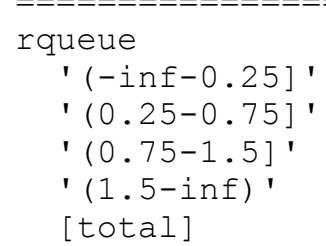

usr

' (-inf-0.005]'

' (0.005-0.985]'

' (0.985-inf)'

[total]
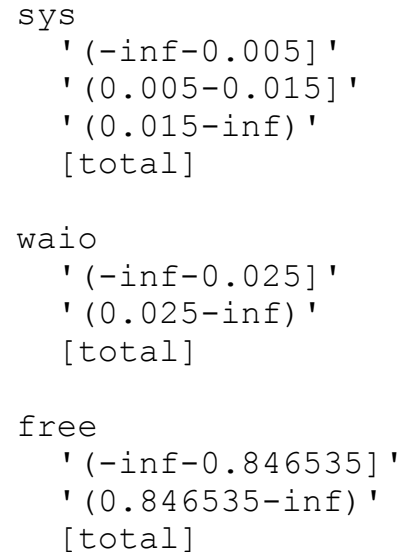

dirty

' (-inf-0.000015]'

' (0.000015-0.000035]'

'(0.000035-0.017355]'

' (0.017355-inf)'

[total]
active
' (-inf-0.002535] '
' (0.002535-0.003255 ]'
'(0.003255-0.004345]'
' (0.004345-0.007655]'
' (0.007655-0.008095]'
'(0.008095-0.01002]'
' (0.01002-0.010225]'
' (0.010225-0.010675] '
' (0.010675-0.013345]'
' (0.013345-0.015505]'
' (0.015505-0.015985]'
' (0.015985-0.016955] '
' (0.016955-0.017775 ]'
' (0.017775-0.063365]'
' (0.063365-inf)'
[total]

buffer

' (-inf-0.000475]'

' (0.000475-0.007455]'

$\begin{array}{rr}368.0 & 52.0 \\ 4.0 & 282.0 \\ 335.0 & 495.0 \\ 1.0 & 23.0 \\ 708.0 & 852.0\end{array}$

$365.0 \quad 52.0$

$14.0 \quad 364.0$

$328.0 \quad 435.0$

$707.0 \quad 851.0$

$468.0 \quad 640.0$

$234.0 \quad 125.0$

$5.0 \quad 86.0$

$707.0 \quad 851.0$

$705.0 \quad 794.0$

$1.0 \quad 56.0$

$706.0 \quad 850.0$

$1.0 \quad 844.0$

$705.0 \quad 6.0$

$706.0 \quad 850.0$

$334.0 \quad 616.0$

$232.0 \quad 170.0$

$141.0 \quad 14.0$

$1.0 \quad 52.0$

$708.0 \quad 852.0$

$\begin{array}{rr}68.0 & 2.0 \\ 60.0 & 67.0 \\ 2.0 & 138.0 \\ 269.0 & 1.0 \\ 58.0 & 52.0 \\ 1.0 & 118.0 \\ 9.0 & 14.0 \\ 40.0 & 13.0 \\ 104.0 & 1.0 \\ 2.0 & 87.0 \\ 13.0 & 11.0 \\ 38.0 & 3.0 \\ 3.0 & 23.0 \\ 51.0 & 1.0 \\ 1.0 & 332.0 \\ 719.0 & 863.0\end{array}$

52.0308 .0 $632.0 \quad 542.0$ 
'(0.007455-inf)'

[total]

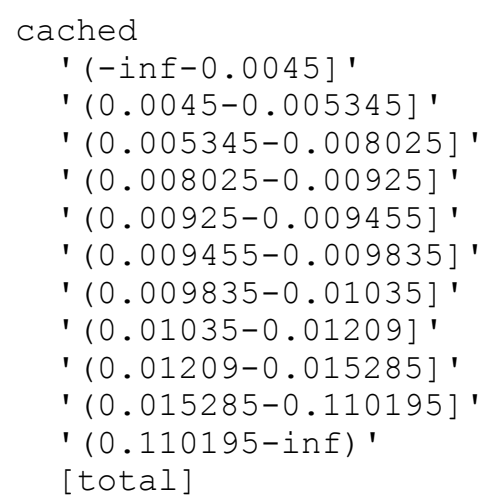

inactive

' (-inf-0.01033] '

'(0.01033-0.01717]'

' (0.01717-0.01817]'

' (0.01817-0.0423]'

' $(0.0423-0.13582]$ '

' (0.13582-inf)'

[total] $\begin{array}{rr}23.0 & 1.0 \\ 707.0 & 851.0\end{array}$

$1.0 \quad 5.0$

$127.0 \quad 6.0$

$1.0 \quad 473.0$

$136.0 \quad 1.0$

$1.0 \quad 57.0$

$68.0 \quad 1.0$

1.0133 .0

$125.0 \quad 1.0$

$1.0 \quad 119.0$

$253.0 \quad 1.0$

$1.0 \quad 62.0$

$715.0 \quad 859.0$

$245.0 \quad 3.0$

$1.0 \quad 17.0$

$125.0 \quad 2.0$

$1.0 \quad 28.0$

$337.0 \quad 2.0$

1.0802 .0

$710.0 \quad 854.0$

$===$ Stratified cross-validation $===$

$===$ Summary $===$

Correctly Classified Instances

Incorrectly Classified Instances

Kappa statistic

Mean absolute error

Root mean squared error

Relative absolute error

Root relative squared error

Total Number of Instances

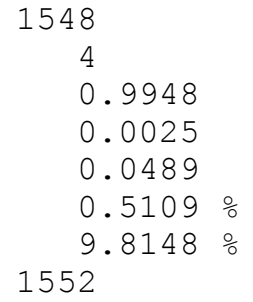

$99.7423 \div$

$0.2577 \%$

$===$ Detailed Accuracy By Class ===

Class

TP Rate FP Rate

LM
1
0.005
0.994
1
0.997
1

Precision

Recall

F-Measure

ROC Area
0.995
0

NLM

Weighted Avg.

0.997

0.002

1

0.995

0.998

1

$===$ Confusion Matrix $===$

\begin{tabular}{rr|rl}
$a$ & $b$ & $<--$ & classified as \\
704 & 0 & $a=$ LM \\
4 & 844 & $b=$ NLM
\end{tabular}

